Portland State University

PDXScholar

Dissertations and Theses

Dissertations and Theses

Spring 8-5-2014

\title{
Predicting Bicyclist Comfort in Protected Bike Lanes
}

Nicholas Mark-Andrew Foster

Portland State University

Follow this and additional works at: https://pdxscholar.library.pdx.edu/open_access_etds

Part of the Transportation Engineering Commons

Let us know how access to this document benefits you.

\section{Recommended Citation}

Foster, Nicholas Mark-Andrew, "Predicting Bicyclist Comfort in Protected Bike Lanes" (2014).

Dissertations and Theses. Paper 1969.

https://doi.org/10.15760/etd.1968

This Thesis is brought to you for free and open access. It has been accepted for inclusion in Dissertations and Theses by an authorized administrator of PDXScholar. Please contact us if we can make this document more accessible: pdxscholar@pdx.edu. 
Predicting Bicyclist Comfort in Protected Bike Lanes

\author{
by \\ Nicholas Mark-Andrew Foster \\ A thesis submitted in partial fulfillment of the \\ requirements for the degree of \\ Master of Science \\ in \\ Civil and Environmental Engineering
}

Thesis Committee:

Christopher Monsere, Chair

Kelly Clifton

Jennifer Dill

Portland State University

2014 
(C) 2014 Nicholas Mark-Andrew Foster 


\begin{abstract}
Long popular in northern Europe, protected bike lanes, also known as "cycle tracks" or "separated bike lanes," are seeing increased interest in the United States. One of the primary benefits of protected bike lanes is that they may provide a higher level of comfort than a standard bike lane that is only delineated by an inches-wide painted stripe. Several methods exist for quantifying the quality of service provided by a roadway for a bicyclist; however, many of these models do not consider protected bike lanes and of those that do, none are based on empirical data from the US. This is problematic as engineers, planners, and elected officials are increasingly looking to objective performance measures to help guide transportation project design and funding prioritization decisions.
\end{abstract}

This thesis addresses this gap by presenting a cumulative logistic model to predict user comfort on protected bike lanes using surveys conducted in the United States. The model is for road segments only and not signalized intersections. It is developed from the results of in-person video surveys conducted in Portland, Oregon. The survey was completed by 221 individuals who viewed 20 video clips each. The model is validated using 3,230 responses to a survey of those who have ridden on protected bike lanes in multiple cities around the US. A cumulative logistic model is used because it predicts the distribution of ratings, providing a clearer picture of a facility's performance than a mean value produced by a simple linear model. The resulting model 
indicates that buffer type, one-way vs. two-way travel, motor vehicle speed, and motor vehicle average daily traffic volumes are all significant predictors of bicyclist comfort in protected bike lanes.

Survey results also show that protected bike lanes are generally more comfortable than other types of on-street infrastructure, consistent with previous research findings. 


\section{Acknowledgments}

Thank you to my wife for putting up with me temporarily leaving my job and moving us to Portland so I could pursue this little adventure and to my daughter for being a constant source of smiles and sleep deprivation. Thank you to Dr. Chris Monsere for chairing this committee and helping me work through the various details that arose throughout the project. Thank you to Dr. Jennifer Dill and Dr. Kelly Clifton for participating in this committee and providing feedback on my experiment design. Thank you to Brian Ray, of Kittelson \& Associates, for being a sounding board as I made the decision to return to school and to the Boise office for keeping my seat warm while I am away. Thank you to Theo Petritsch of Sprinkle Consulting for providing a DVD of the video clips used in NCHRP Project 3-70 so that I could compare video quality. Thank you also to my other family, friends, and colleagues (both here and at Kittelson) for your various shows of support along the way. Finally, thank you to the National Institute for Transportation and Communities and the Summit Foundation for providing the funding for another project that allowed me to work on this thesis. 


\section{Table of Contents}

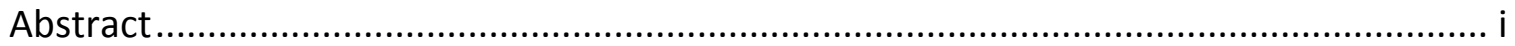

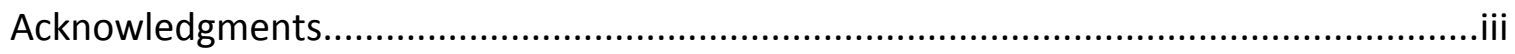

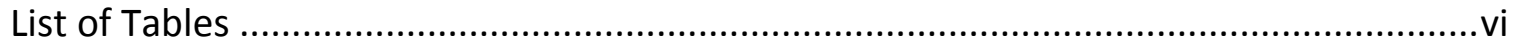

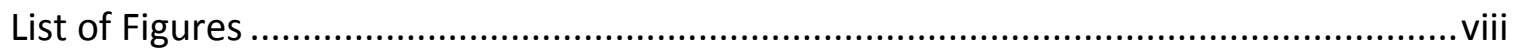

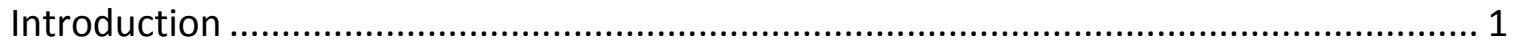

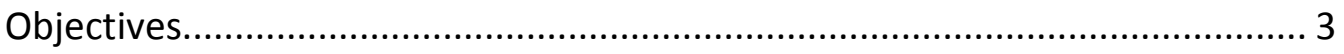

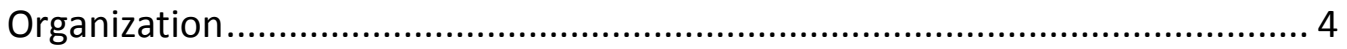

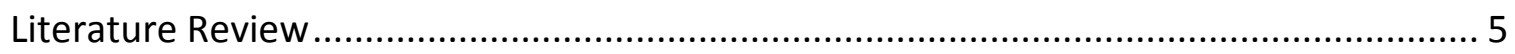

Perceived Safety and Protected Bike Lanes................................................ 5

Methods to Predict Bicyclist Comfort ..................................................... 6

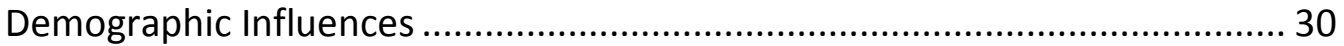

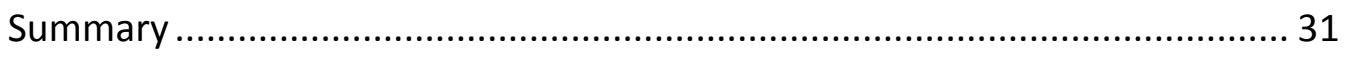

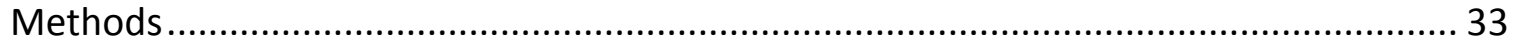

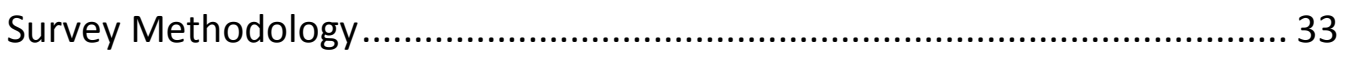

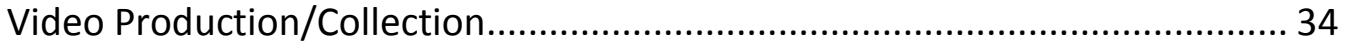

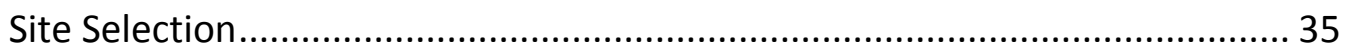

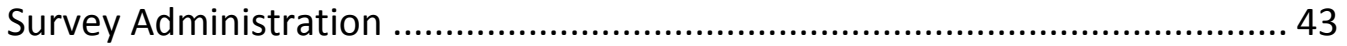

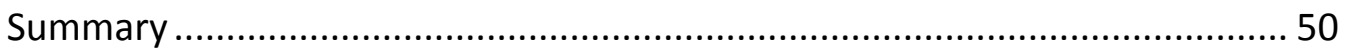

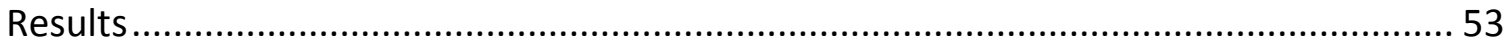

In-Person Video Survey Participants........................................................ 53

Overview of Rating Results ........................................................................ 58

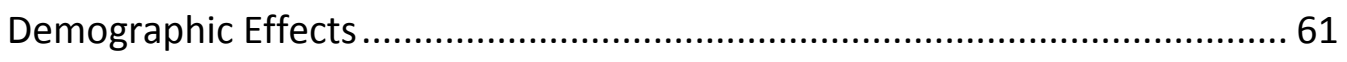

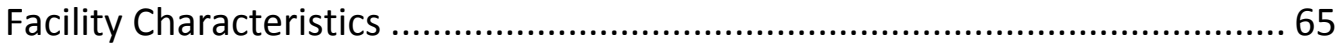

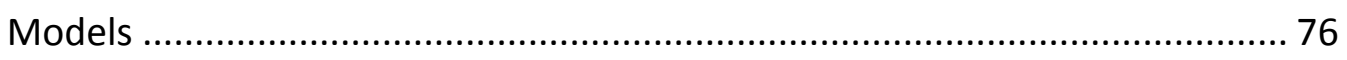

Online Survey Results ............................................................................ 100

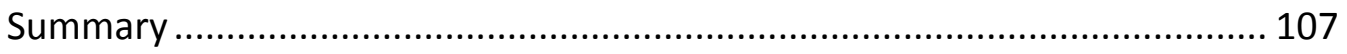

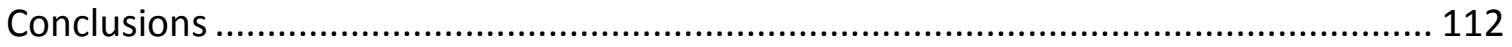


Secondary Objectives....................................................................... 113

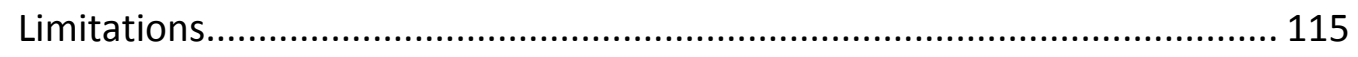

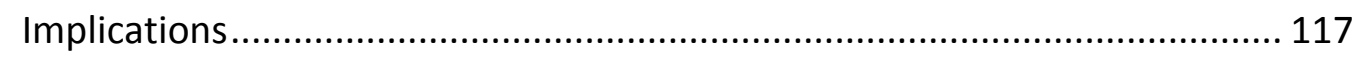

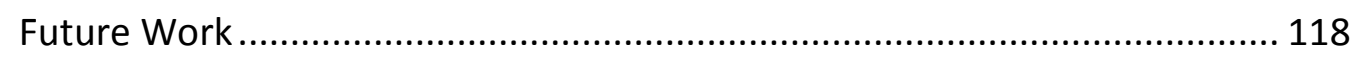

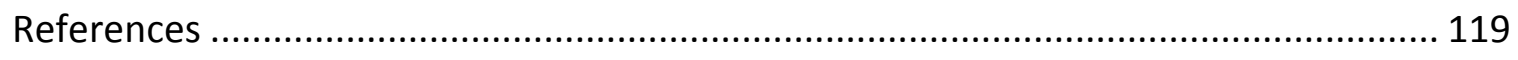

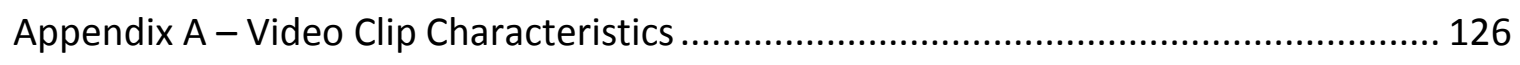

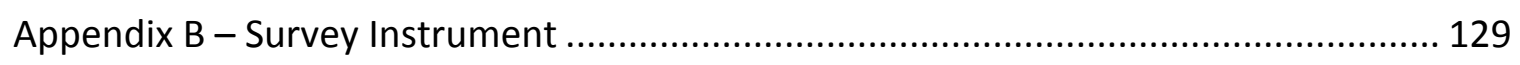




\section{List of Tables}

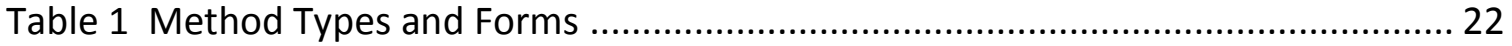

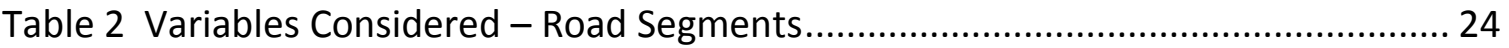

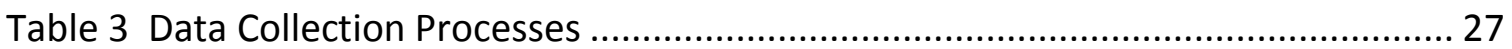

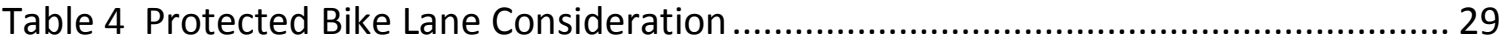

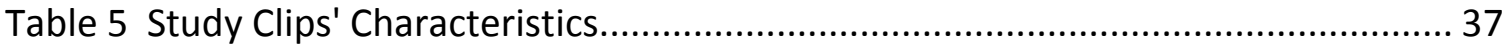

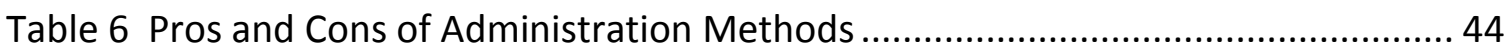

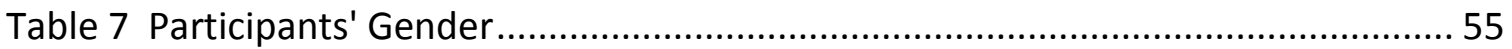

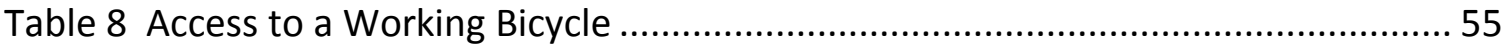

Table 9 Participants' Riding Habits - All Trip Purposes ............................................. 57

Table 10 Responses to Statement "I would like to ride a bicycle more than I do now" . 58

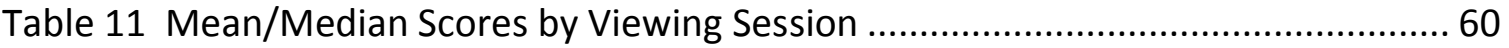

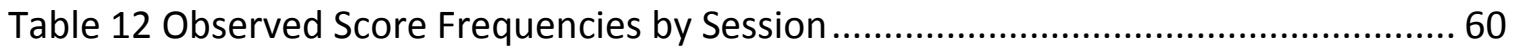

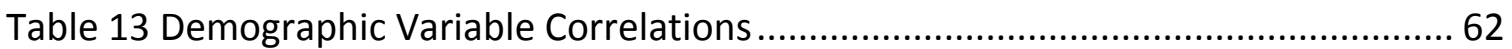

Table 14 Mean and Median Score by Gender - Consistent Clips Only .......................... 64

Table 15 Mean/Median Score by Clip and Characteristics ........................................ 67

Table 16 Observed Median Ratings Compared to HCM 2010 Predicted Ratings............ 69

Table 17 Mean Score by Functional Classification.................................................... 73

Table 18 Mean Score by Surrounding Land-Use ...................................................... 73

Table 19 Pearson Correlations of Various Characteristics ............................................. 75

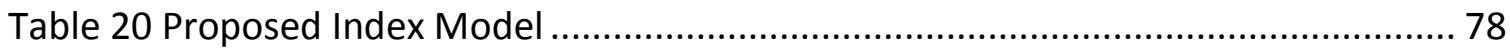


Table 21 Index Model Predicted Scores vs. Observed Scores

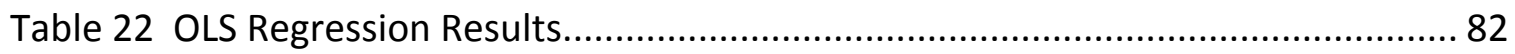

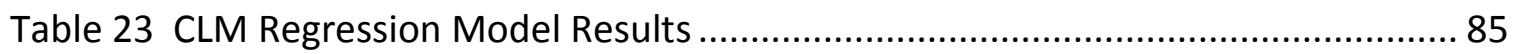

Table 24 Difference between Expected and Observed Rating Distributions - Basic Model

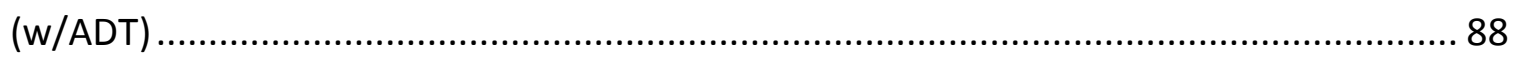

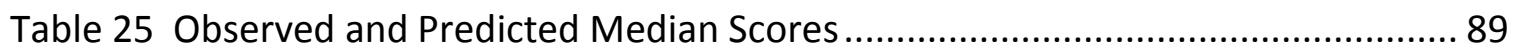

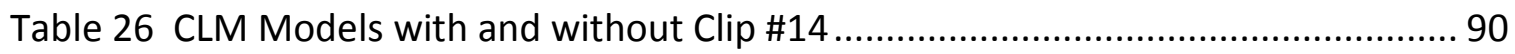

Table 27 Comparison of Predicted and Observed Means - Including Danish Model...... 92

Table 28 Predicted vs. Observed Median Scores for Green Lane Facilities.................... 95

Table 29 Hypothetical Comfort Ratings - Green Lane Surveys ................................... 98

Table 30 In-Person vs. Online Survey Demographic Comparisons $-X^{2}$ Results ............ 103

Table 31 Scores by Clip - Online vs. In-Person Surveys............................................ 104

Table 32 Regression of Score on Demographics and Survey Method.......................... 106 


\section{List of Figures}

Figure 1 HCM BLOS Video Collection Set-up ............................................................ 10

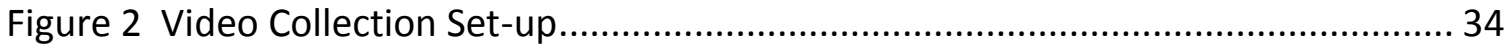

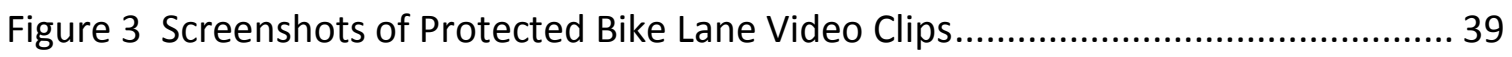

Figure 4 Screenshots of Reference Video Clips ................................................. 42

Figure 5 Front of In-Person Survey Instrument ................................................ 46

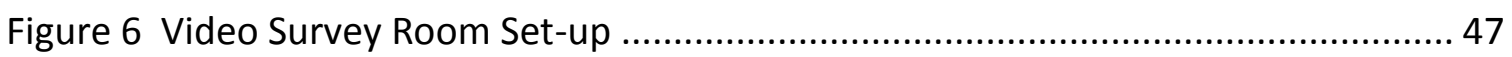

Figure 7 Survey Advertisement at Portland Farmer's Market ................................... 48

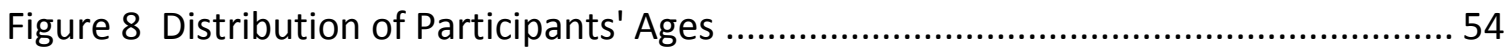

Figure 9 Participants' Bicycle Riding Frequency by Trip Purpose ............................... 56

Figure 10 Distribution of Participant Mean Scores.................................................. 59

Figure 11 Participant Mean Score by Participant Age - Consistent Clips Only ( $n=219)$.. 63

Figure 12 Mean Score by Participant's Riding Frequency - Consistent Clips Only $(n=218)$

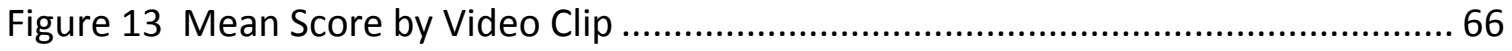

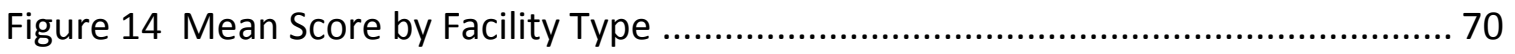

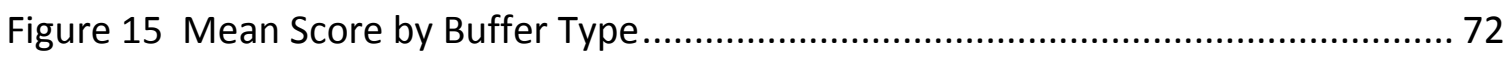

Figure 16 Predicted vs. Observed Scores - OLS Regression Models ............................ 83

Figure 17 Predicted vs. Observed Distribution of Responses by Clip ............................ 87

Figure 18 Comparison of Predicted and Observed Distributions - with and without Clip

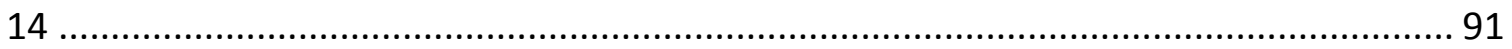


Figure 19 Comparison of Predicted and Observed Values - Including Danish Model ..... 93

Figure 20 Predicted vs. Observed Frequencies - Green Lane Facilities ........................ 97

Figure 21 Respondent Age Groups - Survey Method Comparison.............................. 101

Figure 22 Respondent Gender- Survey Method Comparison .................................. 101

Figure 23 Access to a Working Bicycle - Survey Method Comparison ......................... 102

Figure 24 Respondent Riding Habits by Trip Purpose - Survey Methods Comparison.. 102 


\section{Introduction}

Long popular in northern Europe, protected bike lanes (PBLs), also known as "cycle tracks" or "separated bike lanes," are seeing increased interest in the United States. Around 80 such facilities had been built by 2011, but another 61 protected bike lanes have been built since then, an increase of approximately $76 \%$ (1). One of the primary benefits of protected bike lanes is that they may provide a higher level of comfort than a standard bike lane that is only delineated by an inches-wide painted stripe. Indeed, previous research has shown that people prefer bicycling facilities that are physically separated from traffic to standard bike lanes (2-7). At the same time, as budgets tighten and the reality that we cannot "build ourselves out of traffic congestion" sets in, jurisdictions are looking for methods to measure the performance of their transportation beyond the traditional auto delay and capacity measures. The most recent edition of the Highway Capacity Manual contains analysis procedures for measuring the level-of-service (LOS), also referred to quality of service, user satisfaction, or user comfort, provided by an urban roadway to bicyclists (8). However, it does not include protected bike lanes. There are other methods for predicting comfort from a bicyclist's perspective that do consider protected bike lanes, but they are either based on expert opinion $(9,10)$ or on user surveys in Denmark $(11)$.

This thesis aims to fill in some of this gap by presenting the results of an experiment to develop a model to predict user comfort on protected bike lanes using 
surveys conducted in the United States. The model is for road segments only and not signalized intersections. The primary focus of this research is on the results of an inperson video survey conducted in Portland, Oregon. Video surveys have previously been shown to be an effective substitute for field surveys involving individuals actually riding on the study facilities (12). They also allow for a large group of individuals to view multiple locations that might otherwise be impossible to recreate in a field study (e.g. the video clips include locations in Chicago, Illinois, and San Francisco, California, in addition to Portland). The survey was administered three times in two different locations and 221 different individuals participated in total.

In the survey, participants watched twenty short video clips filmed from a bicyclist's perspective on various types of facilities, including protected bike lanes, standard bike lanes, buffered bike lanes, shared streets, and an off-street path, and rated how comfortable they would feel if they were the bicyclist in the clip on an ' $A$ ' (extremely comfortable) to ' $F$ ' (extremely uncomfortable) scale. Conditions across the different clips varied not only by type of bicycle facility, but also by traffic and roadway conditions (e.g. motor vehicle speed and volume, number of lanes, functional classification, etc.) in order to determine what type of influence they might have on comfort. The protected bike lane clips included two-way and one-way facilities and a variety of buffer types (e.g. planters, parked cars, plastic flexposts, and one raised facility). Respondents also provided demographic data that are analyzed to determine 
how they influence perceived comfort and for understanding the sample used in the survey.

\section{Objectives}

The ultimate goal of this study is to produce a model that is capable of accurately predicting how comfortable a majority of individuals would feel bicycling in a protected bike lane given a certain set of conditions. The model should be easy to use for practitioners, and therefore, should only use variables that are readily available for most collector-level and above roadways (e.g. motor vehicle speed, number of motor vehicle lanes, functional classification, and average daily traffic (ADT) volume). Variables that are considered in other models but may be more difficult to obtain data for (e.g. motor vehicle volume in adjacent lane) will also be tested to determine if their inclusion would significantly improve the model's performance.

In addition to this primary objective, there are a number of other secondary objectives to this study. These objectives are either basic exploratory tasks recognizing this is the first study of protected bike lane comfort in the US or they take advantage of the data being collected for the project to highlight other findings not directly related to the model (e.g. the impact of demographics). These secondary objectives are to determine:

- Are protected bike lanes perceived as more comfortable than other types of onstreet facilities?

- Do different buffer types impact perceived comfort? 
- Is there a difference in perceived comfort on two-way facilities between riding with motor vehicle traffic or against motor vehicle traffic?

- Is there a difference in perceived comfort between two-way and one-way facilities?

- Do motor vehicle volumes in a given video clip impact ratings (i.e. do clips of the same section with different motor vehicle volumes have different ratings?)?

- Motor vehicle volume in the adjacent lane is included in other models (8, $14,17,19) ;$ however it is the author's hypothesis that the physical buffer between the motor vehicle lane and the protected bike lane will mediate this impact to some extent

- Do online surveys produce different results than in-person surveys?

- Does casual advertising to transportation and bicycle related groups produce different demographics and results than outreach to the general community?

Regarding these final two objectives, an online survey was also administered for this project. This survey used the same video clips as the in-person survey, but was advertised through transportation and bicycling focused groups. Nearly 400 individuals participated in the online survey.

\section{Organization}

The remainder of this document is organized as follows. First, prior research related to measuring comfort for bicyclists is reviewed. A following section describes the process for videoing and selecting the clips and administering the surveys. Finally, analysis results and then conclusions are presented. 


\section{Literature Review}

This literature review discusses how perceived safety impacts decisions to bicycle, previous efforts to develop models to predict bicyclist comfort, and the impacts that demographics have on comfort ratings and route choice.

\section{Perceived Safety and Protected Bike Lanes}

A key motivation for analyzing how comfortable a bicyclist may feel on a route is that how safe an individual perceives a route to be will likely influence her or his decision to ride a bicycle on that route, or to ride at all. Sanders (6) conducted an online survey and focus groups of Bay Area residents to better understand how perceived safety influences decisions to ride. This research found that perceived threats to safety (e.g. inattentive drivers, being cut off by a motor vehicle) are significant barriers to bicycling for individuals of all experience levels on par with topographic or lack of bicycle-specific facilities/routes impediments. Similarly, Dill and McNeil (7) conducted a telephone survey of Portland area residents and categorized respondents into one of four groups of bicyclists based on their riding experience, self-reported comfort in different situations, and attitude toward bicycling. They found that at least half of respondents in all but the most advanced bicyclist group ("Strong and Fearless") were at least somewhat concerned about being hit by a motor vehicle while riding. Further, the concern about being hit increased as bicycling experience and comfort decreased, with approximately $84 \%$ of respondents in the "Interested but Concerned" group (the least 
experienced and comfortable group of individuals that do bicycle or might bicycle) being at least somewhat concerned about being hit. This is significant because this group makes up the largest proportion of respondents and is often considered the target population for efforts to increase bicycling.

Constructing protected bike lanes may be a means to attract more individuals to bicycle because they reduce the perceived risk of bicycling. Several surveys have shown that people prefer bicycling facilities that are physically separated from traffic to standard bike lanes (2-7). Sanders (6) found that protected bike lanes were the only type of infrastructure in her survey where experienced bicyclists did not state a higher level of comfort than potential bicyclists. Respondents to the survey conducted by Dill and McNeil (7) that were classified as "Interested but Concerned" also stated a preference for protected bike lanes over standard bike lanes. Finally, in a study of Danish residents Jensen (13) found that $45 \%$ of the respondents stated that they felt "very safe" when bicycling on protected bike lanes, as opposed to about $30 \%$ for standard bike lanes, and just over $10 \%$ for shared streets. This study also found an increase in bicycle and moped volumes of $18-20 \%$ on streets where protected bike lanes were constructed.

\section{Methods to Predict Bicyclist Comfort}

Researchers and practitioners have developed a number of models to quantify how comfortable a bicyclist may feel along a certain route. Somewhat related to these tools for measuring comfort is a model that attempts to predict the relative utility of different bicycle facility types (e.g. off-street paths, on-street bike lanes, shared streets). 
While not directly related to comfort, this effort also provides an indication of what types of facilities bicyclists prefer and the methods used to develop them are similar to those of the comfort models.

The following is a list of the reviewed methods and the year they were published:

- 2010 Highway Capacity Manual (HCM) BLOS (8) - 2011

- Bicycle Stress Level (13) - 1994

- Compatibility of Roads for Cyclists (CRC) Index (15) - 2003

- Danish Road Directorate BLOS $(11,16)$ - 2007 \& 2013

- Florida Department of Transportation (FDOT) BLOS (12, 17, 18, 19, 20) - 19972010

- Federal Highway Administration (FHWA) Bicycle Compatibility Index (BCI) (21) 1998

- FHWA Shared-use Path LOS (22) - 2005

- Fort Collins BLOS (23) - 1997

- Level of Traffic Stress (9) - 2012

- Rural BCl (24) - 2003

- San Francisco Bicycle Environmental Quality Index (BEQI) (10) - 2009

- Simplified Version of HCM BLOS (25) - 2012

- Tilahun, et al. - Travel Time Value (3) - 2007

Each of these methods will be discussed in the subsequent sections as follows.

First, a general overview of each method is provided. Then the methods are compared to each other in terms of their form (e.g. regression-based model, index model, utility model), variables considered, how they were developed, and their applicability to protected bike lanes. 


\section{Method Descriptions}

This section provides a brief description of each of the methods listed above. Additional attention is given throughout this literature review to the tools that are most widely used, based on the author's experience: HCM BLOS, Danish Road Directorate BLOS, FDOT BLOS, FHWA BCl, and Level of Traffic Stress.

\section{Highway Capacity Manual}

One of the major changes to the HCM for its 2010 edition is the introduction of a perception-based level-of-service methodology for non-auto modes on urban streets, including bicyclists. The bicycle LOS methodology in the HCM 2010 is primarily based on the results of National Cooperative Highway Research Program (NCHRP) Project 3-70, which are described in NCHRP Report 616: Multimodal Level of Service Analysis for Urban Streets (27) and NCHRP Web-Only Document 158: Field Test Results of the Multimodal Level of Service Analysis for Urban Streets (28). Given the HCM's stature as one of the most referenced documents by transportation professionals, this methodology is likely the most widely used of those described in this paper.

The HCM provides models for an individual link, which is defined as a section of an urban street in between signalized intersections; signalized intersections; and segments, which are the combination of a link and its upstream signalized intersection (8). The link and signalized intersection models are taken with slight modification from models previously developed for the Florida Department of Transportation (FDOT) by members of the NCHRP project 3-70 research team (27). 
For the bicycle mode, the NCHRP Project 3-70 research team primarily used video surveys to develop the LOS models. This was chosen over field surveys using volunteer or paid riders to avoid the expense and risk. Intercept surveys were also not chosen because of the delay imparted by the survey administration, which could potentially impact LOS opinions. The report notes that video surveys do have limitations, notably they do not completely capture the effect of pavement condition or the suction effect from heavy vehicles passing by. In choosing video surveys, the team built off a similar effort underway at the same time for the Florida Department of Transportation (FDOT), which is described in more detail later on in this literature review, and allowed them to also include some field survey results in their process (27).

Members of the research team filmed the study locations using a professional videographer seated in the front of a Viewpoint bicycle holding a camera and microphone mounted to a metal post at approximately the eye level of a bicyclist, as shown in Figure 1. Study sites, all of which are in Tampa, Florida, were filmed while bicycling at approximately 12 miles-per-hour (MPH). A total of 30 clips were selected for the final study (27). 


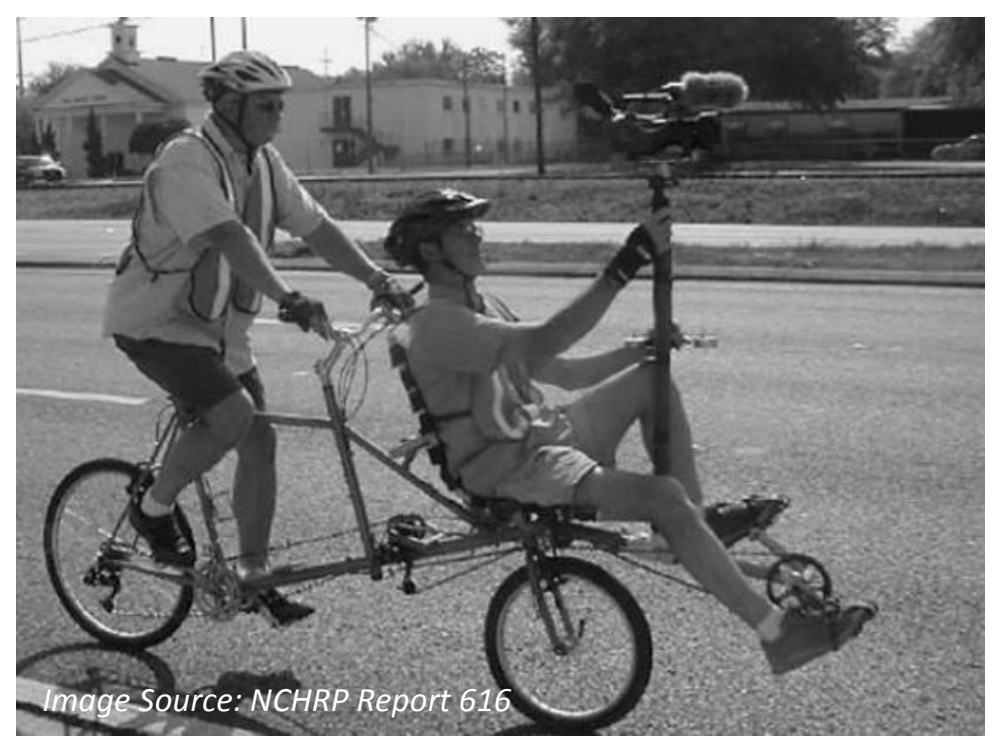

Figure 1 HCM BLOS Video Collection Set-up

The video surveys were conducted in hotel ballrooms in four US cities: Chicago, Illinois; College Station, Texas; New Haven, Connecticut; and San Francisco, California. Participants in each city were recruited through e-mails to senior citizen centers, bicycle clubs, and community and neighborhood associations and by posting flyers around each city. Ultimately, a total of 145 individuals viewed the video clips. Seniors are noted as being overrepresented and single-family home residents are noted as being underrepresented in the sample. Participants committed to a total of $2 \frac{1}{2}$ hours for the survey, which included watching videos and attending a focus group session. However, since the overall project's goal was to develop LOS models for auto drivers, pedestrians, and transit riders, in addition to bicyclists, only 10 bicyclist clips were shown in each city. These clips totaled 13 minutes in viewing time, including a practice clip and time for rating. Four clips were shown in each city, while the other six varied by city. Participants arrived for the beginning of the viewing session in each city and were shown a practice 
clip of each mode before starting that mode's videos. After viewing each clip, respondents were given the opportunity to rate their "perceived service rating" on an A - F scale (27).

These letter grade responses to the survey are converted into numerical values and used to develop the LOS model through ordinary least squares (OLS) regression analysis. The research team elected to use OLS regression to make the models more easily understood by transportation professionals. The final segment model is a combination of a link LOS model and a signalized intersection model. The link and signalized intersection models are taken with slight modification from models previously developed for FDOT by members of the research team (27).

Phase 3 of NCHRP Project 3-70 included field testing of the LOS methods introduced in NCHRP Report 616 with public agencies around the US. This phase did not result in any changes to the bicycle LOS models, but it did lead to guidance that the methodology is not applicable to bus/bike only lanes and that single-family residential driveways should not be counted individually as unsignalized conflict points (28).

The segment model has been criticized by some practitioners for its lack of sensitivity to certain improvements and the limited range of scores it typically provides $(29,30)$. These two issues come about largely as the result of a constant in the model that places the segment score at LOS " $C$ " before the link and intersection scores are factored in. Petritsch, et al. (31) have also noted that the manner in which the score is weighted may not accurately reflect the impact of low-quality facilities and 
intersections. As a means to address these concerns, they are recommending modifications to the model based on their experience and discussions with practitioners and researchers. These modifications include weighting the scores for intersections and links based on the time a bicyclist is exposed to either condition when combining the scores into the segment model and centering the unsignalized conflict density term based on the average density from the survey videos. It is unclear how the new model fits the data used to create the original model.

\section{Bicycle Stress Level (1994)}

Sorton and Walsh (14) developed one of the earlier attempts at a quality-ofservice based evaluation of bicycling on a roadway using empirical data. It is a simple method, considering only lane width, motor vehicle volume, and motor vehicle speed. The initial model was developed based on professional opinion and then validated using video surveys.

\section{Compatibility of Roads for Cyclists Index (2003)}

The Compatibility of Roads for Cyclists (CRC) Index was created by Noel, et al. (15) in reaction to a lack of tools for rural areas. It draws on data collected from approximately 200 cyclists in rural and urban fringe areas in Quebec, Canada. Cyclists were intercepted at 24 different sites and asked to rate the route they were riding. The resulting index contains rating criteria for a number of different categories related to roadway and traffic characteristics. Each category is worth a set number of points, with the total index allowing a maximum of 100 points. 


\section{Danish Road Directorate BLOS (2007 - Segments; 2013 - Intersections)}

The Danish Road Directorate has bicycle LOS models for segments and intersections/crossings. Both models are based on video survey data, with over 580 total participants over multiple showings in the surveys. The project team recorded the video clips using a shoulder mounted camera while riding a bicycle at approximately 12 MPH, the same speed used in the 2010 HCM videos (27). Small groups of Danish residents were shown 39 to 42 video clips (out of a total of more than 200 videos) ranging from 28 seconds to nearly two minutes in each showing, so no participant watched every single clip. The viewings were set up similar to the ones described for the 2010 HCM model. Participants rated their level of satisfaction with the conditions shown in each video on a 1-6 scale. These viewings lasted nearly an hour each and the research team found a slight dip in ratings as time went on, suggesting some level of participation fatigue $(11,16)$.

The final models were developed using logistic regression. Similar to the 2010 $H C M$, the numeric outputs are converted to a letter grade on the A-F scale. The LOS for a facility is identified as the letter grade at which the cumulative probability of a user selecting that grade first reaches, or exceeds, $50 \%$ (11).

\section{Florida Department of Transportation (1997 - 2010)}

FDOT has developed LOS models for roadway links $(12,17,19)$, signalized intersections (18), and shared-use paths that are adjacent to roadways (20). As mentioned in the 2010 HCM BLOS description, FDOT's link and signalized intersection 
LOS models are the starting point for the $2010 \mathrm{HCM}$ models. Consequently they share many characteristics in terms of their structure and the variables they consider.

\section{Link LOS (1997 \& 2007)}

FDOT developed its first link LOS model in 1997 (17) and updated it in 2007 (12, 19). The first iteration of the FDOT link LOS model was developed using field surveys. Participants were solicited via newspaper/radio ads, direct mailings, brochure distribution, and displays at public buildings, schools, major employers, and bike and sports shops. These efforts yielded 150 participants, with experienced cyclists being overrepresented. The participants rode 30 links totaling 17 miles on a Saturday in Tampa, Florida. The links represented a range of conditions from local streets to highspeed arterials. Participants were staggered throughout the course so that they did not ride together. Participants were asked to ride all the links, though they could stop at any time if they no longer felt safe or sufficiently comfortable. Proctors were available at certain locations to provide assistance and to ensure that riders remain spaced apart. Participants rated each link immediately after riding it and were instructed to not consider the signalized intersection on either end of the link (17).

The 2007 update involved a combination of field and video surveys. A media campaign resulted in 79 participants, of whom 75 watched 11 clips and 63 rode 12 links $(12,19)$. Fifty-nine participants completed both surveys. The sample includes a number of inexperienced riders, but regular riders are also overrepresented. The video survey had a total running time of 47 minutes, including transition time between clips. Six of 
the video clips overlapped with the field segments. The video clips were filmed and the survey conducted in a manner similar to that described for the $2010 \mathrm{HCM}$, except that the video clips were run on a continuous loop and individuals were allowed to begin the survey when they arrived, instead of at a set starting time (12). The twelve links ranged in length from 0.3 miles to 1.5 miles and were primarily arterial streets with speed limits ranging from 30 to $50 \mathrm{mph}$. The field survey was conducted on a Saturday in Tampa, Florida, in a manner similar to the previous effort. This update resulted in the addition of a factor to account for the density of unsignalized intersections, but not driveways, along the link (19).

Finally, there was no statistically significant difference between ratings for video and in-field observations of overlapping links, suggesting that the video survey method is as effective as the field surveys (12).

Intersection LOS (2003)

FDOT's intersection LOS model was developed through a field survey conducted in Orlando, Florida, designed similarly to the link LOS surveys. A variety of advertising methods yielded 59 participants. Males and regular riders are overrepresented. The course included 19 signalized intersections covering a range of street classifications from local roads to arterials. An unsignalized intersection and a roundabout were also included in the course for comparison purposes (18). 
Shared-use Path LOS (2010)

FDOT's LOS model for shared-use paths adjacent to roadways was created using a video survey similar to those previously described. The survey was administered in a science and industry museum in Tampa, Florida. Participants were recruited using advertisements placed throughout the museum, correspondence sent to advocacy groups, and advertisements in conjunction with an ongoing bicycle promotional campaign. This resulted in 80 participants participating in the survey, which included 22 continuously running clips of about 36 seconds each, for a total running time of about 15 minutes, including transitions. The sample is skewed toward bicyclists who ride regularly (20).

\section{FHWA Bicycle Compatibility Index (1998)}

FHWA published its Bicycle Compatibility Index in 1998. In the report's title, it is described as A Level of Service Concept. Similar to the 2010 HCM, Danish, and FDOT models, it is a regression model that produces a number converted to a letter grade on the $\mathrm{A}$ - $\mathrm{F}$ scale. The $\mathrm{BCl}$ is based on a video survey conducted similar to those previously described. One difference is that in this survey respondents were asked to provide ratings based on motor vehicle volume, motor vehicle speed, and the road width available to bicyclists, in addition to an overall rating. Surveys were conducted in three cities: Austin, Texas; Chapel Hill, North Carolina; and Olympia, Washington. About 200 individuals participated in the survey, with males and regular riders being 
overrepresented in the sample. They did not find a difference in the ratings across the different cities (21).

A significant difference between the production of the $\mathrm{BCl}$ survey and the other video surveys is that the $\mathrm{BCl}$ videos were all filmed from a stationary camera mounted on a tripod alongside the subject roadways. The research team conducted a small validation effort of this method by having a small sample both watch video clips and stand alongside the same roadways at the location of the camera. They found that the results were somewhat similar, with $31-44 \%$ of the scores on the subject's sheets being an exact match and $81-87 \%$ of them being within one letter grade, depending on the variable being considered (21).

The final models include separate equations for casual recreational, experienced recreational, and experienced commuter bicyclists, in addition to an overall model (21).

\section{FHWA Shared-use Path LOS (2005)}

The shared-use path LOS model developed for FHWA is also based on video survey data using instruments similar to those used in creating the $\mathrm{BCl}$. However, unlike with $\mathrm{BCl}$, the respondents used a $1-5$ scale, instead of $1-6$. Video for the surveys was collected using a helmet camera while bicycling between 9.5 and $13 \mathrm{MPH}$ on various paths. The resulting video is black and white, without audio. According to the project team the quality of the video "ranged from good to marginal" (22). Ultimately 105 participants watched 36 different clips in Raleigh, North Carolina and Washington, D.C. Participants were recruited from bicycle and trail user groups, biasing the sample 
toward experienced riders and males. The videos were approximately 60 seconds long and each viewing session lasted about 80 minutes, including instructional and transitional time (22).

\section{Fort Collins BLOS (1997)}

The City of Fort Collins published a BLOS method in its Multimodal Level of Service Manual (23). It is entirely based on connectivity and not necessarily comfort. It is no longer an adopted method by the City of Fort Collins.

\section{Level of Traffic Stress (2012)}

Mekuria, et al. (9) recently developed a method for measuring the level of traffic stress (LTS) a bicyclist experiences on a route. This methodology was created partially as a reaction to the 2010 HCM BLOS not having tolerance thresholds for different rider groups. The authors identify four levels of stress and the type of rider they believe the stress level is suitable for:

$$
\begin{aligned}
& \text { 1-Children } \\
& \text { 2-Most adults } \\
& 3 \text { - "Enthused and confident" riders } \\
& 4 \text { - "Strong and fearless" riders }
\end{aligned}
$$

The tool has criteria for road segments, signalized intersections, and unsignalized crossings. There are criteria for the four stress levels across different categories for each type of facility with the worst rating determining the LTS. For instance, there are criteria for bike lanes alongside a parking lane in four categories: street width, combined width 
of the bike lane and parking lane, motor vehicle speed, and bike lane blockage; if the LTS is 2 in three of these categories, but 4 in the other, then the LTS for the segment would be 4 . Similarly, the tool is envisioned for network connectivity analyses and the authors recommend that the LTS of a route be the rating of the worst segment or crossing. The criteria are typically fairly simple and use readily available data.

Unlike most of the other methods described here, LTS is not based on empirical data. Instead it is based on the authors' opinions. They do base LTS 2 thresholds on Dutch design criteria whenever possible. This comes from the assumption that since many adults in the Netherlands bicycle their standards must be suitable for most adults.

\section{Rural BCI (2003)}

In response to the FHWA BCl not including rural roads, Jones and Carlson (24) developed a complimentary $\mathrm{BCl}$ for rural roads. Given that it was meant to supplement the FHWA BCl models, the Rural $\mathrm{BCl}$ model is structured in a similar fashion. It is based on video survey data; however, the survey was administered online instead of in a controlled room, as was the case for all the other video surveys discussed in this section. The video was shot from a camera mounted approximately 4.5 feet above the road on a car traveling about $10 \mathrm{MPH}$ in the shoulder of the road or wherever a bicyclist was likely to ride in rural Nebraska.

Approximately 100 participants completed the survey by watching 32 video clips that were 30 seconds long each. Participants were recruited from organized rides, 
popular bike routes, and personal contacts of the authors. Consequently the resulting sample is skewed toward experienced bicyclists and males.

The final models are simpler than the FHWA BCl. The survey results also showed that the FHWA BCl model would not accurately represent perceptions of rural roads.

\section{San Francisco Bicycle Environmental Quality Index (2009)}

The San Francisco Department of Public Health developed its own Bicycle Environmental Quality Index (10). It is a categorical index that considers 22 variables in 5 categories: Intersection design, street design, vehicle traffic, safety, and land-use. Scores can be reported by category or as an overall index. Similar to LTS, the BEQI is based on opinion and not observational data. The department sent out surveys to those it considered experts in the field and regular bicycle riders and used those responses to assign the relative importance of the different variables.

\section{Simplified Version of HCM BLOS (2012)}

Flannery, et al. (25) developed a simplified version of the 2010 HCM BLOS model using a cumulative logistic regression model. This model is derived from the same data as the HCM BLOS method, as one of the paper's co-authors was involved in NCHRP project 3-70. The method is a reaction to the data collection requirements of HCM BLOS and the authors' desire to have a model that shows the distribution of opinions of a subject facility, instead of just the mean score. It uses only four variables: presence of a bike lane or shoulder, posted speed limit, number of travel lanes in each direction, and number of unsignalized conflicts per mile. This method is currently being considered by 
the Oregon Department of Transportation (ODOT) for inclusion in its Analysis Procedures Manual (APM) (33).

\section{Travel Time Value (2007)}

Tilahun, et al. (3) conducted a survey to determine bicyclist route preferences using a video survey. The research team surveyed 167 University of Minnesota employees and asked them to choose between two routes given a certain travel time for each route. A total of five different routes are shown, including an off-road shareduse path, a bike lane without on-street parking, a bike lane with on-street parking, a shared road without parking, and a shared road with parking. Routes are presented in 10 second video clips. The survey was designed to compare all of the facilities to each other, with the higher quality facility presented with a higher travel time. Each pairing was shown four times with the travel time difference changing based on the previous selection(s) (e.g. if the higher quality facility with greater travel time was chosen, the difference between the two would increase for the next iteration and vice versa). Logit and simple linear models estimating the value of different improvements (e.g. adding a bike lane to a street with on-street parking) in terms of travel time are derived from the survey responses.

\section{Methods Comparison}

The following section provides a comparison of the reviewed methods in terms of their form, variables considered, development process, and consideration of protected bike lanes. 


\section{Method Types and Forms}

These methods range from regression-based BLOS models using an A - F scale to categorical indices with final scores in the range of $0-100$ or 1-5.

Table 1 provides a listing of each tool's form and output scale, separated by whether the method is related to measuring bicyclist comfort or the utility of a given route type.

Table 1 Method Types and Forms

\begin{tabular}{|c|c|c|}
\hline Method & Form & Scale \\
\hline \multicolumn{3}{|l|}{ Comfort Methods } \\
\hline 2010 HCM BLOS (8) & Linear Regression & $A-F$ \\
\hline Bicycle Stress Level (14) & Index & $\begin{array}{c}\text { 1-5 (very comfortable - not ride } \\
\text { under any circumstance) }\end{array}$ \\
\hline CRC Index (15) & Index & $0-100$ \\
\hline Danish BLOS $(11,16)$ & Logistic Regression & $A-F$ \\
\hline FDOT BLOS $(12,17-20)$ & Linear Regression & A-F \\
\hline FHWA BCl (21) & Linear Regression & $A-F$ \\
\hline FHWA Shared-use Path LOS (22) & Linear Regression & $A-F$ \\
\hline Fort Collins BLOS (23) & Index & A-F \\
\hline Level of Traffic Stress (9) & Index & 1-5 (lowest stress - prohibited) \\
\hline Rural BCl (24) & Linear Regression & A-F \\
\hline San Francisco BEQI (10) & Index & $\begin{array}{c}\text { 0-100 (highest quality - poor } \\
\text { quality) }\end{array}$ \\
\hline Simplified BLOS (25) & Logistic Regression & A-F \\
\hline \multicolumn{3}{|l|}{ Utility Model } \\
\hline Value of Travel Time (3) & Mixed Regression & N/A \\
\hline
\end{tabular}

Most of the models were developed from some form of regression analysis of user perceptions. The numeric outputs from the analysis are then converted to a letter grade on the six-point ' $A$ ' through ' $F$ ' scale based on each model's own conversion table. This scale is the same used for all other modes in the HCM (8). 
Simple linear regression is the most commonly used analysis method for these models. The research team that developed the FDOT and HCM models notes that they used it because they believe that it is more commonly understood by practitioners (27).

Cumulative logistic regression is used in the Danish LOS models and the proposed simplified version of the HCM BLOS. A benefit of cumulative logistic regression is that it identifies the proportion of users that are likely to rate a facility at each letter grade (e.g. $30 \%$ would rate it a 'C,' $25 \%$ a ' $B$ ', etc...). This provides a more complete look at how the facility is likely to serve its prospective users. In a review of three different comfort methods, Parks, et al. (30) recommends that any future methods be a discrete choice model and not simple linear regression.

Indices are probably the most readily understood and simplest to implement of the three forms. They may involve scoring a facility based on a number of characteristics and summing up the scores $(10,15)$, rating the facility based on a single category $(23)$, or rating the facility in different categories and choosing either the worst criteria as the basis for the final score (9) or combining the scores into a composite value (13).

\section{Variables Considered}

A wide range of variables are considered by the different methods, some of which require only a few inputs, while others require several detailed data. Table 2 summarizes the variables considered by each method for road segments only. 
Table 2 Variables Considered - Road Segments

\begin{tabular}{|c|c|c|c|c|c|c|c|c|c|c|c|c|c|}
\hline \multirow[b]{2}{*}{ Method } & \multicolumn{3}{|c|}{ Operational Variables } & \multicolumn{6}{|c|}{ Geometric Design Variables } & \multicolumn{4}{|c|}{ Other Variables } \\
\hline & $\begin{array}{c}\mathrm{MV}^{1} \\
\text { Speed }\end{array}$ & $\begin{array}{c}\text { MV } \\
\text { Volume }^{2}\end{array}$ & $\begin{array}{c}\text { Heavy } \\
\text { Vehicles }\end{array}$ & $\begin{array}{c}\text { MV } \\
\text { Lane } \\
\text { Width }\end{array}$ & $\begin{array}{c}\text { On- } \\
\text { Street } \\
\text { Parking }\end{array}$ & $\begin{array}{l}\text { \# MV } \\
\text { Lanes }\end{array}$ & $\begin{array}{c}\text { Bike } \\
\text { Facility } \\
\text { Type }^{3}\end{array}$ & $\begin{array}{c}\text { Bike } \\
\text { Facility } \\
\text { Width }\end{array}$ & $\begin{array}{l}\text { Buffer } \\
\text { Width }\end{array}$ & $\begin{array}{l}\text { Pavement } \\
\text { Condition }\end{array}$ & $\begin{array}{l}\text { Land } \\
\text { Use }\end{array}$ & $\begin{array}{c}\text { Unsignalized } \\
\text { Conflicts }\end{array}$ & Other \\
\hline \multicolumn{14}{|c|}{ Comfort Methods } \\
\hline $\begin{array}{l}2010 \\
\text { HCM } \\
\text { BLOS }\end{array}$ & $\mathrm{X}$ & $x$ & $\mathrm{X}$ & $x$ & $x$ & & $\mathrm{BL}, \mathrm{SH}$ & $x$ & & $\mathrm{X}$ & & $x$ & \\
\hline $\begin{array}{l}\text { Bicycle } \\
\text { Stress } \\
\text { Level }\end{array}$ & $x$ & $x$ & & $x$ & & & & & & & & & \\
\hline $\begin{array}{l}\text { CRC } \\
\text { Index }\end{array}$ & $\mathrm{X}$ & $x^{4}$ & $x$ & & & & $\mathrm{SH}$ & $\mathrm{X}$ & & $x$ & & $x$ & $x^{5}$ \\
\hline $\begin{array}{l}\text { Danish } \\
\text { BLOS }\end{array}$ & $x$ & $x^{4}$ & & $x$ & $\mathrm{x}$ & $x$ & $\begin{array}{c}\text { BL, PL, } \\
\text { SH }\end{array}$ & $x$ & $x$ & & $x$ & & $x^{6}$ \\
\hline $\begin{array}{l}\text { FDOT } \\
\text { BLOS }\end{array}$ & $\mathrm{X}$ & $x$ & $x$ & $x$ & & & & $\mathrm{X}$ & & $x$ & & $\mathrm{X}$ & \\
\hline $\begin{array}{l}\text { FHWA } \\
\mathrm{BCl}\end{array}$ & $x$ & $x^{7}$ & & $x$ & $x$ & & $\mathrm{BL}, \mathrm{SH}$ & $x$ & & & $x$ & & \\
\hline $\begin{array}{l}\text { Shared- } \\
\text { use Path } \\
\text { LOS }\end{array}$ & & & & & & & & $x$ & & & & & $x^{8}$ \\
\hline $\begin{array}{l}\text { Ft Collins } \\
\text { BLOS }\end{array}$ & & & & & & & $\mathrm{BL}, \mathrm{P}$ & & & & & & $x^{9}$ \\
\hline $\begin{array}{l}\text { Level of } \\
\text { Traffic } \\
\text { Stress }\end{array}$ & $x$ & & & & $x$ & $x$ & $\mathrm{BL}, \mathrm{PL}$ & $\mathrm{x}$ & & & $x$ & & \\
\hline Rural BCl & & & $X$ & & & & & $\mathrm{X}$ & & & & & \\
\hline SF BEQI & $x$ & $x^{5}$ & $x$ & & $x$ & $x$ & $B L, S P$ & $x$ & & $x$ & $x$ & $x$ & $x^{10}$ \\
\hline $\begin{array}{l}\text { Simplified } \\
\text { BLOS }\end{array}$ & $x$ & & & & & $x$ & $\mathrm{BL}, \mathrm{SH}$ & & & & & $x$ & \\
\hline
\end{tabular}




\begin{tabular}{|c|c|c|c|c|c|c|c|c|c|c|c|c|c|}
\hline \multirow[b]{2}{*}{ Method } & \multicolumn{3}{|c|}{ Operational Variables } & \multicolumn{6}{|c|}{ Geometric Design Variables } & \multicolumn{4}{|c|}{ Other Variables } \\
\hline & $\begin{array}{c}\text { MV }^{1} \\
\text { Speed }\end{array}$ & $\begin{array}{c}\text { MV } \\
\text { Volume }^{2}\end{array}$ & $\begin{array}{c}\text { Heavy } \\
\text { Vehicles }\end{array}$ & $\begin{array}{c}\text { MV } \\
\text { Lane } \\
\text { Width }\end{array}$ & $\begin{array}{c}\text { On- } \\
\text { Street } \\
\text { Parking }\end{array}$ & $\begin{array}{l}\text { \# MV } \\
\text { Lanes }\end{array}$ & $\begin{array}{c}\text { Bike } \\
\text { Facility } \text { Type }^{3}\end{array}$ & $\begin{array}{c}\text { Bike } \\
\text { Facility } \\
\text { Width }\end{array}$ & $\begin{array}{l}\text { Buffer } \\
\text { Width }\end{array}$ & $\begin{array}{l}\text { Pavement } \\
\text { Condition }\end{array}$ & $\begin{array}{l}\text { Land } \\
\text { Use }\end{array}$ & $\begin{array}{l}\text { Unsignalized } \\
\text { Conflicts }\end{array}$ & Other \\
\hline $\begin{array}{l}\text { Value of } \\
\text { Travel } \\
\text { Time }\end{array}$ & & & & & $\mathrm{x}$ & & $\mathrm{x}$ & & & & & & $x^{11}$ \\
\hline
\end{tabular}

$\mathrm{MV}=$ motor vehicle

${ }^{2}$ Volumes are for the outside motor vehicle lane (e.g. adjacent to bike lane or in shared lane), unless otherwise noted

${ }^{3} \mathrm{BL}=$ Bike Lane, $\mathrm{P}=\mathrm{Path}, \mathrm{PL}=$ Protected Bike Lane, $\mathrm{SH}=$ Shoulder - all methods that consider facility type include shared streets, too

${ }^{4}$ Two-way volume

${ }^{5}$ Roadside characteristics (e.g. vegetation or obstacles), slope

${ }^{6}$ Passed pedestrians, presence of sidewalk, presence of bus stop

${ }^{7}$ All lanes in direction of analysis

${ }^{8}$ Meeting events, presence of a centerline

${ }^{9}$ Network connectivity

${ }^{10}$ Network connectivity, traffic calming, trees, lighting, signs, bicycle parking, slope

${ }^{11}$ Season (summer vs. winter), demographics, experience, travel time 
The most commonly considered factors include motor vehicle speeds, the width of the space available for bicyclists (e.g. bike lane width, shared lane width), the type of facility available (e.g. bike lane, shared lane), motor vehicle volumes, and on-street parking. The width of the outside motor vehicle lane is also commonly included in LOS models. While these overall factors are common, how they are treated varies across the methods, depending in part on the type of method.

There is overlap among what factors are identified as the most important by the efforts to develop these methods. These factors include facility type $(17,19,25)$, motor vehicle volumes $(11,19)$, facility width $(19,24)$, and pavement condition $(11,19)$. Despite the identified importance of pavement condition by these studies, it is not included in many of the methods. Jensen (11) and Jones and Carlson (24) note that they intentionally did not consider it because this information is not readily available and it is often not under the control of the designers. Mekuria, et al. (9) do not include it in LTS because their method is focused entirely on stress imparted by motor vehicle traffic.

\section{Data Collection}

As was previously described, many of these models are based on empirical data. Table 3 summarizes the data collection efforts for these methods and identifies which methods are not based on data. 
Table 3 Data Collection Processes

\begin{tabular}{|c|c|c|c|c|}
\hline Method & \# Participants & $\begin{array}{c}\text { \# Study } \\
\text { Videos/Sites }\end{array}$ & Survey Type & Video Method \\
\hline \multicolumn{5}{|l|}{ Comfort Methods } \\
\hline 2010 HCM BLOS & 145 & $30^{1,2}$ & Video & Moving Bicycle \\
\hline Bicycle Stress Level & 61 & 23 & Video $^{3}$ & Stationary Camera \\
\hline CRC Index & 200 & 24 & Intercept & $\mathrm{n} / \mathrm{a}$ \\
\hline Danish BLOS & $180-407^{4}$ & $56-95^{1,4}$ & Video & Moving Bicycle \\
\hline FDOT BLOS & $60-150^{4}$ & $21-30^{4}$ & $\begin{array}{l}\text { Field Ride/ } \\
\text { Video }\end{array}$ & Moving Bicycle \\
\hline FHWA BCl & 202 & $78^{1}$ & Video & Stationary Camera \\
\hline $\begin{array}{l}\text { FHWA Shared-use } \\
\text { Path LOS }\end{array}$ & 105 & 36 & Video & Moving Bicycle \\
\hline Fort Collins BLOS & \multicolumn{4}{|c|}{ None - Not Based on Empirical Data } \\
\hline Level of Traffic Stress & \multicolumn{4}{|c|}{ None - Not Based on Empirical Data } \\
\hline Rural $\mathrm{BCl}$ & 101 & 32 & Video & Moving Car \\
\hline San Francisco BEQI & \multicolumn{4}{|c|}{ None - Not Based on Empirical Data } \\
\hline Simplified BLOS & \multicolumn{4}{|c|}{ Used Same Data as 2010 HCM BLOS } \\
\hline \multicolumn{5}{|l|}{ Utility Model } \\
\hline Value of Travel Time & 167 & 5 & Video & Moving Bicycle \\
\hline
\end{tabular}

${ }^{1}$ Not all video clips shown at each viewing session

${ }^{2}$ Some overlap with FDOT BLOS

${ }^{3}$ Survey only used to validate model

${ }^{4}$ These include multiple efforts (e.g. intersection, segment, shared-use models), so a range is shown

Most of the methods are based on some form of survey data. Frequently this involves recording video of different routes and/or intersections and showing them to participants in some type of controlled environment (e.g. a room with a projector, screen, and speakers) $(3,11,12,13,16,20,21,22)$, though they may be shown via an internet survey (24). These videos are usually filmed from a moving bicycle $(3,11,12$, $16,20,22$ ), but they may also be recorded on a camera in a car (24) or a stationary camera posted alongside the road $(13,21)$. Field rides, where individuals ride and then rate each segment, or surveys where bicyclists riding along the study routes are intercepted are also used. While field rides provide complete immersion for the participants, video surveys are often preferred to avoid the potential risks that come 
with placing individuals in potentially dangerous conditions $(12,21,27)$ and because of the opportunity to control the conditions experienced by all participants (21).

Survey administrators have typically been able to recruit between 60 and 200 participants. Jensen (11) was able recruit over 400 participants to participate in the Danish segment LOS study by directly contacting over 3,000 Denmark citizens. Nearly all of the studies recruited participants at least in part through advertisements targeted towards bicyclists (e.g. e-mails to bicycle clubs, advertisements at bike shops, joint advertising with a bicycle promotion campaign), except the Bicycle Stress Level (9), Danish (11, 16), and Value of Travel Time (3) efforts.

Participants watched video of, or rode on, 20 to 40 facilities in most of the surveys. In the majority of surveys, participants watched or rode on all of the study sites, but in the three instances cited in the table above, a different sampling of sites was shown at different viewing sessions. This kept the viewing times manageable for surveys with a high number of video clips. The video clips in most surveys were between 30 and 60 seconds long; though a few surveys had at least some clips over one minute long (11, $12,27)$. Total video times ranged from about 15 minutes $(20,27)$, to around 45 minutes (12), to an hour or longer $(11,16,22)$. The 2010 HCM BLOS video was on the shorter end of the range because participants also watched videos from a pedestrian's and driver's perspectives and participated in focus groups (27). Conversely, the longer video sessions included breaks and the Danish sessions also included videos from a pedestrian's perspective, used for a pedestrian LOS model. Finally, Jensen (11) found that participant 
ratings tended to drop a bit as time went on in the longer showings, suggesting that fatigue may become a factor.

\section{Applicability to Protected Bike Lanes}

Given that protected bike lanes have not been a commonly constructed type of bicycle infrastructure in the U.S., not every method discussed here takes into account the effect that the separation and physical buffer have on bicyclist comfort. Table 4 identifies the comfort methods that consider protected bike lanes.

Table 4 Protected Bike Lane Consideration

\begin{tabular}{||l|c||}
\hline \multicolumn{1}{|c|}{ Method } & Considers Protected Bike Lanes? \\
\hline \hline 2010 HCM BLOS & No \\
\hline Bicycle Stress Level & No \\
\hline CRC Index & Yes \\
\hline Danish BLOS & Partially \\
\hline FDOT BLOS & No \\
\hline FHWA BCl & No \\
\hline FHWA Shared-use Path & \\
LOS & No \\
\hline Fort Collins BLOS & Yes \\
\hline Level of Traffic Stress & No \\
\hline Rural BCl & Partially \\
\hline San Francisco BEQI & No \\
\hline Simplified BLOS & \\
\hline
\end{tabular}

Most of the methods to predict bicyclist comfort do not consider protected bike lanes. Protected bike lanes are commonly found in Denmark, so it is no surprise that Jensen (11) included them in the development of the Danish segment BLOS model. Mekuria, et al. (9) recommend that all protected bike lanes be assigned the least stressful level of traffic stress. FDOT's LOS model for sidepaths adjacent to roadways does take into account separation width; however, it is for grade-separated paths only 
and not for in-street facilities (20). Similarly, the San Francisco BEQI includes bike paths (10); though these are not necessarily the same as protected bike lanes.

\section{Demographic Influences}

This section describes the influence that gender, age, and bicycling experience may have on comfort ratings and route preferences.

\section{Age and Gender}

The methods to predict bicyclist comfort described previously have produced mixed results in terms of whether age and gender impact comfort ratings. Jensen (11) found no significant correlation between demographics and scores for the Danish LOS model; though his study did observe that men and younger individuals generally felt more comfortable. Tilahun, et al. (3) found that gender and age produced similar trends in their utility model but were not significant predictors at the $95 \%$ confidence level. However, Petritsch, et al. (12) found age and gender to both be significant predictors in their work to develop the FDOT LOS model, again with men and younger individuals providing more comfortable ratings.

Other research has found gender to be a significant factor in route choices. Dill and Gliebe (32) conducted a study of Portland area bicyclists that included using GPS to track their routes. The study found that women were more likely than men to go out of their way to avoid higher traffic streets and had a higher stated preference for avoiding traffic. In their survey of Vancouver, B.C. area residents, Winters and Teschke (4) found that men and women had similar preference ratings for protected bike lanes, but that 
women were less likely than men to choose to ride on major streets. Garrard, et al. also found that women are more likely to prefer paths separated from traffic compared to bike lanes or shared streets.

\section{Bicycling Experience}

The methods to predict bicyclist comfort described previously have produced more definitive results in terms of the impact that bicycling experience has on comfort ratings. The studies that produced Bicycle Stress Level (14), FDOT BLOS (19), and FHWA $\mathrm{BCl}$ (21) all found that more experienced riders are typically more comfortable than less experienced riders.

Route choice studies have produced similar results. Dill and Gliebe (32) found that respondents to their survey that were infrequent cyclists were more likely to state a preference for avoiding traffic. Winters and Teschke (4) showed that less experienced and potential cyclists had a higher preference for protected bike lanes relative to other on-street facilities compared to respondents who cycled at least once per week.

These findings are notable as they indicate that models based on samples where experienced bicyclists are overrepresented may provide more favorable comfort scores than is likely to be experienced by much of the rest of the population, especially in regards to non-protected facilities along higher volume streets.

\section{Summary}

The perceived safety of bicycling is an important factor for individuals in deciding whether to bicycle, and if so, where to ride. This is particularly true for less confident 
riders. Protected bike lanes are generally perceived as being safer and more comfortable than other on-street bicycle infrastructure (e.g. bike lanes, marked routes), especially for less experienced riders.

Several methods currently exist for assessing bicyclist comfort along a route. They range in complexity from simple indices to regression-based mathematical models. These methods are based on opinion, field surveys of bicyclists, and/or video surveys, which have been shown to produce similar results to field surveys. However, most of the existing methods do not account for protected bike lanes. Of the two methods that do explicitly consider on-street protected bike lanes, neither is based on empirical data from the US.

Demographics influence how comfortable an individual is likely to feel bicycling on a given route. Younger people and men are typically more comfortable bicycling in a given situation, though this correlation is not always significant. Individuals who bicycle regularly also tend to state a higher level of comfort bicycling than those who ride less frequently or not at all.

The following chapter describes this project's methods, including how they have been designed to capture a range of participants in terms of age, gender, and bicycling experience. 


\section{Methods}

The following sections summarize the survey methodology, site selection, video clip data collection, and survey administration.

\section{Survey Methodology}

As noted in the Literature Review chapter, previous models based on user surveys have been conducted using video surveys, where individuals watch a clip and rate how they would perceive the experience, or field rides, where participants ride through a segment and/or intersection and provide a rating. Video survey is the chosen method for this project. It is preferred in this case to field rides because it is more efficient, and allows people to rate conditions not found locally. Further, previous research has shown video survey results to be comparable to field ride results (12).

A separate ongoing Portland State University project, Lessons from the Green Lanes: Evaluating Protected Cycling Facilities in the US (hereafter referred to as the Green Lane project), which the author has also worked on, did ask individuals who have ridden on select protected bike lanes to rate their level of comfort. These data are not used for model building because these ratings are for an entire route, making it difficult to understand what characteristics influence the ratings. They are used later on in this paper for comparison purposes with model results, but the results of this comparison are more informational than definitive. 


\section{Video Production/Collection}

High-definition video was taken while biking along each study site using a GoPro Hero 3 camera mounted at a bicyclist's eye level. The camera mount was a metal post attached to a bike's handlebars, as shown in Figure 2. Filming took place in multiple locations, and as a result, multiple bicycles were used in the process. Care was taken to ensure that the camera was mounted level at the bicyclist's eye level on each bicycle. Audio was recorded by using an external stereo microphone with a windscreen. The author rode each study route multiple times with the camera recording. He tried to maintain a constant speed in the range of 10-14 miles-per-hour (MPH) while filming, which is about the speed of an average bicyclist (32) and comparable to previous efforts $(11,22,24,27)$.

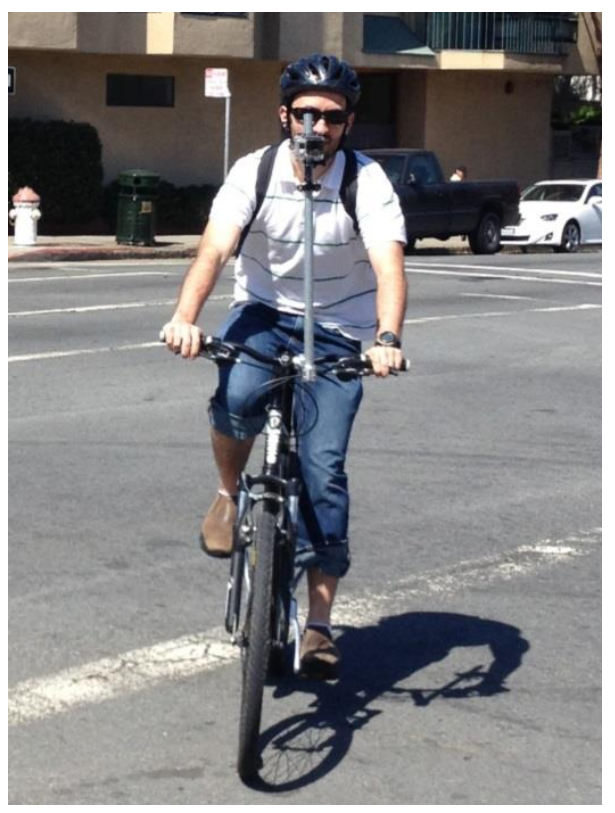

Figure 2 Video Collection Set-up 
This filming method was developed after initial test runs in Portland, Oregon, and Austin, Texas. During these runs various audio and recording modes were tried out. Unfortunately, a satisfactory mounting system and audio set-up was not in place prior to the trip to Austin, Texas, the timing of which was based on the Green Lane project's schedule. The video from Austin's facilities could not be used in the survey; though it was used for reference purposes for the Green Lane project.

One of the challenges to using a fixed-metal pole for the camera mount is that it doesn't dampen road vibration well. To mitigate this effect, each of the chosen clips was post-processed to smooth the bumpiness of the video using iMovie 2009. This program is effective at smoothing slight bumps; however the roughness of the pavement still shows on clips from routes with significant cracking or otherwise rough surfaces.

\section{Site Selection}

Two general groups of sites were selected for this project: protected bike lanes to be used for model development and sites of more common infrastructure types (e.g. standard bike lanes, shared streets, and off-street paths) to be used for comparison purposes.

The primary goal in selecting protected bike lane sites was to include a variety of different buffer types and have both one-way and two-way facilities represented. Candidate sites were limited to those located in cities being studied for the aforementioned Lessons from the Green Lane project and only those cities visited by the 
project team after the filming methodology was finalized (i.e. Chicago and San Francisco, in addition to Portland).

Reference sites were chosen to determine how individuals would perceive their comfort biking on protected bike lanes as compared to more common situations. The final chosen reference sites include traditional bike lanes, with and without adjacent onstreet parking; a bike lane buffered by a second stripe (not considered a protected bike lane since there is no physical vertical object); a shared street; a bike boulevard (a street with speed humps, shared lane markings, and traffic diverters); and an off-street path.

Many more locations were filmed than could be included in this project. In total, around 90 different runs were made, resulting in over 5 hours of video. Each of these runs was reviewed and the time that each of the following occurred was recorded:

- Motor vehicle passes a bicyclist

- A signalized intersection interrupts a segment

- A change in the facility occurs

- An unusual occurrence that may influence ratings occurs (e.g. a vehicle blocking the bike lane, a bike lane located adjacent to a steep undeveloped hillside)

This information was first used to make an initial cut of candidate videos. Potential 20 to 30 second segment clips were identified from the remaining videos. Thirty seconds was the target length for each clip, but in order to avoid including a signalized intersection, some clips had to be shorter in length. These clips were categorized by facility and buffer type, as well as the number of passing motor vehicles. From this final set of clips an initial list of 20 clips ranging from 21 to 30 seconds in length was selected for showing, for a total video running time of just under 15 minutes. 
It was determined after the first in-person survey that three of the clips were providing redundant information and they were replaced by three other clips to provide a greater variety of clips for the remaining in-person surveys and the online survey.

Table 5 summarizes the most relevant characteristics of each clip. The order of the clips was determined using a random number generator in Excel. For a more complete description of the characteristics of each clip, please see Appendix 'A.'

Table 5 Study Clips' Characteristics

\begin{tabular}{|c|c|c|c|c|c|c|}
\hline Clip \# & Facility & Buffer Type & $\begin{array}{c}\text { MV Volume } \\
\text { in Adjacent } \\
\text { Lane } \\
\text { (veh/hr) }\end{array}$ & $\begin{array}{c}\text { MV } \\
\text { Speed } \\
(\mathrm{MPH})^{1}\end{array}$ & $\begin{array}{c}\text { ADT } \\
\text { Volume }^{2}\end{array}$ & $\begin{array}{c}\text { \# of } \\
\text { MV } \\
\text { Travel } \\
\text { Lanes } \\
\end{array}$ \\
\hline 5 & 1-way PBL & Parked Cars & 338 & 25 & 12,800 & 2 \\
\hline 12 & 1-way PBL & Parked Cars & 840 & 30 & 9,200 & 2 \\
\hline 18 & 1-way PBL & Parked Cars & 1,286 & 30 & 9,200 & 2 \\
\hline 1 & 1-way PBL & Planters & 257 & 25 & 10,000 & 2 \\
\hline 11 & 1-way PBL & Planters & 600 & 25 & 10,000 & 2 \\
\hline $17 a^{3}$ & 1-way PBL & Planters & 857 & 25 & 10,000 & 2 \\
\hline 8 & 1-way PBL & Posts & 343 & 30 & 28,200 & 3 \\
\hline 15 & 1-way PBL & Posts & 960 & 30 & 9,200 & 2 \\
\hline $20 b^{3}$ & 1-way PBL & Posts & 600 & 30 & 11,800 & 2 \\
\hline 19 & 1-way PBL & $\begin{array}{c}\text { Raised; Parked } \\
\text { Cars }\end{array}$ & 360 & 35 & 4,400 & 2 \\
\hline 2 & 2-way PBL (against traffic) & Parked Cars & 360 & 25 & 7,800 & 2 \\
\hline 14 & 2-way PBL (against traffic) & Parked Cars & 864 & 25 & 15,900 & 3 \\
\hline $20 a^{3}$ & 2-way PBL (against traffic) & Parked Cars & 840 & 25 & 7,800 & 2 \\
\hline 6 & 2-way PBL (with traffic) & Parked Cars & 277 & 25 & 15,900 & 3 \\
\hline 16 & 2-way PBL (with traffic) & Parked Cars & 626 & 25 & 15,900 & 3 \\
\hline $3 b^{3}$ & Bike Boulevard & $\mathrm{n} / \mathrm{a}$ & 0 & 25 & 700 & 2 \\
\hline 13 & Bike Lane & $\mathrm{n} / \mathrm{a}$ & 360 & 35 & 15,200 & 6 \\
\hline $17 b^{3}$ & Bike Lane w/ Parking & $\mathrm{n} / \mathrm{a}$ & 1,080 & 25 & 8,100 & 2 \\
\hline $3 a^{3}$ & Buffered Bike Lane & Double stripe & 840 & 35 & 15,200 & 3 \\
\hline 7 & Buffered Bike Lane & Double stripe & 360 & 35 & 15,200 & 3 \\
\hline 10 & Buffered Bike Lane & Double stripe & 1,200 & 35 & 15,200 & 3 \\
\hline 9 & Off-street Path & $\mathrm{n} / \mathrm{a}$ & $\mathrm{n} / \mathrm{a}$ & $\mathrm{n} / \mathrm{a}$ & $\mathrm{n} / \mathrm{a}$ & $\mathrm{n} / \mathrm{a}$ \\
\hline 4 & Shared Street & $\mathrm{n} / \mathrm{a}$ & 360 & 30 & 2,900 & 2 \\
\hline
\end{tabular}

${ }^{1}$ Posted speed, except for clip 30b, where $85^{\text {th }}$-percentile speed was provided by the City of Chicago

'Taken from each City's website or provided by the City when requested; rounded to nearest 100

${ }^{3} \mathrm{After}$ the first round of in-person surveys it was determined that the information provided by clips $3 a$, $17 a$, and 20a was redundant to other clips from the same route; therefore three new clips replaced them for the next two rounds of in-person surveys and the online survey. 
The selected clips cover a range of facility types and buffer types. When converted to hourly traffic flow, the motor vehicle volume in the lane adjacent to the study facility ranges from 0 to 1,286 vehicles per hour. Posted motor vehicle speeds range from 25 to $35 \mathrm{MPH}$ and average daily traffic (ADT) volumes range from about 740 to over 28,000 vehicles per day. Most of the roadways included in the clips have two

motor vehicle travel lanes, though a few have three travel lanes, and one features six travel lanes.

Some of the clips are taken from the same, or similar, location on a given street in order to determine if the number of motor vehicles passing the bicyclist in the adjacent motor vehicle lane influences participant ratings.

\section{Protected Bike Lane Clips}

The following section describes the protected bike lane video clips. Figure 3 contains representative screen shots of the protected bike lane clips. 


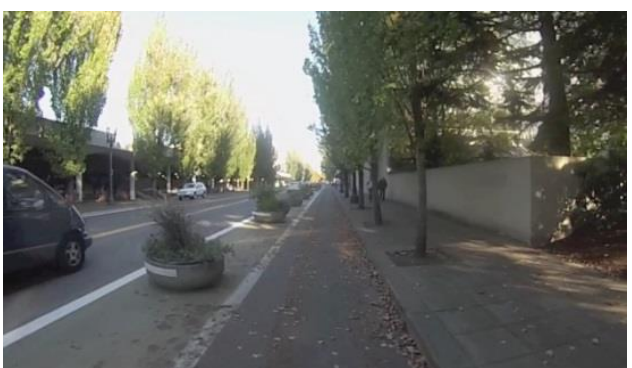

$\# 1,11,17 a-$ NE Multnomah St

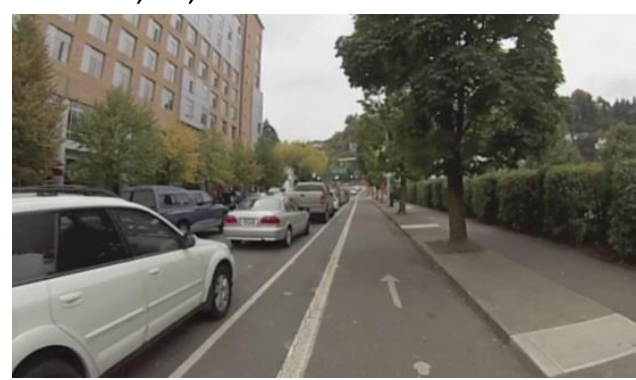

\#5 - SW Broadway St

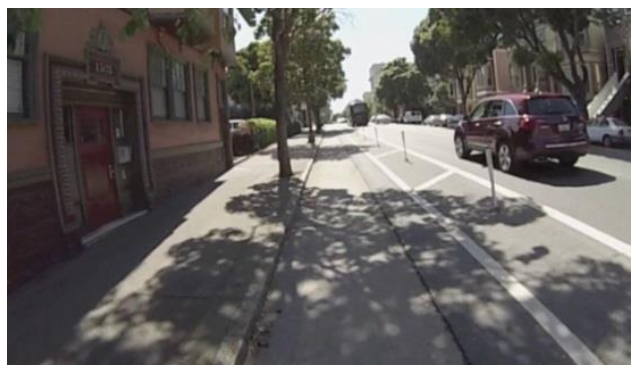

\#8- Fell St

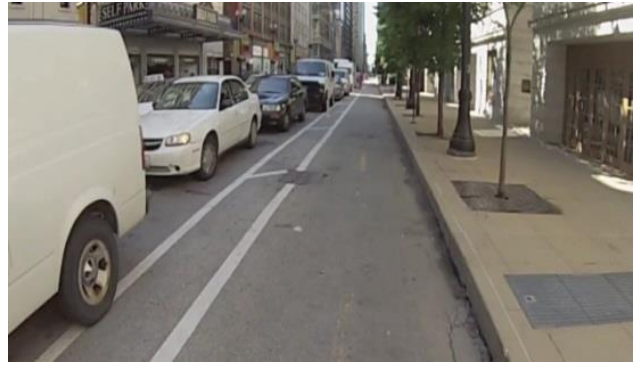

\#14 - Dearborn St

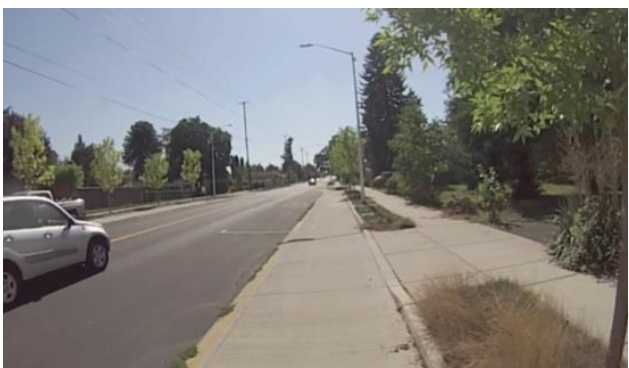

$\# 19$ - Cully Blvd

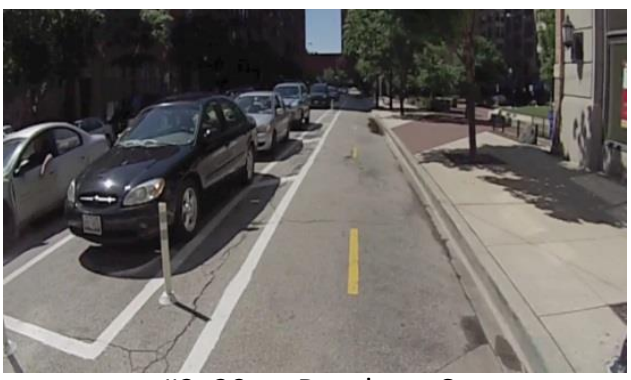

\#2, 20a - Dearborn St

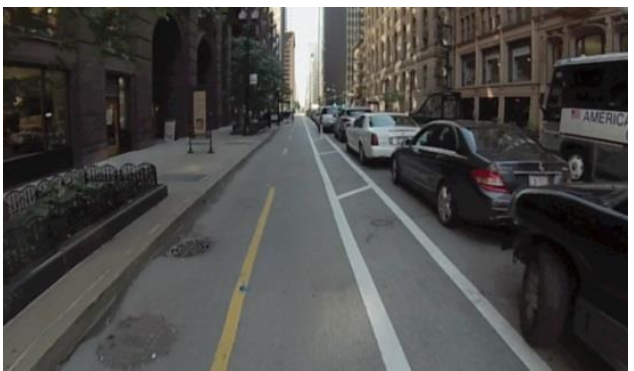

\#6, 16 - Dearborn St

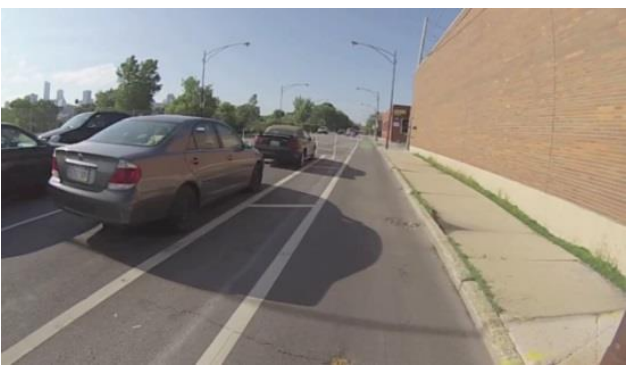

\#12, 18 - Elston Ave

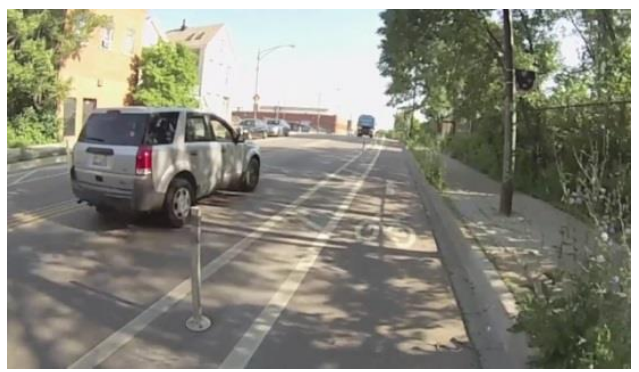

\#15 - Elston Ave

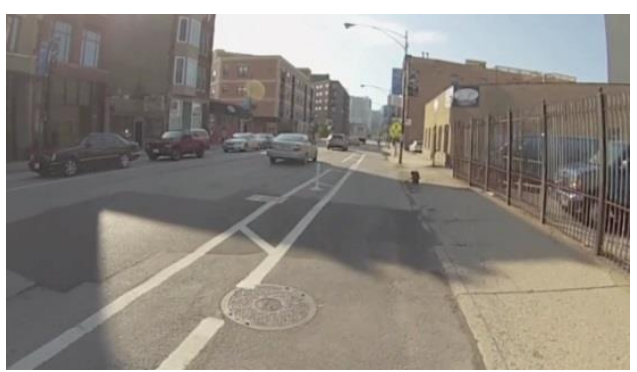

\#20b - Milwaukee Ave

Figure 3 Screenshots of Protected Bike Lane Video Clips 
Clips \#1, 11 and $17 a$ are all from the same section of NE Multnomah Street in Portland and represent a one-way protected bike lane with planters in the buffer strip. The clips are differentiated by the number of motor vehicles that pass the bicyclist in each clip. After reviewing the results from the first round of in-person surveys, it was noted that the scores for these three clips were similar, so clip \#17a was pulled in favor of another standard bike lane clip.

Clips \#2 and 20a are taken from Dearborn Street in downtown Chicago and represent a bicyclist riding against traffic in a two-way protected bike lane on a one-way street with parked cars forming the buffer. This section of Dearborn Street has one fewer motor vehicle travel lane and a lower ADT volume than other sections shown in clips \#6, 14, and 16. After reviewing the results from the first round of in-person surveys, it was noted that the scores for these two clips were similar, so clip \#20a was pulled in favor of another protected bike lane with posts clip.

Clip \#5 is a bicyclist riding in a one-way protected bike lane buffered by parked cars on SW Broadway Street through Portland State University near downtown Portland.

Clips \#6 and 16 are a bicyclist riding with the flow of motor vehicle traffic in a two-way protected bike lane buffered by parked cars on Dearborn Street in downtown Chicago. The two clips are on different sections of the road, but feature mostly similar characteristics, the exception being the number of passing motor vehicles is different. 
Clip \#8 is a bicyclist riding in a one-way protected bike lane buffered by plastic flexposts on Fell Street in San Francisco.

Clips \#12 and 18 are taken on Elston Avenue in Chicago and represent a one-way protected bike lane buffered by parked cars. The two clips are differentiated by the number of passing motor vehicles in each clip.

Clip \#14 is a bicyclist riding against the flow of motor vehicle traffic on a two-way protected bike lane buffered from one-way Dearborn Street in downtown Chicago by parked cars.

Clip \#15, like clips 12 and 18, is taken from Elston Avenue in Chicago; however, this section of the one-way protected bike lane is buffered from traffic by plastic flexposts, not parked cars.

Clip \#19 is from Cully Boulevard in Portland and features a one-way protected bike lane that is elevated above the road, but lower than the adjacent sidewalk. The bike lane is buffered by parked cars, but unlike all other sites with on-street parking, the parking was not occupied during the filming of the clip.

Clip \#20b is a bicyclist riding along a one-way protected bike lane buffered from traffic on Milwaukee Avenue in Chicago by plastic flexposts.

\section{Reference Clips}

Figure 4 contains the same for the reference video clips. Following the figures is a discussion of the clips. 


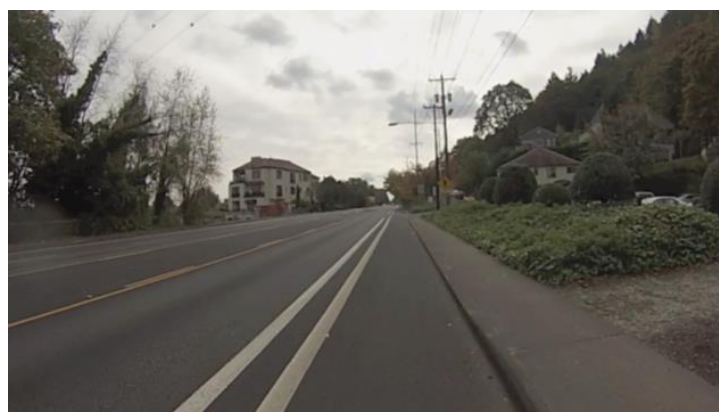

\#3a, 7, 10 - SW Barbur Blvd

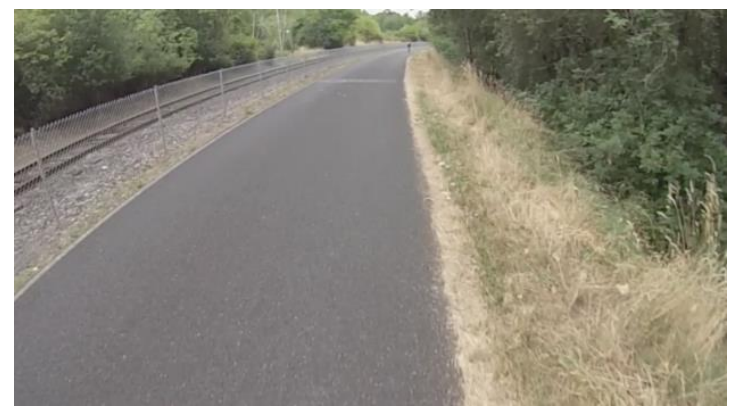

\#9 - Springwater Trail

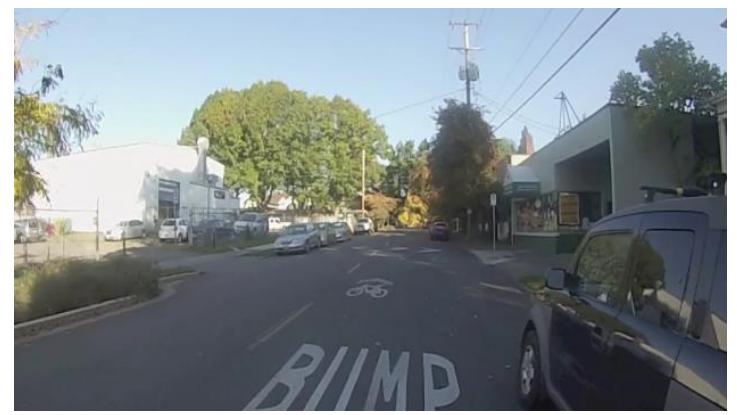

\#3b - SE Ankeny St

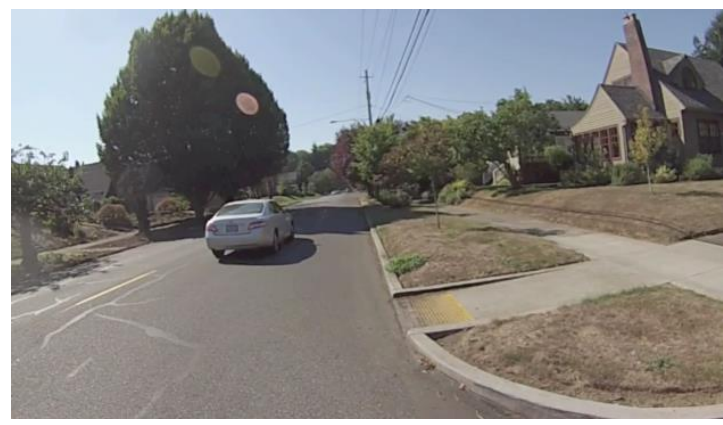

\#4 - NE Knott St

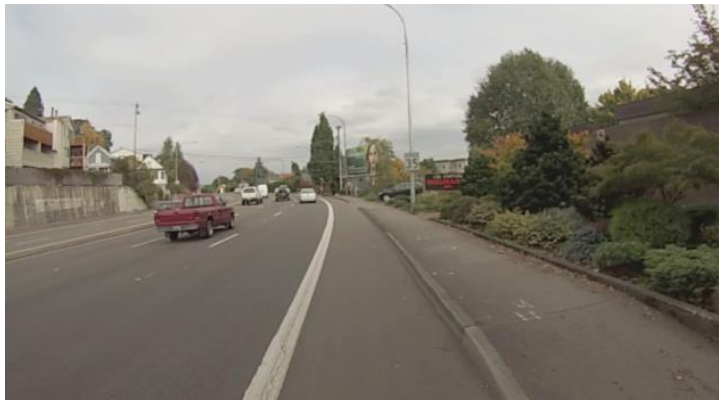

\#13 - SW Barbur Blvd

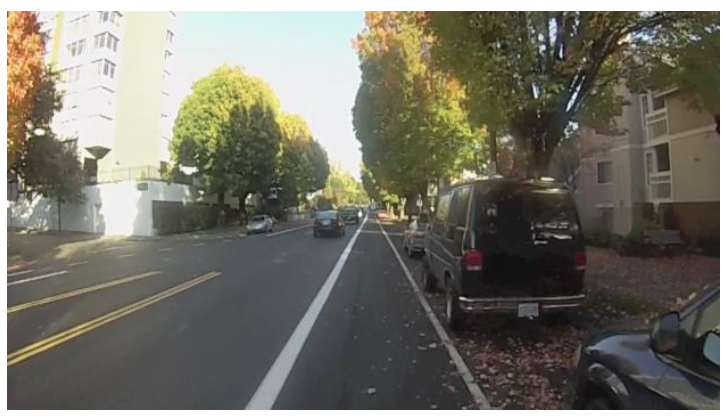

$\# 17 \mathrm{~b}-$ NE Multnomah St

Figure 4 Screenshots of Reference Video Clips

Clips \#3a, 7, and 10 are from SW Barbur Boulevard in Portland and feature a standard bike lane that is buffered from traffic by a second painted bike lane stripe. The clips are differentiated by the number of passing motor vehicles in each clip. After reviewing the results from the first round of in-person surveys, it was noted that the scores for these three clips were similar, so clip \#3a was pulled in favor of a bicycle boulevard. 
Clip \#4 is NE Knott Street in Portland and represents a shared collector-level street.

Clip \#9 is the Springwater Trail in Portland and is an off-street shared-use pathway.

Clip \#13 is a bicyclist riding in a standard bike lane on SW Barbur Boulevard in Portland. Clip \#3b is taken from SE Ankeny Street in Portland and represents a bicycle boulevard with traffic calming (e.g. speed bumps) and shared lane markings.

Clip \#17b is a bicyclist riding in a standard bike lane in between motor vehicle traffic and on-street parking on NE Multnomah Street in Portland. It is immediately east of the protected bike lane in clips \#1, 11, and 17a.

\section{Survey Administration}

The following section describes the administration of the survey, including survey types considered and the day-of administration process.

\section{Survey Type}

Administering the survey in-person or on-line was considered at the outset of the project. Table 6 summarizes some of the relative pros and cons of each method. 
Table 6 Pros and Cons of Administration Methods

\begin{tabular}{|c|c||}
\hline \multicolumn{1}{|c|}{ In-Person } & Online \\
\hline \hline $\begin{array}{c}\text { Pros } \\
\text { Control over picture and sound quality }\end{array}$ & $\begin{array}{c}\text { Easier to pursue additional respondents if initial } \\
\text { efforts do not produce enough (i.e. don't have to } \\
\text { rent a room again) }\end{array}$ \\
\hline $\begin{array}{c}\text { On-site representative can answer questions and } \\
\text { deliver instructions }\end{array}$ & $\begin{array}{c}\text { Minimal risk of responses being linked to } \\
\text { incorrect clip }\end{array}$ \\
\hline $\begin{array}{c}\text { Minimal risk of individuals taking survey more } \\
\text { than once }\end{array}$ & Can obtain a broader geographic mix \\
\hline More likely to get a varied demographic mix & Cons \\
\hline \hline $\begin{array}{c}\text { May become time and money intensive if } \\
\text { capture rate is low }\end{array}$ & Excludes individuals without internet access \\
\hline $\begin{array}{c}\text { Lack of geographic diversity } \\
\text { Respondents may not properly link their score } \\
\text { sheets to video clip numbers }\end{array}$ & $\begin{array}{c}\text { Potential for bias in responses due to differing } \\
\text { video/audio quality among respondent } \\
\text { computers }\end{array}$ \\
\hline $\begin{array}{c}\text { Potential complications from equipment failure } \\
\text { individual }\end{array}$ & $\begin{array}{c}\text { No project representative present to ask } \\
\text { questions or offer instructions }\end{array}$ \\
\hline \hline
\end{tabular}

Ultimately, given the above pros and cons list, chiefly that there is control over the picture and sound quality, and that it has been used by other methods $(11,12,20$, $21,27)$, the author and his thesis committee determined that in-person surveys were the best option for this effort. If an online survey were to produce similar results to an in-person survey, the ability to distribute the online survey more readily to a wide audience would give it a significant advantage over the in-person survey. Recognizing this, an on-line survey was also created to test whether the results from such a survey would be significantly different from an in-person survey.

Further, a number of prior efforts have advertised to bicycle-focused groups as part of their recruitment efforts $(17,18,19,20,21,22,24,27)$. This has the potential to bias results; however, it also presents a simple and effective way to attract participants 
to such a survey. Therefore, it was also decided that the online survey would be advertised through bicycle and transportation-focused groups in order to better understand how this might influence participant demographics and responses.

\section{Survey Instrument}

The survey instrument was designed to make it comparable to previous methods, to be simple and easy to understand, and to collect enough demographic information to examine potential biases in the sample. Respondents are asked to rate each clip on a scale from ' $A$ ' (extremely comfortable) to ' $F$ ' (extremely uncomfortable). The ' $A$ ' through ' $F$ ' scale is intuitively understood by most people and is comparable to the six point scales used in the $2010 \mathrm{HCM}$ and Danish LOS methods $(8,11)$. Once they have viewed all the clips, participants are asked to provide the following demographic information:

- Age

- Gender

- If they have any physical limitations that prevent them from riding a bicycle (yes/no)

- If they have access to a working bicycle (yes/no)

- How often they ride a bicycle for commuting, recreation/exercise, and for other purposes (Never, 1-2 times/month, 1-2 times/week, 3-5 times/week, or 6+ times/week)

- The extent to which they agree disagree with the statement "I would like to ride a bicycle more than I do now" 
Figure 5 shows part of the front of the in-person survey instrument. The full instrument can be found in Appendix 'B.'

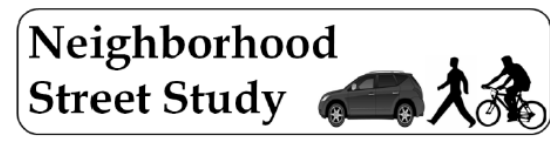

Video Clip Questionnaire

Please circle the letter grade that best represents how comfortable you would feel riding a bicycle in each situation shown. Please match the clip \# on this survey sheet to the number shown on the video. Thank you!

$A=$ Extremely Comfortable, $F=$ Extremely Uncomfortable

\begin{tabular}{|c|c|c|c|c|c|c|}
\hline Clip \# & \multicolumn{6}{|c|}{ Rating } \\
\hline \hline 1 & A & B & C & D & E & F \\
\hline 2 & A & B & C & D & E & F \\
\hline 3 & A & B & C & D & E & F \\
\hline
\end{tabular}

Figure 5 Front of In-Person Survey Instrument

\section{Day of In-Person Survey Procedures/Set-up}

The in-person survey was conducted three times. The first two surveys took place from approximately 9:00 a.m. to 1:00 p.m. during the weekly Portland Farmer's Market located at the Portland State University (PSU) campus on November 16 and 23, 2013. There are several farmer's markets in the Portland area, but the one held at PSU is the largest. It was chosen as a location for the survey because it attracts a good range of people, in terms of age, gender, and bicycling habits. Given that it was late in the season, so most markets had closed, and one of the weekends was before Thanksgiving, it was expected that the market would be drawing from around the region and not just inner Portland.

The survey itself was conducted in a room in the PSU student union building, setup with a projector, screen and external sound system, as shown in Figure 6. Lights were 
turned off in the room; though the blinds were left open just enough to allow participants to be able to read their sheets. The audio was turned up to a volume that represented actual traffic conditions. The clips were played on a continuous loop with the clip number appearing before each one started, so participants were instructed to find the first clip number that appeared after they entered the room on their grading sheet and begin from there, continuing until they came back to where they started. Eight-seconds of grading time were provided after each clip, too.

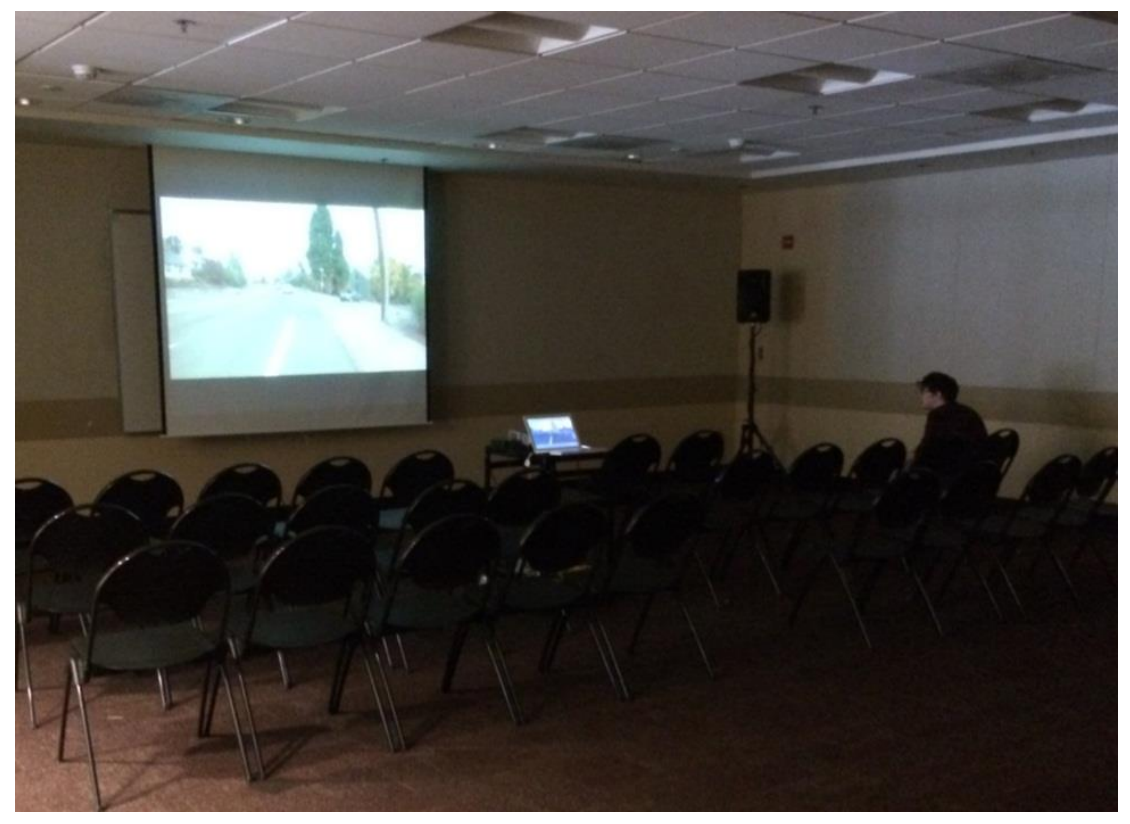

Figure 6 Video Survey Room Set-up

The survey was advertised through signs placed outside of the entrance to the student union where the Farmer's Market was taking place, as shown in Figure 7. Participants were offered a $\$ 5$ token to be spent at the Farmer's Market in exchange for their participation in the survey. This incentive was chosen out of a desire to offer something that would enhance individual's experience at the market. One vendor 
located near the signs also appreciated the incentive and picked up the signs when the wind knocked them over on a few occasions. Participants followed the signs and checked-in with members of the project team stationed at a table outside the room where they received instructions and a survey form. Once they had completed the survey, they returned the form to the project team, filled out a form with their contact information for PSU recordkeeping purposes that was kept separate from the survey forms, and received the incentive.

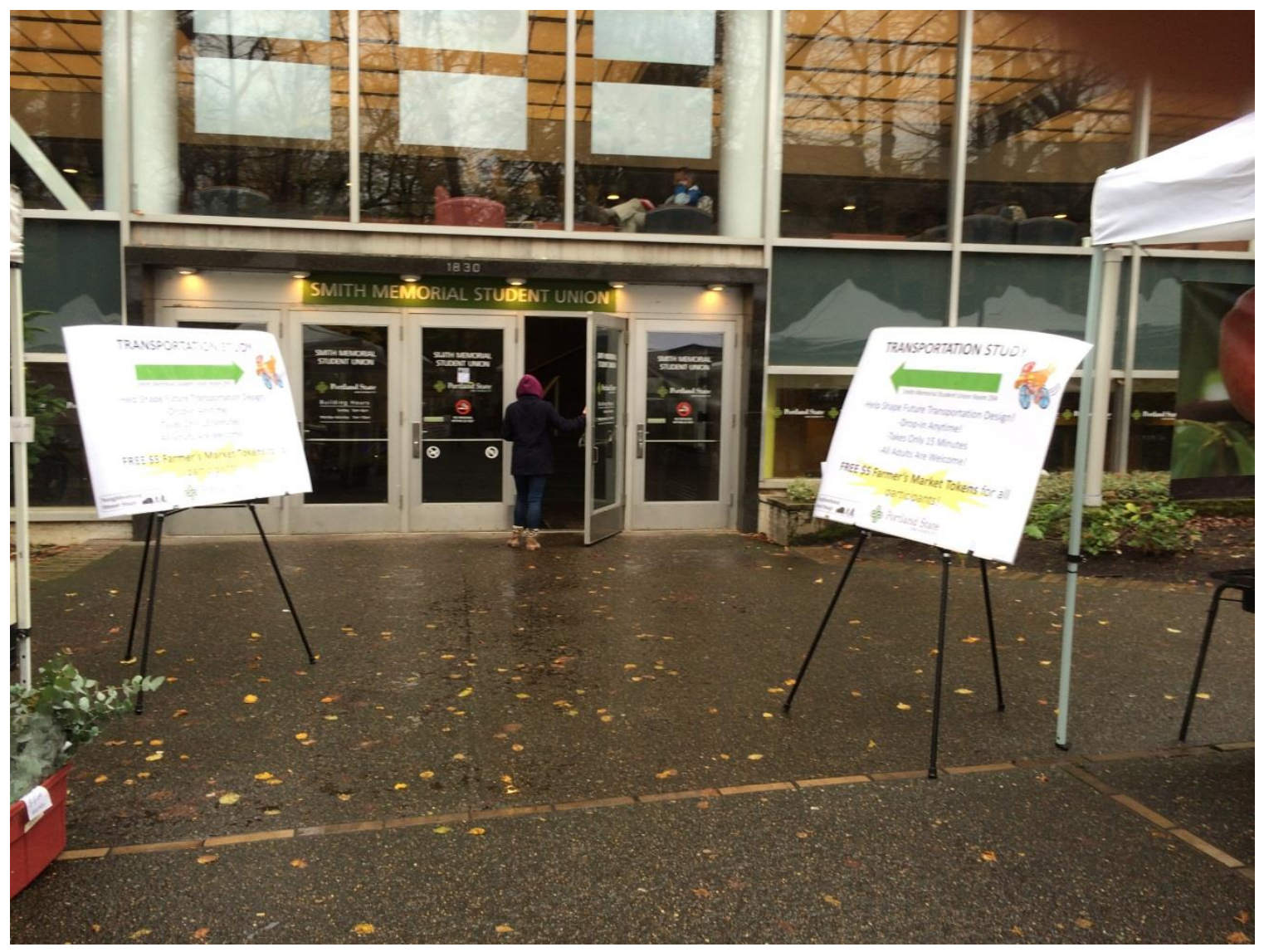

Figure 7 Survey Advertisement at Portland Farmer's Market

The third and final in-person survey took place at the Oregon Museum of Science and Industry (OMSI) on December 4, 2013 from 5:00 to 10:00 p.m. The survey coincided 
with the monthly OMSI After Dark event, in which the museum is only open to those age 21 years or older and local food and beverage vendors set up around the museum. This event was chosen because it eliminated the difficulty of trying to recruit parents with children to take the survey, which was only open to those age 18 years or older, and because it is a popular event drawing hundreds of guests from around the area.

The set-up and process at OMSI was mostly similar to the farmer's market. There were a few differences. Instead of a $\$ 5$ farmer's market token, participants were offered a $\$ 5$ voucher to be used at one of the vendors or at the museum eatery. Signs could not be placed in the museum so project volunteers instead went out and recruited participants. This ended up being an important change, as the room the survey was held in was not in an obvious location, so it helped having people to show participants the way.

\section{Online Survey}

The online survey was similar to the in-person survey. It used the same 20 video clips as the latter two in-person surveys. The same rating system and demographic questions were also used. However, the online survey did not show the clips in the same order. Instead, it requested that participants watch at least ten clips that were selected by the author (clips 3b, $7,8,11-16$, and 20b). These ten clips provide a variety of protected bike lane situations and a couple reference clips. After watching these first ten clips, participants could choose to watch two, four, six, eight, or all ten remaining clips. The reasoning behind allowing fewer clips being watched is that no incentive was 
being offered and it was felt that getting at least some data from many participants was better than having only a few people watch all twenty clips.

The online survey was first advertised starting on February 13, 2014. Initial advertising channels included:

- Association of Pedestrian and Bicycle Professionals (APBP) listserv

- PSU Students in Transportation Engineering and Planning (STEP) listserv, which includes alumni and faculty, in addition to current students

- PSU Civil and Environmental Engineering Department's Facebook page and weekly newsletter

- Oregon Transportation Research and Education Consortium (OTREC) Twitter and Facebook

- Committee members social media accounts

Participants were asked how they heard about the survey. Based on the responses to this question, the following points can be gleaned:

- The initial APBP and OTREC posts were cited frequently

- Several local public agency bike programs and local bike advocacy groups spread the message to their constituents

- Organizations from Knoxville, Tennessee were cited the most often of those who passed on one of the original advertisements

\section{Summary}

Video survey, where individuals watch a video clip taken from the bicyclist perspective along a given route and then rate how comfortable they would feel on an ' $A$ ' through ' $F$ ' scale were they the bicyclist in the video, is used in this project. It is chosen over field rides because it is more efficient and allows people to rate conditions not found locally. In addition to the comfort ratings, participants also provide basic demographic information, including age, gender, and bicycling habits. 
High-definition video is recorded along several different routes using a camera mounted to a bicycle at bicyclist eye level. In total, 23 video clips ranging from 20 to 30 seconds in length are selected for the survey, with 20 being shown at a given time (three of the original 20 are replaced after the first iteration of the survey) for a total video running time of just less than 15 minutes. Most of the clips are from protected bike lanes and represent a range of buffer types (e.g. planters, parked cars, plastic posts), traffic conditions (i.e. motor vehicle speed and volume), and one and two-way bicycle travel. Multiple clips from the same facility are shown in certain instances in order to isolate the impact that a change in motor vehicle volume in the video has on stated comfort. In addition to the protected bike lane clips, a number of videos are included that represent more common bicycle routes (e.g. off-street paths, bike lanes, and shared streets). These clips are included for reference purposes to understand how comfortable protected bike lanes are in relation to the more common infrastructure types.

The primary survey for this project is administered in-person in a room with a projector, screen, and speakers. In-person administration is chosen over an online survey because of the ability to control the audio and video quality and it is how other similar surveys have been administered. The in-person survey is administered three times at locations where a range of participants are captured: the Portland Farmer's Market at PSU and the Oregon Museum of Science and Industry. 
An online survey is also conducted and it is advertised through transportation and bicycle-focused channels (e.g. APBP listserv, OTREC social media). The purpose of the online survey is to determine how the different administration and advertising methods impact the results compared to an in-person survey advertised to a broader range of the population.

The next chapter describes the results of these efforts. 


\section{Results}

The following section summarizes the results of the data analysis. This discussion is primarily focused on the results of the in-person surveys and includes an overview of the participant demographics, correlation between scores and different facility and demographic characteristics, and a discussion of potential models to predict scores of other facilities. The results of the in-person surveys are compared to the online surveys to evaluate the potential use of online surveys for use in future studies. Finally, the results of the surveys are compared to responses of a survey conducted for the Green Lane project of individuals who actually have ridden on some of the study facilities.

\section{In-Person Video Survey Participants}

A total of 221 individuals participated in the in-person video survey. Survey participants provided basic demographic and bicycle riding experience information. The resulting sample provides a wide range of participants in terms of age, gender, and bicycle riding experience. This mix is further described below.

Age

Figure 8 shows that the age of participants is distributed widely from 18 years old, the minimum age to participate in the survey, to 89 years old. 


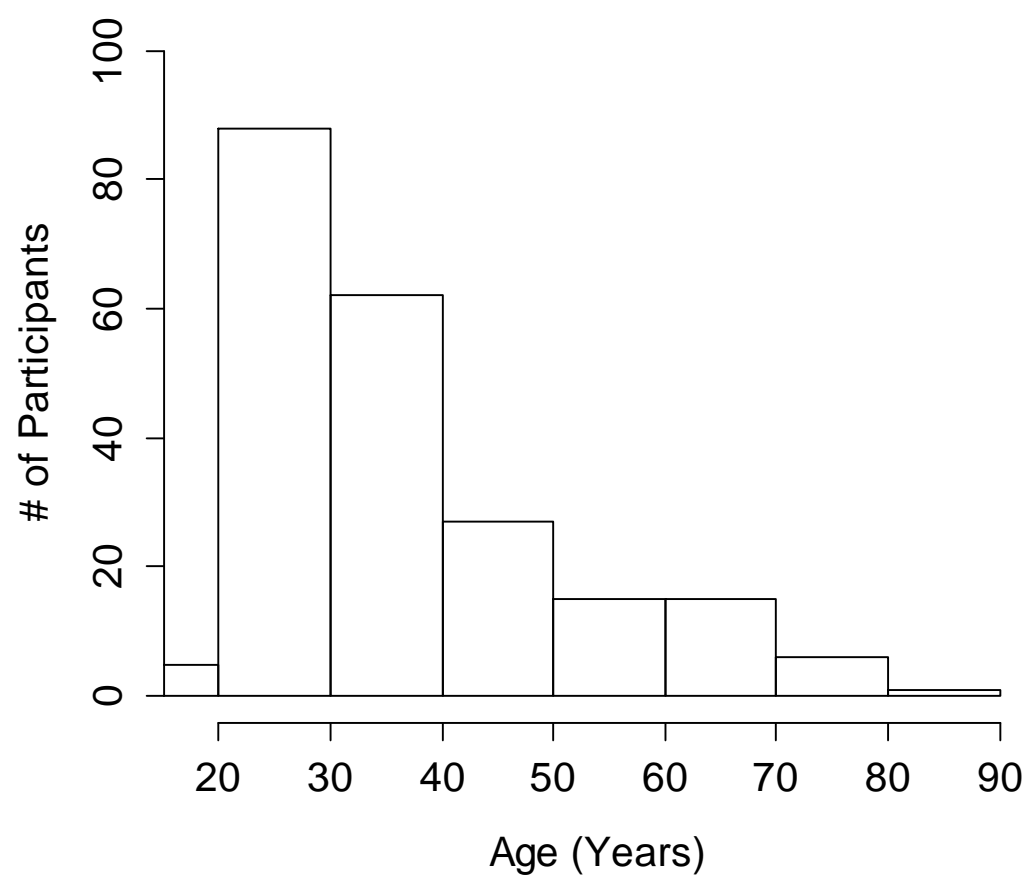

Figure 8 Distribution of Participants' Ages

The sample does skew toward younger participants, with a median age of 32 years. This distribution is younger than the samples in the FDOT and HCM BLOS studies $(17,19,27)$. The interquartile range of ages spans 17 years, from 27 years old to 44 years old. Nearly $20 \%$ of the sample is age 50 years or older. The average age of the sample, approximately 36 years old, is similar to the mean from the FHWA BCI sample (21).

\section{Gender}

Females are slightly more represented than males in the sample, but they are fairly evenly split, as shown in Table 7. This split is similar to the sample for the Danish 
LOS (11) study. Females make up a larger proportion of the sample for this study as compared to the FDOT BLOS (19) and FHWA BCl (21) efforts

Table 7 Participants' Gender

\begin{tabular}{|l|c|}
\hline \multicolumn{1}{|c|}{ Gender } & \% of Participants (n) \\
\hline \hline Female & $52 \%(115)$ \\
\hline Male & $47 \%(103)$ \\
\hline Other & $<1 \%(1)$ \\
\hline No Response & $1 \%(2)$ \\
\hline
\end{tabular}

\section{Access/Limitations}

The majority of participants have access to a working bicycle, as shown in Table

8.

Table 8 Access to a Working Bicycle

\begin{tabular}{||l|c|}
\hline Access to a Working Bicycle & \% of Participants (n) \\
\hline \hline Yes & $79 \%(175)$ \\
\hline No & $20 \%(44)$ \\
\hline No Response & $1 \%(2)$ \\
\hline
\end{tabular}

Nearly all participants are capable of riding a bicycle, with only one respondent having a physical limitation and two respondents not answering the question.

\section{Bicycle Riding Habits}

Participants provided an estimate of how frequently they ride a bicycle for commuting to/from work/school, recreation, and for other purposes. Figure 9 summarizes the responses to this question. 


\section{Commuting}

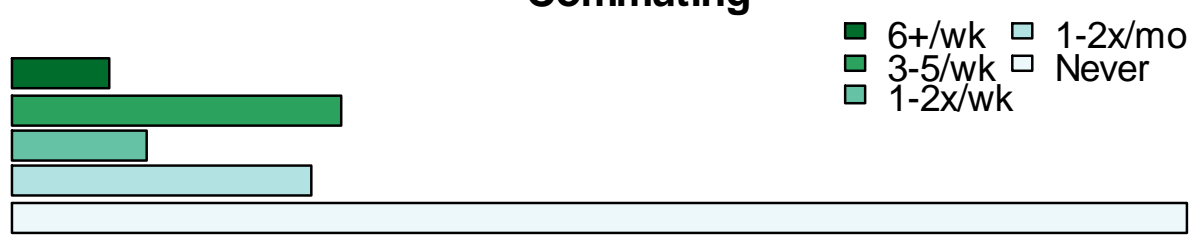

Recreation

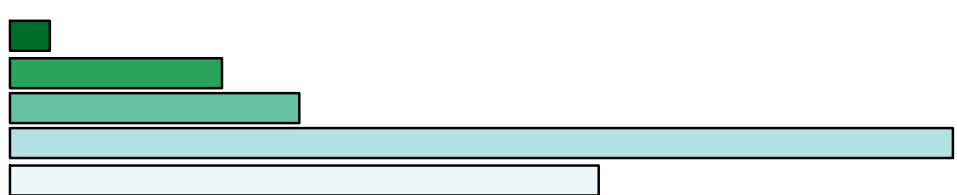

Other Purposes

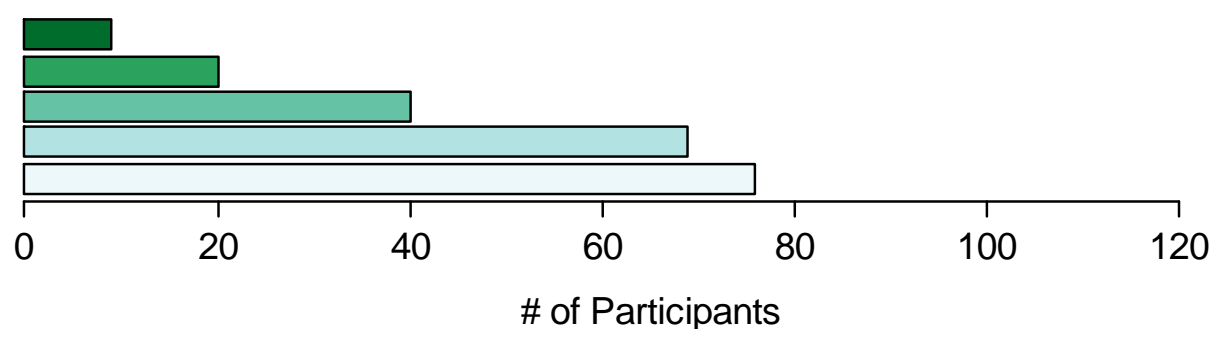

Figure 9 Participants' Bicycle Riding Frequency by Trip Purpose

Most respondents are not regular bicycle riders. Of those that do ride, recreation is the most popular reason for riding, with just over $70 \%$ (154) of respondents bicycling at least once per month for recreation. Comparatively, approximately $64 \%$ (138) said the same about other purposes and only around $42 \%$ (89) commute by bicycle at least once per month. 
To better understand participants' overall riding habits, Table 9 summarizes how often respondents report bicycling for any purpose.

Table 9 Participants' Riding Habits - All Trip Purposes

\begin{tabular}{|l|c|}
\hline Riding Frequency & \% of Participants (n) \\
\hline \hline $6+/$ week & $6 \%(14)$ \\
\hline $3-5 x /$ week & $20 \%(44)$ \\
\hline $1-2 x /$ week & $16 \%(35)$ \\
\hline $1-2 x /$ month & $34 \%(75)$ \\
\hline Never & $23 \%(50)$ \\
\hline No Response & $1 \%(3)$ \\
\hline
\end{tabular}

Only about one-fourth of respondents are frequent bicycle riders (3+ times/week), while nearly the same proportion report never riding a bicycle. Approximately one-half of respondents are occasional riders, reporting that they bicycle from once per month to twice per week.

\section{Attitude}

Participants are asked if they would like to bicycle more often than they currently do. As shown in Table 10 nearly $90 \%$ responded that they would like to ride more often. Of those that disagreed with the statement, just over half, eight, ride a bicycle at least three times per week. Therefore, only about 3\% of respondents do not ride often and are not interested in riding more often. This suggests that the sample generally has a positive attitude toward bicycling, even if they do not necessarily ride very often themselves. 
Table 10 Responses to Statement "I would like to ride a bicycle more than I do now"

\begin{tabular}{||l|c||}
\hline \multicolumn{1}{|c|}{ Response } & \% of Participants (n) \\
\hline \hline Strongly Agree & $55 \%(121)$ \\
\hline Somewhat Agree & $33 \%(73)$ \\
\hline Somewhat Disagree & $4 \%(9)$ \\
\hline Strongly Disagree & $3 \%(6)$ \\
\hline No Opinion & $4 \%(9)$ \\
\hline No Response & $1 \%(2)$ \\
\hline
\end{tabular}

The sample generally represents a wide range of individuals, comparable to, or more diverse than, previous studies. However, it skews younger and bicycles more frequently than the general population and generally has a favorable attitude toward bicycling. To determine what impacts these demographics may have on the comfort ratings, correlations between demographic characteristics and comfort ratings are discussed later in this chapter.

\section{Overview of Rating Results}

For analysis purposes, the letter grades are converted to numeric values, with an ' $A$ ' being a 1 and a ' $F$ ' being a 6 . The average score of all clips for each participant typically falls within the ' $B$ ' to ' $C$ ' range. Several mean scores are close to 'A,' while a few are in the ' $D$ ' to ' $E$ ' range. A histogram of the results show that mean scores are approximately normally distributed, though skewed left. This distribution is shown in Figure 10. 


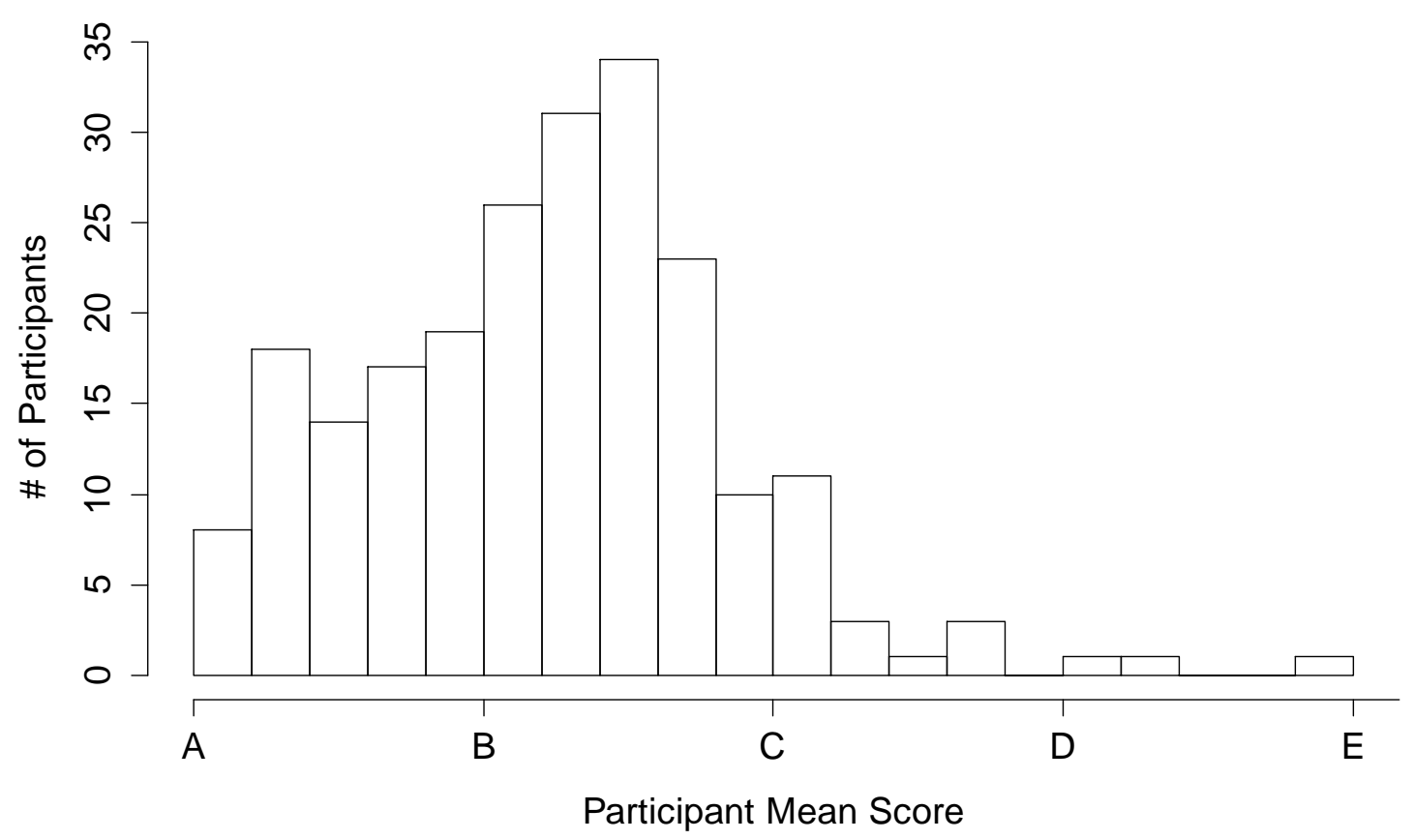

Figure 10 Distribution of Participant Mean Scores

\section{Scores by Session}

In-person surveys were completed across three different sessions. While efforts were made to ensure that the viewing experience was as consistent as possible across each session, the third session was held in a different location than the first two. Demographics are relatively consistent across the first two sessions, but the sample for the third session is younger, rides less frequently, and has a higher proportion of female respondents. Therefore, the results from each session are compared to each other to determine if differences between the sessions has a significant impact on viewer ratings. Table 11 summarizes the mean and median scores from each session for all clips watched, as well as for only the 17 clips that are consistent between all three sessions. 
Table 11 Mean/Median Scores by Viewing Session

\begin{tabular}{|l|c|c||}
\hline \multicolumn{1}{|c|}{ Session (n) } & $\begin{array}{c}\text { Mean/Median } \\
\text { Score (all clips) }\end{array}$ & $\begin{array}{c}\text { Mean/Median } \\
\text { Score (17 clips) }\end{array}$ \\
\hline \hline Farmer's Market-1 (73) & 2.24/B & $2.25 / \mathrm{B}$ \\
\hline Farmer's Market-2 (73) & $2.23 / \mathrm{B}$ & $2.21 / \mathrm{B}$ \\
\hline OMSI (75) & $2.27 / \mathrm{B}$ & $2.21 / \mathrm{B}$ \\
\hline
\end{tabular}

The mean scores for each session are relatively similar, for all clips and for only the 17 consistent clips. An ANOVA test of the scores shows that the differences between mean scores are not statistically significant $(p=0.77$ for all clips and $p=0.66$ for the 17 consistent clips). Median scores are identical for all sessions, too.

Examining these data further, Table 12 shows the proportion of individual scores within each grade level for each session for all clips and only for the 17 consistent clips.

Table 12 Observed Score Frequencies by Session

\begin{tabular}{|c|c|c|c|c|c|c|}
\hline \multirow[b]{2}{*}{ Session (n) } & \multicolumn{6}{|c|}{ \# of Scores } \\
\hline & A & B & C & D & $E$ & $\mathbf{F}$ \\
\hline \multicolumn{7}{|c|}{ All Clips } \\
\hline Farmer's Market-1 (73) & $37 \%$ & $28 \%$ & $19 \%$ & $8 \%$ & $5 \%$ & $3 \%$ \\
\hline Farmer's Market-2 (73) & $34 \%$ & $31 \%$ & $22 \%$ & $8 \%$ & $4 \%$ & $2 \%$ \\
\hline OMSI (75) & $34 \%$ & $31 \%$ & $19 \%$ & $10 \%$ & $3 \%$ & $3 \%$ \\
\hline \multicolumn{7}{|c|}{17 Consistent Clips Only } \\
\hline Farmer's Market-1 (73) & $37 \%$ & $28 \%$ & $19 \%$ & $8 \%$ & $5 \%$ & $2 \%$ \\
\hline Farmer's Market-2 (73) & $36 \%$ & $30 \%$ & $20 \%$ & $9 \%$ & $3 \%$ & $2 \%$ \\
\hline OMSI (75) & $36 \%$ & $31 \%$ & $18 \%$ & $10 \%$ & $3 \%$ & $3 \%$ \\
\hline
\end{tabular}

Chi-squared tests reveal that the frequency distribution of these scores is not independent of the viewing session ( $p=0.02$ for all clips; $p=0.04$ for 17 consistent clips only). In particular, when only the 17 consistent clips are considered, there were more ' $E$ ' ratings in the first Farmer's market session than would be expected $(47$, residual $=$ 2.88) and fewer ' $E$ ' ratings at the OMSI session than would be expected (48, residual = 2.23). All other residuals were between 1.0 and -1.0. Comparisons of only two sessions 
at a time show that the difference in frequency distributions are only significant between the first Farmer's Market session and the OMSI session (chi-squared p-value = 0.01). Given the difference in demographics between these sessions, this result is not surprising.

\section{Demographic Effects}

Previous studies have produced mixed results in terms of whether demographics impact comfort ratings. Jensen (11) found no significant correlation between demographics and scores for the Danish LOS model; though his study did observe that men and younger individuals generally felt more comfortable. While not a LOS model, Tilahun, et al. (3) found that gender and age produced similar trends in their utility model but were not significant predictors at the $95 \%$ confidence level. However, Petritsch, et al. (12) found age and gender to both be significant predictors in their work to develop a LOS model for FDOT, with the trends being similar to those previously described. Harkey, et al. (21) and Sorton and Walsh (14) also found that more experienced riders are typically more comfortable than less experienced riders. Winters and Teschke (4) also found gender and cycling experience to be significant predictors of route type preference.

Correlations between scores and demographics are analyzed here in order to determine what types of biases may exist within the sample. Correlations between demographics and scores can also provide professionals and policymakers with insights into what types of treatments may be better received by certain population subgroups. 
Table 13 provides a summary of Pearson correlations between demographic variables and clip scores for the 17 consistent clips only.

Table 13 Demographic Variable Correlations

\begin{tabular}{||l|c|c||}
\hline \multicolumn{1}{|c|}{ Variable } & $\begin{array}{c}\text { R (p-value) - Mean } \\
\text { Score }^{\mathbf{1}}\end{array}$ & $\begin{array}{c}\mathbf{R} \text { ( } \mathbf{p} \text {-value) - } \\
\text { Individual Clip Scores }\end{array}$ \\
\hline \hline Age & $0.12(0.09)$ & $0.06(<0.01)^{*}$ \\
\hline Gender (0=Male) & $0.05(0.44)$ & $0.03(0.11)$ \\
\hline Riding Habits & $-0.19(<0.01)^{* *}$ & $-0.10(<0.01)^{* *}$ \\
\hline
\end{tabular}

${ }^{1}$ Positive correlation indicates less comfortable as variable increases

*Significant at the $95 \%$ confidence level

$* *$ Significant at the $99 \%$ confidence level

The demographic variables are weakly correlated with the scores of individual

clips, as well as the mean score for each participant. The correlation between gender and score is not significant. The following subsections discuss these variables further.

\section{Age}

Figure 11 shows the distribution of mean scores by participant age for the consistent clips. 


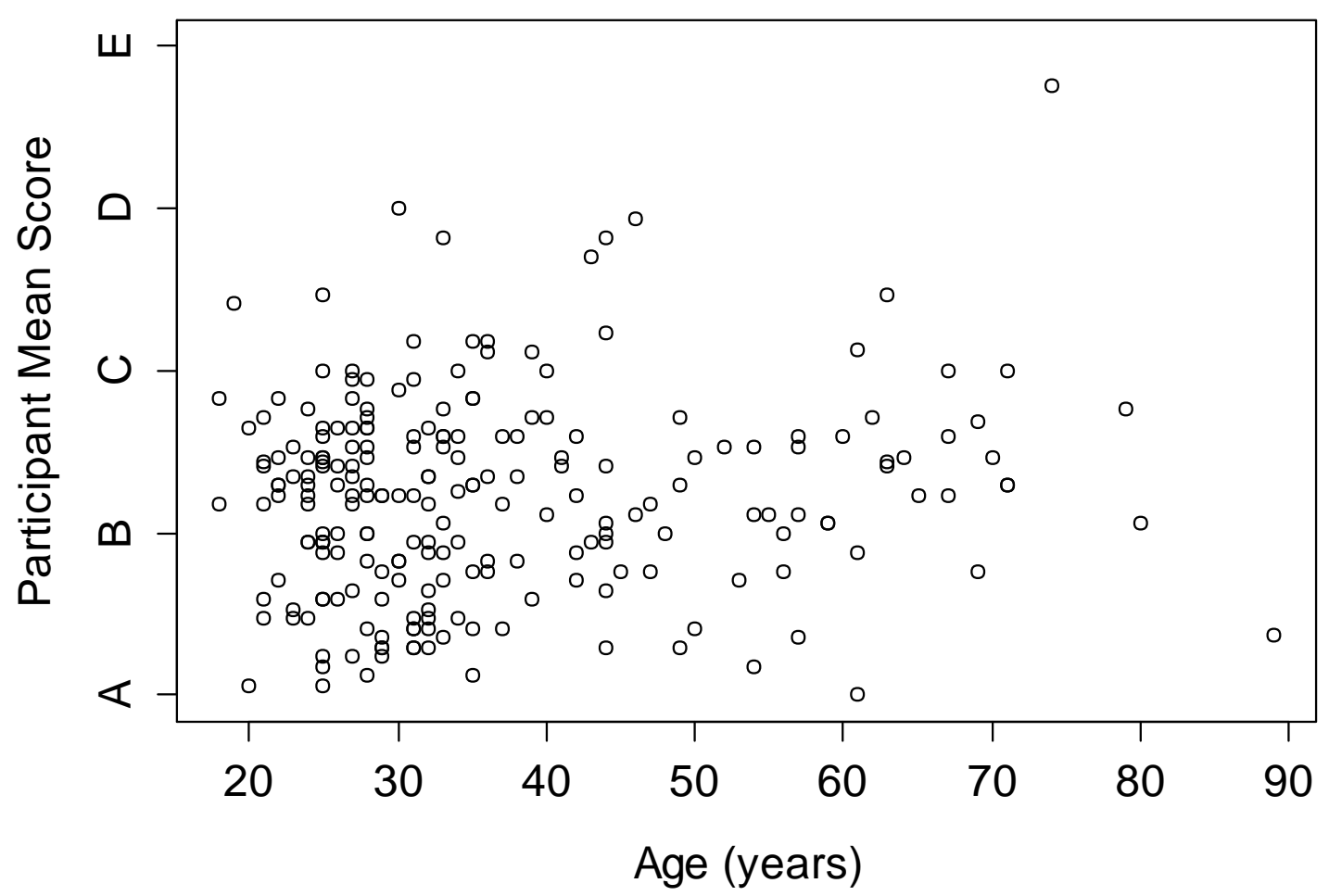

Figure 11 Participant Mean Score by Participant Age - Consistent Clips Only ( $=219)$

Mean scores generally vary widely by age. A regression analysis of participant mean score (consistent clips only) on age indicates that age is a significant predictor of mean score $(p<0.01)$, but its effect is minimal, with the mean score increasing by 0.005 points (less comfortable) on average for each increase in year of age and an $R^{2}$ value of less than 0.01 .

\section{Gender}

Table 14 summarizes the mean and median score for the consistent clips by gender from this study. 
Table 14 Mean and Median Score by Gender - Consistent Clips Only

\begin{tabular}{|l|c|}
\hline \multicolumn{1}{|c|}{ Gender $^{1}$} & Mean/Median Score \\
\hline \hline Female & $2.25 / \mathrm{B}$ \\
\hline Male & $2.18 / \mathrm{B}$ \\
\hline
\end{tabular}

${ }^{1}$ The sample size (1) for "other" responses is small, so only female/male are analyzed

There is a difference in mean scores between the two genders, and as expected, females on average felt slightly less comfortable. However, the difference in mean scores is minimal and not statistically significant (Welch two-sample t-test $p$ value = $0.11)$

\section{Riding Habits}

It has previously been shown that those who ride more frequently tend to respond that they would feel more comfortable in certain situations than those who do not ride as often $(14,21)$. Figure 12 shows the mean score based on how often respondents report bicycling for any purpose.

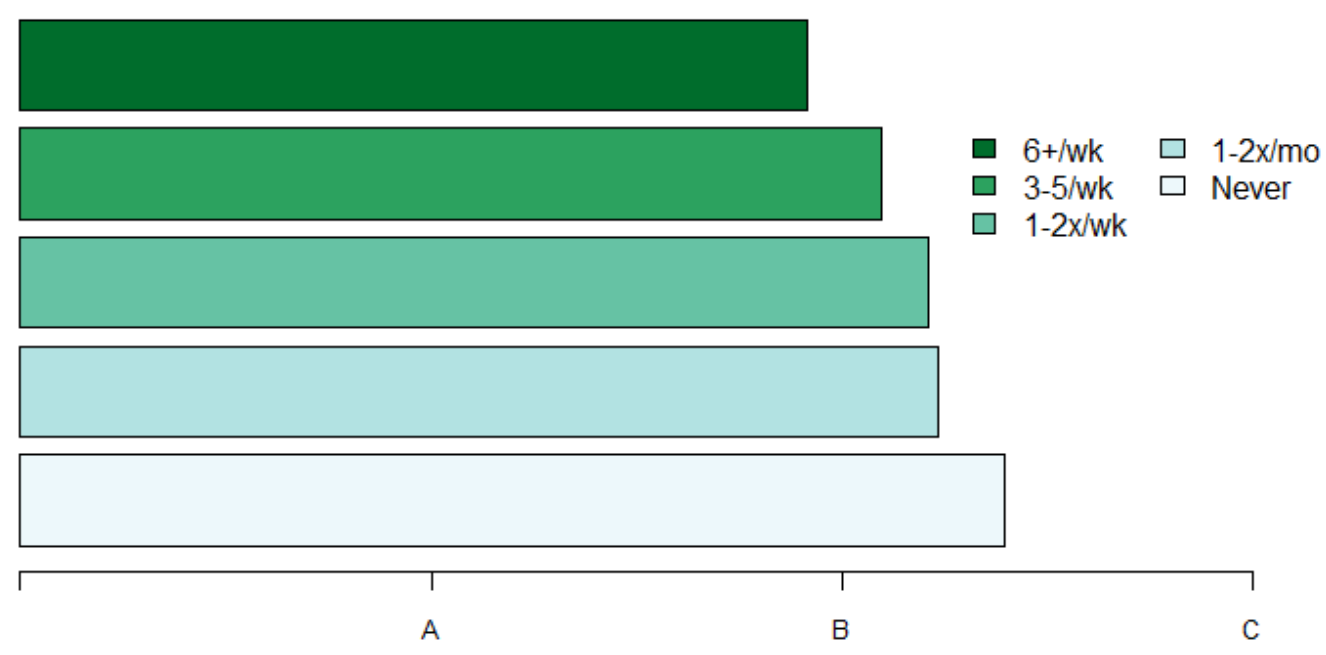

Mean Score

Figure 12 Mean Score by Participant's Riding Frequency - Consistent Clips Only ( $\mathrm{n=218}$ ) 
Individuals that report riding more frequently also report higher levels of perceived comfort. An ANOVA test shows that these results are significant on the whole $(F=9.31, p<0.01)$. The largest significant difference occurs between those that never ride and those that ride at least once or twice per month, which a Tukey post-hoc test reveals is significant $(p=0.03)$. The Tukey post-hoc test reveals that the difference between all other pairings of adjacent groups is not significant at the $95 \%$ confidence level. More frequent riding does lead to individuals providing more comfortable ratings; however, the difference is only significant between large differences in riding habits.

\section{Facility Characteristics}

The primary purpose of this study is to identify the effects that different facility characteristics have on perceived bicyclist comfort, since these are the important design decisions that planners and engineers must make in designing and planning new protected bike lanes.

\section{Individual Clips}

Figure 13 shows the average score for each clip and Table 15 summarizes the corresponding facility characteristics. 


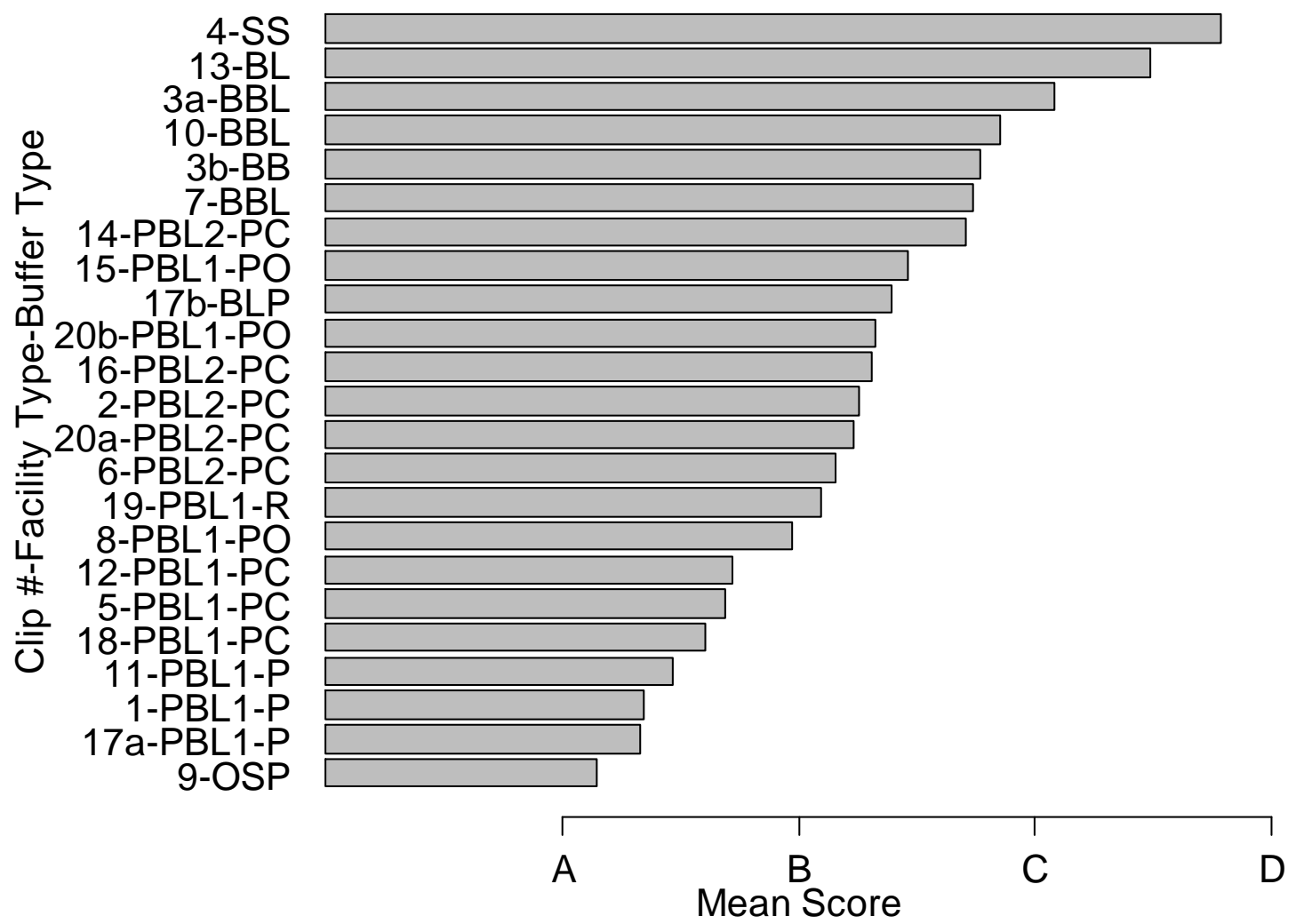

BB=Bike Boulevard; BBL=Buffered Bike Lane; BL=Bike Lane; BLP=Bike Lane w/ Parking; $\mathrm{OSP}=$ Off-Street Path;PBL1=1-way Protected Bike Lane; PBL2=2-way Protected Bike Lane; SS=Shared Street; $\mathrm{PC}=$ Parked Cars; $\mathrm{P}=$ Planters; $\mathrm{PO}=$ Posts

Figure 13 Mean Score by Video Clip 
Table 15 Mean/Median Score by Clip and Characteristics

\begin{tabular}{|c|c|c|c|c|c|c|}
\hline Clip \# & Facility & Buffer Type & $\begin{array}{c}\text { MV Volume } \\
\text { in Adjacent } \\
\text { Lane } \\
\text { (veh/hr) }\end{array}$ & $\begin{array}{c}\text { Mean/ } \\
\text { Median } \\
\text { Score }\end{array}$ & $\begin{array}{l}\text { Standard } \\
\text { Deviation }\end{array}$ & $\begin{array}{c}\text { Interquartile } \\
\text { Range }\end{array}$ \\
\hline 9 & Off-Street Path & $\mathrm{N} / \mathrm{A}$ & $\mathrm{N} / \mathrm{A}$ & $1.14 / \mathrm{A}$ & 0.64 & $A$ \\
\hline $17 a$ & 1-Way PBL & Planters & 857 & $1.33 / \mathrm{A}$ & 0.78 & $A$ \\
\hline 1 & 1-Way PBL & Planters & 257 & $1.34 / \mathrm{A}$ & 0.63 & $A-B$ \\
\hline 11 & 1-Way PBL & Planters & 600 & $1.46 / \mathrm{A}$ & 0.68 & $A-B$ \\
\hline 18 & 1-Way PBL & Parked Cars & 1,286 & $1.60 / \mathrm{A}$ & 0.80 & $A-B$ \\
\hline 5 & 1-Way PBL & Parked Cars & 338 & $1.69 / \mathrm{A}$ & 0.89 & $A-B$ \\
\hline 12 & 1-Way PBL & Parked Cars & 840 & $1.72 / \mathrm{A}$ & 0.92 & $A-B$ \\
\hline 8 & 1-Way PBL & Posts & 343 & $1.97 / \mathrm{B}$ & 0.94 & $A-C$ \\
\hline 19 & 1-Way PBL & Raised/Parking $^{1}$ & 360 & 2.09/B & 1.05 & $A-C$ \\
\hline 6 & 2-Way $\mathrm{PBL}^{2}$ & Parked Cars & 277 & 2.16/B & 1.05 & $A-C$ \\
\hline $20 a$ & 2-Way $\mathrm{PBL}^{3}$ & Parked Cars & 840 & $2.23 / \mathrm{B}$ & 1.20 & $A-C$ \\
\hline 2 & 2-Way $\mathrm{PBL}^{3}$ & Parked Cars & 360 & $2.25 / \mathrm{B}$ & 1.18 & $A-C$ \\
\hline 16 & 2-Way $\mathrm{PBL}^{2}$ & Parked Cars & 626 & $2.31 / \mathrm{B}$ & 1.14 & $A-C$ \\
\hline $20 b$ & 1-Way PBL & Posts & 600 & $2.32 / \mathrm{B}$ & 1.10 & $\mathrm{~B}-\mathrm{C}$ \\
\hline $17 b$ & $\begin{array}{c}\text { Bike Lane w/ } \\
\text { Parking }\end{array}$ & None & 1080 & $2.39 / B$ & 1.05 & $B-C$ \\
\hline 15 & 1-Way PBL & Posts & 960 & $2.46 / \mathrm{B}$ & 1.13 & $B-C$ \\
\hline 14 & 2-Way $\mathrm{PBL}^{3}$ & Parked Cars & 864 & $2.71 / \mathrm{C}$ & 1.31 & B-C \\
\hline 7 & $\begin{array}{c}\text { Buffered Bike } \\
\text { Lane }\end{array}$ & Double Stripe & 360 & $2.73 / C$ & 1.22 & B-C \\
\hline $3 b$ & Bike Boulevard & None & 0 & $2.77 / \mathrm{B}$ & 1.49 & $B-D$ \\
\hline 10 & $\begin{array}{c}\text { Buffered Bike } \\
\text { Lane }\end{array}$ & Double Stripe & 1200 & $2.86 / C$ & 1.23 & $B-C$ \\
\hline $3 a$ & $\begin{array}{c}\text { Buffered Bike } \\
\text { Lane }\end{array}$ & Double Stripe & 840 & $3.08 / C$ & 1.30 & $B-D$ \\
\hline 13 & Bike Lane & None & 360 & $3.48 / \mathrm{C}$ & 1.25 & $C-D$ \\
\hline 4 & Shared Street & None & 360 & $3.78 / \mathrm{D}$ & 1.34 & C-E \\
\hline
\end{tabular}

${ }^{1}$ The on-street parking in clip \#19 was not occupied at all. In all other clips with on-street parking it is near full or fully occupied.

${ }^{2}$ Clip is riding in the same direction as motor vehicle traffic

${ }^{3}$ Clip is riding against the flow of motor vehicle traffic

The average score for each clip varies between ' $A$ ' and ' $D$ ', with many clips in the ' $B$ ' to ' $C$ ' range. An ANOVA analysis of the scores for each clip indicates that these results are significant on the whole $(\mathrm{p}<0.01)$. A Tukey post-hoc analysis reveals that the differences between the mean scores for each clip are mostly significant at the $p<.01$ level. 
Observations to note from the table and figure above, and the above mentioned ANOVA and Tukey post-hoc analysis include:

- The off-street shared-use path (clip \#9) has the best ratings

- Its mean score is not significantly different from those for the one-way protected bike lane with planters on NE Multnomah Street (clip \#'s 1, 11, 17a; $p=0.95,0.21,0.99$ from Tukey post-hoc analysis)

- One-way protected bike lanes score better than two-way

o There was only one 2-way facility, though

- Volumes in the clip seem to have minimal, if any, effect (i.e. clips of the same facility tend to be clustered together and not necessarily ordered by volume)

- They are either not a significant factor or the clips are too short

- In addition to the NE Multnomah Street protected bike lane and the off-street shared-use path, the protected bike lanes with parked car buffers on Elston Avenue (clip \#'s 12, 18) and SW Broadway Avenue (clip \#5) all have median scores of ' $A$ '

- They also have an interquartile range (IQR) of 1 and standard deviations less than 1.0 , suggesting ratings are pretty tightly grouped and $75 \%$ of responses are ' $\mathrm{B}$ ' or better

- Elston Avenue with posts (clip \#15) is significantly lower than Elston Avenue with parked cars (clip \#'s 12, 18)

- This could be due in part to going under a bridge and having a heavy truck go by in clip \#15

- Dearborn Street results suggest there is no difference between traveling with (clips \#'s 6, 16) or against traffic (clip \#'s 20a, 2, 14), except for clip \#14, on a twoway facility so separate calculations are not necessary for the different directions

- Clip \#14 has a puddle in it that causes the bicyclist to have to move to the oncoming bike lane at the end of the clip, which may impact the score

- The two buffered sections on SW Barbur Boulevard (clips \#'s 7, 10) scored better than the non-buffered section of the same road (clip \#13)

- A third buffered section (clip \#3a) is not significantly different ( $p=0.43$ ), but its sample size is also smaller $(n=73)$, as it was only shown at one session.

- SW Barbur Boulevard is also wider in the non-buffered clip

- The median score is ' $C$ ' for all clips on SW Barbur Boulevard, regardless of the presence or absence of a buffer 
- The bike boulevard clip (clip \#3b) has a relatively low average score, but its median score is a ' $\mathrm{B}$ ' and it has the highest standard deviation, 1.49.

- Some very low scores drug it way down

The differences between facility types and, in particular, protected bike lane clips will be discussed in greater detail in following subsections.

\section{Comparison to HCM Predictions}

The 2010 HCM BLOS method can be applied to the clips used in this video survey that illustrate typical bicycle facilities (i.e. shared streets and bike lanes). Table 16 compares the observed scores from the video survey to the scores predicted by the 2010 HCM BLOS link methodology after moving the unsignalized conflicts term to the link model as recommended by Petritsch, et al (31).

Table 16 Observed Median Ratings Compared to HCM 2010 Predicted Ratings

\begin{tabular}{||c|c|c|c||}
\hline Clip \# & Facility & $\begin{array}{c}\text { Observed } \\
\text { Median } \\
\text { Rating }\end{array}$ & $\begin{array}{c}\text { HCM 2010 Link } \\
\text { BLOS Predicted } \\
\text { Rating }\end{array}$ \\
\hline \hline 3b & Bike Boulevard & B & A \\
\hline 4 & Shared Street & D & A \\
\hline 13 & Bike Lane & C & A \\
\hline 17b & Bike Lane w/ Parking & B & B \\
\hline
\end{tabular}

The HCM methodology generally predicts better scores than observed during the video rating session, except for the clip that featured a bike lane alongside parking. $A$ primary reason for this clip receiving the ' $\mathrm{B}$ ' rating from the $\mathrm{HCM}$ method is that it had higher traffic volumes in the adjacent motor vehicle lane than did the other clips. These results suggest that the $H C M$ link results may be optimistic for how the general population might rate a facility. Note that if the HCM segment method (link and 
intersection combined) were employed instead of just the link method, all clips would receive a ' $D$ ' rating, even with the intersection score set to 0 , due in large part to the constant included in the segment model that provides all segments a base rating of ' $\mathrm{C}$.'

\section{Facility Type}

As was noted above, the off-street path has the most comfortable score, followed by one-way and then two-way protected bike lanes (PBLs). Figure 14 shows the mean score by facility type, for all clips.

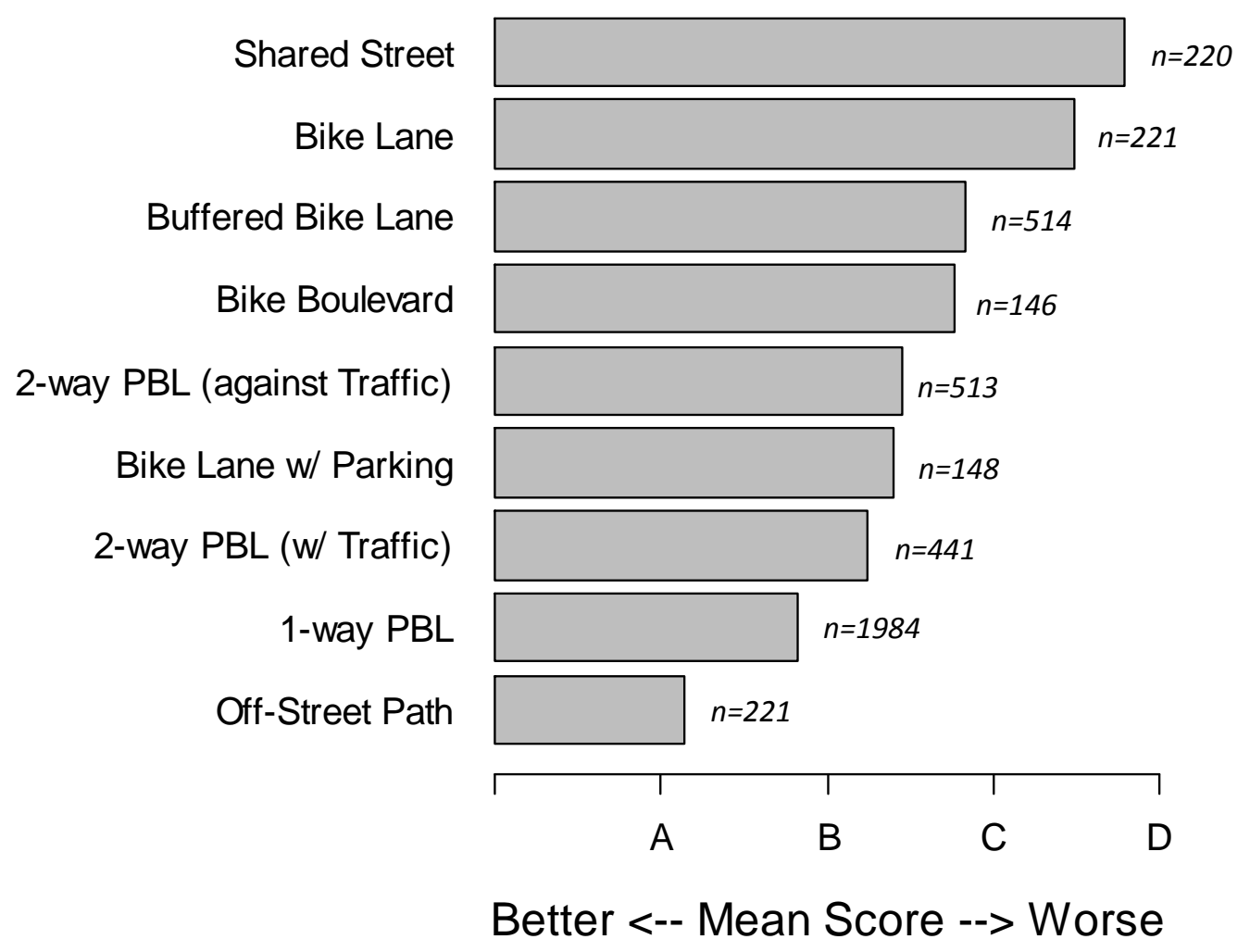

Figure 14 Mean Score by Facility Type

The relative preference for different facility types is mostly consistent with previous route preference research $(3,4,32)$. The exception to this is that the bike lane 
with parking facility type is ranked higher than the two-way PBL and the bike boulevard. This is possibly a function of there only being one clip representing a bike lane with parking and it is on a residential collector with a $25 \mathrm{MPH}$ speed limit. Also, the ratings for the bike boulevard clip have the largest standard deviation in the study and the median score for the bike boulevard is the same, 'B,' as the bike lane with parking clip.

An ANOVA test reveals that on the whole, the difference in mean scores by facility type is significant $(p<0.01)$. A Tukey post-hoc analysis of the ANOVA reveals that most facility types are significantly different from each other at $95 \%$ confidence level. Exceptions to this are the following groupings (all $p>0.05$ ):

- 2-way PBL (w/ traffic) - 2-way PBL (against traffic) - Bike lane with parking

- Bike lane w/ parking - 2-way CT (against) - Bike Boulevard

- Bike boulevard - Buffered bike lane

- Bike lane - Shared street The primary implication of these findings for protected bike lanes is that contraflow riding may not significantly influence comfort on a two-way protected bike lane. The lack of significance of the difference in the other facility types shown in the bullets above may be due to the relatively smaller sample sizes of the non-protected facilities, as shown in Figure 14.

The remainder of this analysis is primarily focused on the protected facilities.

\section{Buffer Type}

Figure 15 shows the mean score by buffer type for all protected bike lane clips. 


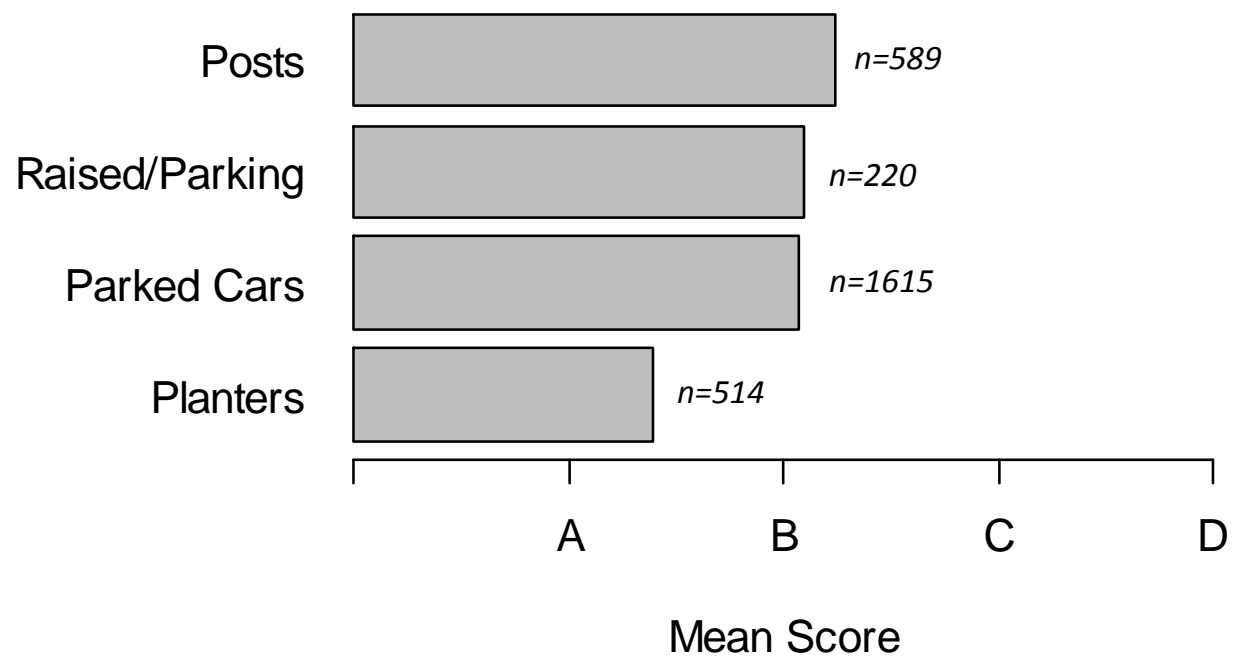

Figure 15 Mean Score by Buffer Type

Facilities with planters in the buffer had the most comfortable mean score, followed by parked cars, and then posts. Participant scores are regressed on buffer type and the resulting linear regression model indicates that approximately $7 \%$ of the variation in scores of protected facilities is due to the buffer type $(p<0.01)$.

A Tukey post-hoc analysis of an ANOVA of buffer type and score reveals that most buffer types are significantly different from each other at the $95 \%$ confidence level. The exceptions to this are raised/parking and parked cars and raised/parking and posts. There is only one clip that has a raised facility, so the sample size is small.

When only one-way protected bike lanes are analyzed, the correlation between buffer type and mean scores increases to where buffer type explains about $12 \%$ of the variance in mean scores. Most buffer types are still significantly different from each other at the $95 \%$ confidence level, except raised/parking and posts. 


\section{Functional Classification}

Table 17 summarizes the mean comfort score by adjacent roadway functional classification for all protected facilities and for one-way protected facilities only.

Table 17 Mean Score by Functional Classification

\begin{tabular}{||l|c|c||}
\hline Functional Classification & $\begin{array}{c}\text { Mean Score - All } \\
\text { Protected Facilities }\end{array}$ & $\begin{array}{c}\text { Mean Score - One-way } \\
\text { Protected Facilities }\end{array}$ \\
\hline \hline Collector & 2.00 & 1.76 \\
\hline Arterial & 1.95 & 1.95 \\
\hline
\end{tabular}

When all protected facilities are considered, arterials have a mean score that is more comfortable than collectors. This seems counterintuitive and may be in part due to the two-way facility on Dearborn Street being classified a collector. When only oneway facilities are considered, facilities on arterials have a higher mean score and this difference is significant (Welch t-test $p$-value $<0.01$ ).

\section{Surrounding Land-use}

Table 18 summarizes the mean comfort score by the surrounding land-use for all protected facilities.

Table 18 Mean Score by Surrounding Land-Use

\begin{tabular}{|l|c|}
\hline \multicolumn{1}{|c|}{ Land-Use Category } & $\begin{array}{c}\text { Mean Score - All } \\
\text { Protected Facilities }\end{array}$ \\
\hline \hline Residential & 2.09 \\
\hline Commercial/Office & 1.57 \\
\hline Industrial & 2.00 \\
\hline Central Business District & 2.22 \\
\hline \hline
\end{tabular}

Protected bicycling facilities had the most comfortable mean score in commercial/office areas, followed by industrial areas and central business districts (CBDs). This ordering makes some intuitive sense. The outlier appears to be the 
residential land-use; however, its sample is only one clip (\#19), so conclusions cannot be drawn.

\section{Other Factors}

Pearson correlations are estimated for a number of other variables to determine how well they might predict changes in rider comfort. In certain cases, a review of the data and previous research $(17,19,27)$ indicates that a transformed variable (e.g. natural log of motor vehicle traffic) may provide a better fit than the original variable. Pearson correlations are also estimated for the transformed variables. Table 19 summarizes the results of this analysis for all protected facilities, as well as for one-way protected facilities only. Note that a positive correlation indicates that an increase in that variable is correlated with a decrease in comfort. 
Table 19 Pearson Correlations of Various Characteristics

\begin{tabular}{|c|c|c|}
\hline Variable & $\begin{array}{c}R \text { (p-value) - All } \\
\text { Protected Facilities }\end{array}$ & $\begin{array}{l}\text { R (p-value) - One-way } \\
\text { Protected Facilities }\end{array}$ \\
\hline $\begin{array}{l}\text { Volume in Adjacent } \\
\text { Lane (raw count) }\end{array}$ & $0.02(0.18)$ & $0.06(0.01)^{*}$ \\
\hline $\begin{array}{l}\text { In(Volume in Adjacent } \\
\text { Lane (raw count)) }\end{array}$ & $0.05(<0.01)^{* *}$ & $0.07(<0.01)^{* *}$ \\
\hline $\begin{array}{l}\text { Volume in Adjacent } \\
\text { Lane (hourly flow } \\
\text { rate) }\end{array}$ & $0.04(0.04)^{*}$ & $0.04(0.08)$ \\
\hline $\begin{array}{l}\text { In(Volume in Adjacent } \\
\text { Lane (hourly flow } \\
\text { rate)) }\end{array}$ & $0.06(<0.01)^{* *}$ & $0.06(<0.01)^{* *}$ \\
\hline Motor Vehicle Speed & $0.03(0.16)$ & $0.25(<0.01)^{* *}$ \\
\hline $\begin{array}{l}\text { Average Daily Traffic } \\
\text { Volume }\end{array}$ & $0.09(<0.01)^{* *}$ & $0.02(0.4)$ \\
\hline $\begin{array}{l}\text { Total Volume in Clip } \\
\text { (raw count) }\end{array}$ & $0.04(0.04)^{*}$ & $-0.02(0.29)$ \\
\hline $\begin{array}{l}\text { Total Volume in Clip } \\
\text { (hourly flow rate) }\end{array}$ & $0.06(<0.01)^{* *}$ & $-0.04(0.10)$ \\
\hline $\begin{array}{l}\text { \# of Unsignalized } \\
\text { Conflicts }^{1} \text { (raw count) }\end{array}$ & $0.03(0.12)$ & $0.22(<0.01)^{* *}$ \\
\hline $\begin{array}{l}\text { \# of Unsignalized } \\
\text { Conflicts } 1 / \text { mile }\end{array}$ & $0.03(0.06)$ & $0.22(<0.01)^{* *}$ \\
\hline $\begin{array}{l}\text { Number of travel } \\
\text { lanes }\end{array}$ & $0.18(<0.01)^{* *}$ & $0.06(0.01)^{*}$ \\
\hline Facility Width & $0.22(<0.01)^{* *}$ & N/A - No difference \\
\hline Buffer Width & $-0.002(0.93)$ & $-0.17(<0.01)^{* *}$ \\
\hline In(Buffer Width) & $-0.03(0.13)$ & $-0.21(<0.01)^{* *}$ \\
\hline
\end{tabular}

*Significant at the $95 \%$ confidence level

**Significant at the $99 \%$ confidence level

${ }^{1}$ Includes commercial driveways and public street intersections

On their own, all of the variables shown in the table are weakly correlated with comfort ratings. In certain cases, the relationship is the opposite of what one might intuitively expect (e.g. an increase in total volumes leads to a decrease (improvement) in comfort rating), but most of these situations are not significant at the $95 \%$ confidence level. The highest correlation for all protected facilities is facility width; however, this is likely acting as a surrogate measure of one-way vs. two-way travel as the wider facilities are two-way and the more narrow ones are one-way. The second highest correlation for 
all protected facilities is the number of travel lanes. For one-way protected facilities only, the highest correlations involve unsignalized conflicts and motor vehicle speed.

The low correlation values do not necessarily mean these variables are not important for predicting bicyclist comfort. Instead, they indicate that the relationship between these characteristics and comfort may be complex with some level of interdependency between variables. The characteristics of the chosen clips do not allow for each variable to be examined in isolation so regression modeling will be required to control for other variables to identify which variables are significant predictors of comfort.

\section{Models}

The following section reviews possible models to use to predict rider comfort on protected cycling facilities.

\section{Variable Selection}

The variables considered for these models are:

- Buffer type

- Facility type (1-way vs. 2-way) - Not included in index model

- Motor vehicle speed

- Number of motor vehicle travel lanes

- ADT (as a substitute for number of motor vehicle travel lanes)

These variables are chosen because much of this information is typically available, or easily obtained, for most roads. Note that ADT and number of motor vehicle travel lanes are used separately and both are included here for comparing the 
performance of using one variable instead of the other. These listed variables also have some of the highest Pearson correlation values with the comfort scores for either all protected facilities or one-way protected facilities only, as shown in the previous section. Further, the latter three variables are among the most commonly included items in other models, as shown in Table 2. Facility type is included only in the regression modeling because it allows for partial contributions of variables to be analyzed, while the index model uses the worst rating for any variable, and there is only one 2-way facility.

Other variables that have been considered, but excluded from the model, are facility width, pavement condition, and the density of unsignalized conflicts. There is not enough variation in the facility width of the sample protected bike lanes, as all of the one-way facilities are approximately seven-feet wide, to include this variable. Pavement condition is commonly used in other models; however it is also sometimes excluded because it is not readily available data and not under the control of designers $(11,24)$. For these latter reasons, it is also excluded here. Unsignalized conflict density is not included in the final models because this information is not typically readily available and it can be difficult to collect for a large study area.

Other variables will be considered in exploratory regression analyses for comparison purposes. 


\section{Index Model}

An index model, similar to the one used in LTS (9), could be a simple and effective way to evaluate the comfort of protected bicycle facilities. This type of model uses look-up tables to determine the final comfort score. The model is built using the median score for each of the protected facility clips. Median score is used because it represents the score at which at least $50 \%$ of individuals will rate the facility. This is similar to the processed used in the Danish LOS model for how scores are assigned (11).

Table 20 shows the proposed comfort score for each variable in the model. To use this table, first compare the characteristics of the study facility to each row of the table. The highest scoring row is then used to determine the facility's score (e.g. a protected bike lane with planters in the buffer on a two-lane road with an ADT volume of 12,000 vehicles and a posted speed of $35 \mathrm{MPH}$ would have a rating of ' $\mathrm{B}$ ' due to the speed of $35 \mathrm{MPH})$.

Table 20 Proposed Index Model

\begin{tabular}{||l|c|c||}
\hline \multirow{2}{*}{\multicolumn{1}{|c|}{ Variable }} & \multicolumn{2}{c||}{ Comfort Score } \\
\cline { 2 - 3 } Buffer Type & A & B \\
\hline \hline \multirow{2}{*}{ Motor Vehicle Speed (MPH) } & $\begin{array}{c}\text { Planters } \\
\text { Parked Cars }\end{array}$ & Posts \\
\hline ADT (vehicles) & $<=30$ & 35 \\
\hline \# of MV Travel Lanes & $<15,000$ & $>=15,000$ \\
\hline \hline
\end{tabular}

The model only includes comfort scores 'A' and 'B,' because the median scores for the protected bike lane clips only exceed ' $B$ ' in one instance on Dearborn Street, in 
which a large puddle causes the rider to have to shift to the oncoming lane in the twoway facility.

Table 21 compares the results of applying the model in Table 20 to the actual results from the protected bike lane clips. Note that using either ADT or the number of motor vehicle travel lanes would not change the results in this table.

Table 21 Index Model Predicted Scores vs. Observed Scores

\begin{tabular}{|c|c|c|c|}
\hline Clip \# & Predicted Median Score & Observed Median Score & Difference \\
\hline 1 (1-way - P) & $A$ & $A$ & None \\
\hline 2 (2-way - PC) & A & B & Better \\
\hline 5 (1-way - PC) & $A$ & $A$ & None \\
\hline 6 (2-way - PC) & B & B & None \\
\hline 8 (1-way - PO) & B & B & None \\
\hline 11 (1-way - P) & $\mathrm{A}$ & $\mathrm{A}$ & None \\
\hline 12 (1-way - PO) & $\mathrm{A}$ & $\mathrm{A}$ & None \\
\hline 14 (2-way - PC) & $\mathrm{B}$ & $\mathrm{C}$ & Better \\
\hline 15 (1-way - PC) & $\mathrm{B}$ & $\mathrm{B}$ & None \\
\hline 16 (2-way - PC) & $\mathrm{B}$ & $\mathrm{B}$ & None \\
\hline 17a (1-way - P) & A & A & None \\
\hline 18 (1-way - PC) & $A$ & $A$ & None \\
\hline 19 (1-way - R) & $B$ & B & None \\
\hline 20a (2-way - PC) & $A$ & $B$ & Better \\
\hline 20b (1-way - PO) & $B$ & B & None \\
\hline
\end{tabular}

${ }^{1}$ Directionality and buffer type indicated in parentheses. $\mathrm{P}=$ Planters; $\mathrm{PC}=$ Parked Cars; $\mathrm{PO}=$ Posts; $R=$ Raised/Parking (mostly unoccupied)

The model correctly predicts the median score for all but three of the clips. It predicts a score one letter grade better than the observed score for the three clips where it differs. Two of these clips, 2 and 20a, feature the same section of Dearborn Street. The median score of these two clips is the same as for most other clips on Dearborn Street (clips 6 and 16); however, the ADT volume on this section of Dearborn Street is lower than the other sections, only 7,800 vehicles, and there are only two motor vehicle travel lanes, while there are three in the other sections. This suggests that 
either the traffic characteristics are not significantly influential to alter the observed score for these sections or that there is another aspect of the video or roadway not captured by the model that is mitigating the lower volumes and fewer travel lanes (e.g. being located in downtown Chicago). Finally, this discrepancy between observed and predicted scores could be corrected by adding a term to the index model that stipulates that two-way facilities are a comfort score of 'B.' However, there is only one two-way facility studied here and it is in the downtown of one of the biggest cities in the country, so it is not necessarily representative of all two-way facilities (e.g. the author has ridden on two-way facilities on Bluebonnet Lane and Rio Grande Streets in Austin, Texas, and found both to be more comfortable than Dearborn Street. Other surveys results presented later in this section also show that riders find these two facilities to be more comfortable than Dearborn Street).

The model also under-predicts the score of clip \#14. This is likely due to the presence of the puddle in the video that causes the subject rider to shift to the other lane of the facility.

\section{Regression Modeling}

Two types of regression analysis are employed to analyze the video clip data, ordinary least squares (OLS) and cumulative logistic. Many practitioners are familiar with the basics of OLS regression and for this reason it is used in the $2010 \mathrm{HCM}$ and FDOT methods (27). It is also the form used in the FHWA BCl and Rural $\mathrm{BCl}$ methods. However, OLS regression also has its limitations when it comes to modeling ordered 
response data. The residuals from ordered response data are often non-normally distributed, which violates one of the assumptions of OLS regression, and OLS regression can predict values outside the allowable range (i.e. one to six). Therefore, a cumulative logistic model (CLM) is also used. The CLM model predicts the probability that a user will provide a given comfort score for a facility. This can also be interpreted as the percentage of the population that would view the facility at a given comfort rating. A single score for the facility can be determined based on when the cumulative probability reaches a certain threshold (e.g. Jensen (11) recommends using the score at which the cumulative probability hits $50 \%$ because that means at least half the population would provide that score or better).

Three models are presented for each type of analysis. The first two are named the Basic Model and use only the variables described in the previous section. They are differentiated from each other by one using the number of motor vehicle lanes and the other using ADT. The third is an exploratory model determined by the statistical software package, $R$, using stepwise regression $(35-40)$. The purpose of this is to identify how well a basic model that uses readily available data compares to a more complicated model that may require data that is difficult to gather. The Exploratory Model may also offer insights into other variables that could be added to one of the Basic Models. 


\section{OLS Regression}

Table 22 summarizes the three OLS regression models. These are presented primarily for informational purposes.

Table 22 OLS Regression Results

\begin{tabular}{||c|c|c|c||}
\hline Variable & $\begin{array}{c}\text { Basic Model } \\
\text { Coefficient }\end{array}$ & $\begin{array}{c}\text { Basic Model (w/ } \\
\text { ADT) Coefficient }\end{array}$ & $\begin{array}{c}\text { Exploratory Model } \\
\text { Coefficient }\end{array}$ \\
\hline \hline Intercept & $2.62^{* *}$ & $2.52^{* *}$ & $3.14^{* *}$ \\
\hline Planter Buffer & $-0.91^{* *}$ & $-0.99^{* *}$ & -0.40 \\
\hline Parked Car Buffer & $-0.61^{* *}$ & $-0.69^{* *}$ & 0.53 \\
\hline Raised/Parking ${ }^{2}$ Buffer & -0.16 & $-0.35^{*}$ & $0.96^{* *}$ \\
\hline Two-Way Facility & $0.72^{* *}$ & $0.70^{* *}$ & $0.55^{* *}$ \\
\hline MV Speed & -0.005 & $\mathrm{n} / \mathrm{a}$ & -0.03 \\
\hline \# of MV Lanes & -0.09 & $\mathrm{n} / \mathrm{a}$ & $\mathrm{n} / \mathrm{a}$ \\
\hline $\begin{array}{c}\text { ADT (1,000 vehicles/day) } \\
* \text { MV Speed }\end{array}$ & $\mathrm{n} / \mathrm{a}$ & $-0.0006^{* *}$ & $0.21^{* *}$ \\
\hline $\begin{array}{c}\text { In(Motor Vehicle Volume } \\
\text { in Adjacent Lane } \\
\text { (Veh/hr)) }\end{array}$ & $\mathrm{n} / \mathrm{a}$ & $\mathrm{n} / \mathrm{a}$ & $-0.97^{* *}$ \\
\hline In(Buffer Width) & $\mathrm{n} / \mathrm{a}$ & $\mathrm{n} / \mathrm{a}$ & 0.13 \\
\hline $\mathrm{R}^{2}$ & 0.12 & 0.12 & $<0.01$ \\
\hline Model p-value & $<0.01$ & $<0.01$ & \\
\hline \hline
\end{tabular}

${ }^{1}$ The reference facility has a posts buffer and is a one-way protected bike lane

${ }^{2}$ Parking is not expected to be occupied often

* Significant at the $95 \%$ confidence level

$* *$ Significant at the $99 \%$ confidence level

The overall performance of the two Basic Models is similar, with each one having an $\mathrm{R}^{2}$ value of 0.12 . However, the number of motor vehicle lanes is not a significant predictor at the $95 \%$ confidence level, while the ADT (1,000 vehicles/day) * MV Speed term is significant at the $99 \%$ confidence level. Also, in the Basic Model (w/ ADT), the Raised/Parking Buffer variable is significant at the $99 \%$ confidence level, while it is not significant in the other Basic Model.

The Exploratory Model performs better than the two Basic Models, explaining approximately $1 \%$ more of the variance in comfort score. To achieve this, two variables 
are added to, and one removed, from the Basic Model. One of the new variables incorporates the motor vehicle volume in the adjacent lane, similar to the HCM LOS methodology. Note that the parked car buffer and planter buffer variables are not significant in the Exploratory Model.

All three OLS regression models are significant at the $99 \%$ confidence level.

Figure 16 compares the mean scores by clip predicted by each of the three models in Table 22 to the observed mean score from the in-person surveys.

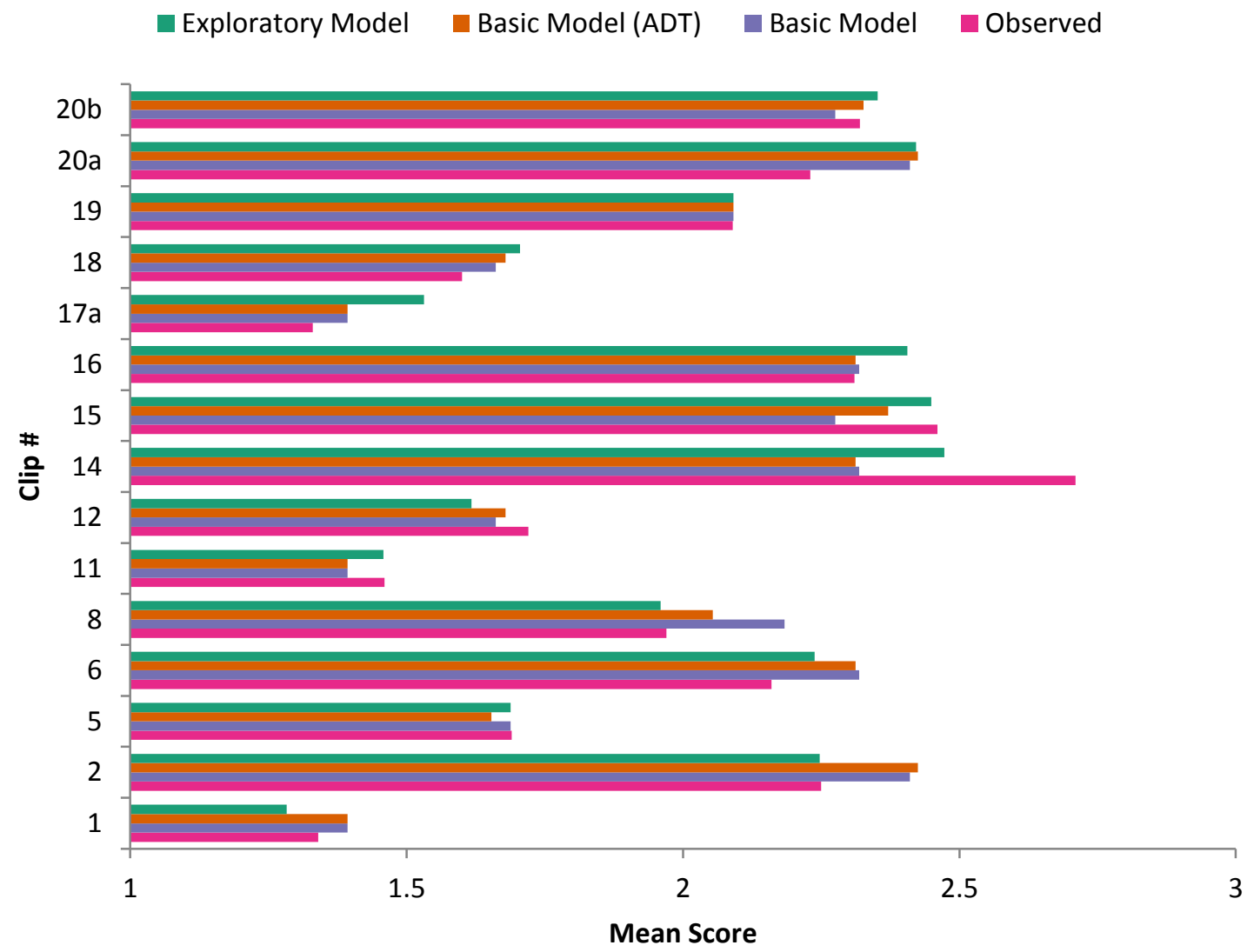

Figure 16 Predicted vs. Observed Scores - OLS Regression Models

As the figure shows, the predicted mean scores by clip are mostly similar to the mean scores observed in the in-person video survey. Both versions of the Basic Model 
are off by $5 \%$ on average from the observed scores, while the Exploratory Model is off by an average of $4 \%$. Similarly, the difference between the Basic Model's predicted mean from the observed mean is only significant at the $95 \%$ confidence level for six (clips \#2, 6, 8, 14, 15, and 20a) out of the fifteen clips. When ADT is used in the Basic Model, only five of its predicted means (clips $\# 2,6,14,18$, and 20a) are different at the 95\% confidence level, but six of the Exploratory Model's predicted means (clips \#12, 14, $16,17 a, 18$, and 20a) are significantly different at the same level.

The models typically vary in terms of where the significant differences are. However, all three models predict mean scores that are significantly different than observed scores for clips \#14 and 20a. For clip \#14a, the models underpredict the score by $9 \%$ to $15 \%$. This is not surprising though, as it has been previously noted that the observed score for this clip is higher than comparable ones, likely due to the large puddle in the bike lane at the end of the clip. The models also overpredict the score for clip \#20a by about 8 to $9 \%$ each. Note that this clip only had 73 observations in the video survey as it was only shown at the first Farmer's Market session.

In summation, all three models have relatively similar fits to the observed data. The Basic Model (w/ ADT) generally outperforms the Basic Model with the number of motor vehicle lanes. The Exploratory Model only offers mixed results when compared to the Basic Model (w/ ADT) while requiring data that are less likely to be available. Therefore, the Basic Model ( $w /$ ADT) is the recommended one of the three OLS regression models, if an OLS regression model must be used. 


\section{Logistic Regression}

Table 23 summarizes the CLM regression models. They are arrived at using the same process as the OLS regression models.

Table 23 CLM Regression Model Results

\begin{tabular}{|c|c|c|c|}
\hline Variable $^{1}$ & $\begin{array}{c}\text { Basic Model } \\
\text { Coefficient/(odds } \\
\text { ratio) } \\
\end{array}$ & $\begin{array}{l}\text { Basic Model (w/ } \\
\text { ADT) Coefficient/ } \\
\text { (odds ratio) } \\
\end{array}$ & $\begin{array}{c}\text { Exploratory Model } \\
\text { Coefficient/(odds } \\
\text { ratio) } \\
\end{array}$ \\
\hline Planter Buffer & $-1.91 /(0.15)^{* *}$ & $-2.04 /(0.13)^{* *}$ & $-0.55 /(0.58)$ \\
\hline Parked Car Buffer & $-1.18 /(0.31)^{* *}$ & $-1.31 /(0.27)^{* *}$ & $0.003 /(12.33)^{* *}$ \\
\hline Raised/ Parking ${ }^{2}$ Buffer & $-0.28 /(0.75)$ & $-0.60 /(0.55)^{* *}$ & $1.95 /(7.01)^{* *}$ \\
\hline Two-Way Facility & $1.30 /(3.65)^{* *}$ & $1.28 /(3.60)^{* *}$ & $0.92 /(2.51)^{* *}$ \\
\hline MV Speed & $-0.01(0.99)$ & $\mathrm{n} / \mathrm{a}$ & $\mathrm{n} / \mathrm{a}$ \\
\hline \# of MV Lanes & $-0.13(0.87)$ & $\mathrm{n} / \mathrm{a}$ & $\mathrm{n} / \mathrm{a}$ \\
\hline $\begin{array}{l}\text { ADT (1,000 vehicles/day) } \\
* \text { MV Speed }\end{array}$ & $\mathrm{n} / \mathrm{a}$ & $-0.0009(1.00)^{* *}$ & $\mathrm{n} / \mathrm{a}$ \\
\hline $\begin{array}{c}\text { In(MV Volume in Adjacent } \\
\text { Lane (Veh/hr)) }\end{array}$ & $\mathrm{n} / \mathrm{a}$ & $\mathrm{n} / \mathrm{a}$ & $0.35 /(1.42)^{* *}$ \\
\hline Buffer Width & $\mathrm{n} / \mathrm{a}$ & $\mathrm{n} / \mathrm{a}$ & $-0.45 /(0.64)^{* *}$ \\
\hline Intercept: A-B & -1.62 & -1.46 & -0.29 \\
\hline Intercept: B-C & -0.003 & 0.17 & 1.34 \\
\hline Intercept: C-D & 1.42 & 1.59 & 2.77 \\
\hline Intercept: D-E & 2.42 & 2.59 & 3.78 \\
\hline Intercept: E-F & 3.47 & 3.65 & 4.84 \\
\hline Log Likelihood & $-3,676$ & $-3,671$ & $-3,657$ \\
\hline
\end{tabular}

${ }^{1}$ The reference facility has a posts buffer and is a one-way protected bike lane

${ }^{2}$ Parking is not expected to be occupied often

*Significant at the $95 \%$ confidence level

**Significant at the $99 \%$ confidence level

Comparing the CLM regression results yields similar findings as the OLS regression findings. The Basic Model (w/ ADT) has better performance than the Basic Model with the number of motor vehicle volumes. The CLM Exploratory Model adds and subtracts the same variables from the Basic Model as the OLS regression Exploratory Model and also produces better results than the two Basic Models. All three models are statistically significant predictors of comfort rating at the $95 \%$ confidence level $(p<0.01$ for all three compared to the null model using a chi-squared test). 
Only the Basic Model (w/ ADT) has coefficients that are all significant predictors at the $95 \%$ confidence level. In this model, the odds of an individual rating a facility one grade better than a similar facility with a posts buffer increase by approximately $670 \%$ if there is a planter buffer, $270 \%$ if there is a parked cars buffer that is mostly occupied with cars, and $82 \%$ if it is raised slightly above the street grade with an unoccupied parking buffer. Conversely, the odds of an individual rating the facility one letter grade worse increase by about $260 \%$ if it is a two-way protected bike lane. A one unit change in ADT $(1,000)$ multiplied by motor vehicle speed has minimal impact on the odds of an individual's rating changing.

Figure 17 compares the predicted distribution of responses for each protected bike lane clip from each model to the observed distribution of responses. 


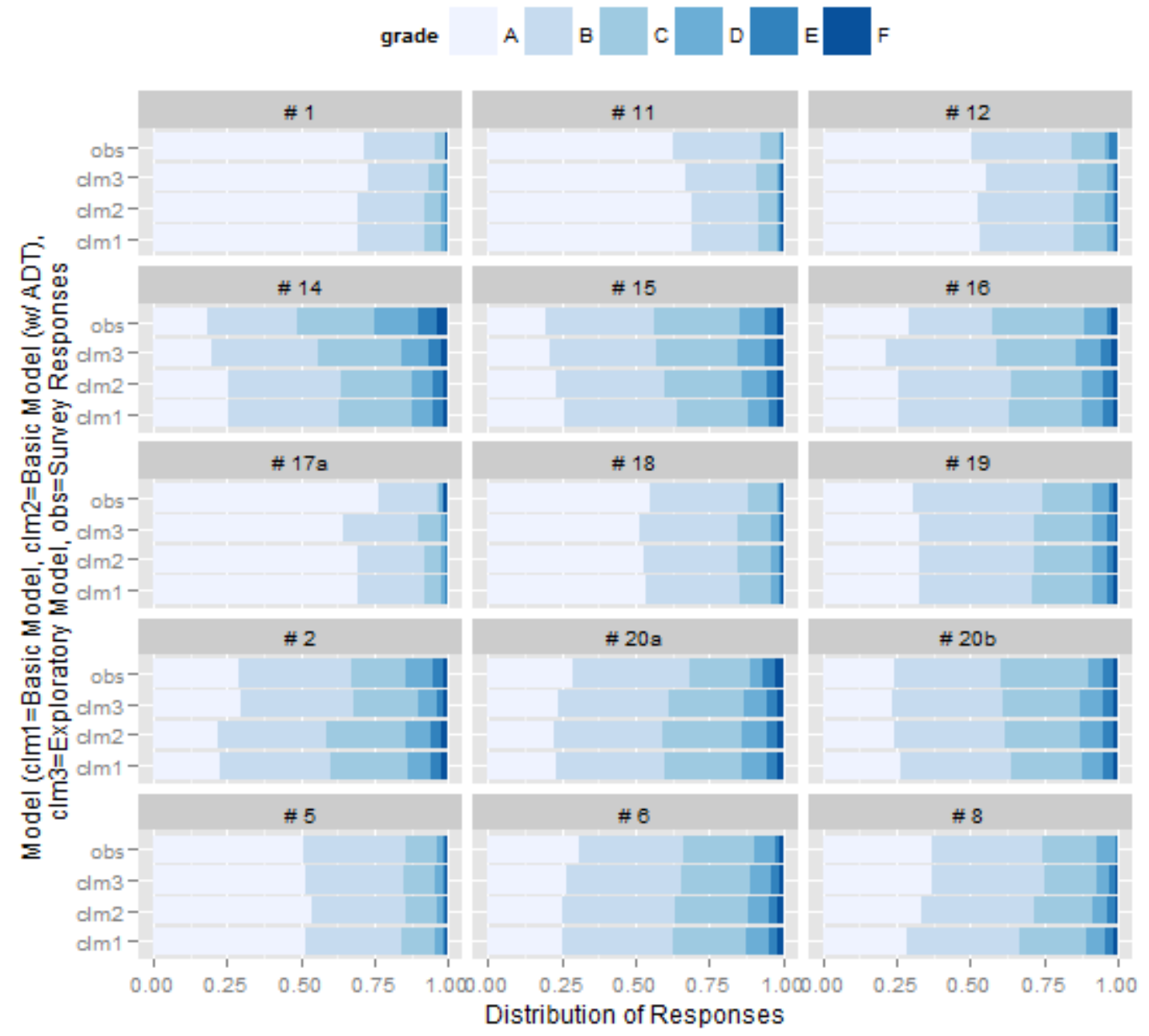

Figure 17 Predicted vs. Observed Distribution of Responses by Clip

As the figure shows, the models predict distributions that are relatively similar to what is observed in the video surveys. On average, the distribution predicted by the Basic Model differs by a total of $14 \%$ for each clip (calculated as the sum of the absolute values of the differences between the predicted and observed proportions for each letter grade, which is in some ways a double-counting of differences as a $1 \%$ difference in one group will necessitate a counter $1 \%$ difference in another group(s)), which drops to about $13 \%$ for the Basic Model (w/ ADT) and 12\% for the Exploratory Model. 
Distrubtions for a given letter grade for each clip are typically only a few percentage points different (e.g. the Basic Model (w/ ADT) predicts $23 \%$ of the population will view clip \#1 as a ' $\mathrm{B}$ ', while $24 \%$ were observed in the survey to rate it as a ' $\mathrm{B}$ '). There are only two instances where the predicted score for any given grade is off by $10 \%$ or more (both of the Basic Models predict $10 \%$ more in the ' $\mathrm{B}$ ' range than was observed for clip \#16).

Table 24 shows how the distributions predicted by the Basic Model (w/ADT) differ from the observed distributions.

Table 24 Difference between Expected and Observed Rating Distributions - Basic Model (w/ADT)

\begin{tabular}{|c|c|c|c|c|c|c|}
\hline \multirow[b]{2}{*}{ Clip } & \multicolumn{6}{|c|}{ Letter Grade Distribution Difference (Expected-Observed) } \\
\hline & A & B & C & D & $\mathbf{E}$ & $\mathbf{F}$ \\
\hline 1 & $-2 \%$ & $-1 \%$ & $2 \% *$ & $1 \% *$ & $1 \% *$ & $0 \% *$ \\
\hline 2 & $-7 \% *$ & $-1 \%$ & $8 \% *$ & $0 \%$ & $0 \%$ & $0 \%$ \\
\hline 5 & $2 \%$ & $-3 \% *$ & $0 \%$ & $1 \% *$ & $0 \% *$ & $0 \%$ \\
\hline 6 & $-5 \% *$ & $2 \% *$ & $0 \%$ & $1 \%$ & $1 \% *$ & $1 \% *$ \\
\hline 8 & $-3 \%$ & $0 \%$ & $2 \%$ & $-1 \%$ & $1 \% *$ & $1 \% *$ \\
\hline 11 & $7 \% *$ & $-7 \% *$ & $-1 \%$ & $1 \% *$ & $0 \%$ & $0 \% *$ \\
\hline 12 & $2 \%$ & $-2 \%$ & $0 \%$ & $1 \% *$ & $-2 \% *$ & 1\%* \\
\hline 14 & $7 \% *$ & $8 \% *$ & $-2 \%$ & $-7 \% *$ & $-3 \% *$ & $-2 \% *$ \\
\hline 15 & $4 \% *$ & $0 \%$ & $-3 \%$ & $0 \%$ & $-1 \%$ & $0 \%$ \\
\hline 16 & $-4 \% *$ & $10 \% *$ & $-7 \% *$ & $0 \%$ & $2 \% *$ & $-1 \%$ \\
\hline 18 & $-2 \%$ & $-1 \%$ & $1 \%$ & $2 \% *$ & $1 \% *$ & $0 \%$ \\
\hline 19 & $2 \%$ & $-5 \% *$ & $3 \%$ & $0 \%$ & $1 \% *$ & $-1 \%$ \\
\hline $17 a$ & $-7 \% *$ & $3 \% *$ & $5 \% *$ & $0 \%$ & $1 \% *$ & $-1 \% *$ \\
\hline $20 a$ & $-7 \% *$ & $-3 \% *$ & $6 \% *$ & $4 \% *$ & $0 \%$ & $-1 \%$ \\
\hline $20 b$ & $0 \%$ & $2 \% *$ & $-4 \% *$ & $3 \%$ & $-1 \%$ & $0 \%$ \\
\hline
\end{tabular}

*Significant at the $95 \%$ confidence level

Just over half of the differences are significant at the $95 \%$ confidence level. However, less than half (16 out of 47 ) of the significant differences occur in the ' $A$ ' to ' $B$ ' range, which contains the largest distributions. A similar trend exists for the other two models.

Notable differences between the observed and predicted values include: 
- Clip \#2 - the model significantly underpredicts the proportion of individuals in the ' $A$ ' rating group by $7 \%$, spreading out this difference over the rest of the five groups.

- Clip \#14 - The model predicts $15 \%$ more individuals in the ' $A$ ' to ' $B$ ' range than was observed. The other two models similarly overpredict in this same range. Again, this clip had a standing puddle in it and its scores are below other similar clips, so this is not surprising.

As a final comparison of model performance to the observed results, Table 25 compares the observed and predicted median scores for each clip.

Table 25 Observed and Predicted Median Scores

\begin{tabular}{|c|c|c|c|c||}
\hline Clip & Observed & $\begin{array}{c}\text { Basic } \\
\text { Model }\end{array}$ & $\begin{array}{c}\text { Basic } \\
\text { Model (w/ } \\
\text { ADT) }\end{array}$ & $\begin{array}{c}\text { Exploratory } \\
\text { Model }\end{array}$ \\
\hline \hline 1 & A & A & A & A \\
\hline 2 & B & B & B & B \\
\hline 5 & A & A & A & A \\
\hline 6 & B & B & B & B \\
\hline 8 & B & B & B & B \\
\hline 11 & A & A & A & A \\
\hline 12 & A & A & A & A \\
\hline 14 & C & B & B & B \\
\hline 15 & B & B & B & B \\
\hline 16 & B & B & B & B \\
\hline 18 & A & A & A & A \\
\hline 19 & B & B & B & B \\
\hline $17 a$ & A & A & A & A \\
\hline $20 a$ & B & B & B & B \\
\hline $20 b$ & B & B & B & B \\
\hline
\end{tabular}

The models correctly predict the median score for all but one of the clips. All three predict a better median score for clip \#14, which is expected given the clip is rated lower than other similar clips, as previously noted.

All three of the cumulative logistic regression models perform reasonably well at predicting the median score and distribution of ratings for the protected bike lane video 
clips they are based on. The Basic Model (w/ ADT) generally outperforms the Basic Model with number of lanes. The Exploratory Model only offers mixed results when compared to the Basic Model (w/ ADT) while requiring data that are less likely to be available. Therefore, the Basic Model (w/ ADT) is the recommended model.

\section{Modeling with Clip \#14 Removed}

As has been cited multiple times previously, clip \#14 appears to be an outlier.

There is a large puddle that forces the bicyclist to move out of the correct lane and into the oncoming lane of the two-way facility, though there are no oncoming bicyclists. Survey respondents provided it a lower score than similar facilities and the models consistently predict better scores for it than were observed. Therefore, a regression analysis is run on a dataset that excludes clip \#14. Table 26 contains the results of this analysis, comparing it to the previous analysis using the full dataset.

Table 26 CLM Models with and without Clip \#14

\begin{tabular}{|c|c|c|}
\hline Variable $^{1}$ & $\begin{array}{l}\text { Basic Model (w/ } \\
\text { ADT) Coefficient - } \\
\text { Full Dataset }\end{array}$ & $\begin{array}{l}\text { Basic Model (w/ } \\
\text { ADT) Coefficient - } \\
\text { without Clip \#14 }\end{array}$ \\
\hline Planter Buffer & $-2.04^{* *}$ & $-2.13^{* *}$ \\
\hline Parked Car Buffer & $-1.31 * *$ & $-1.38 * *$ \\
\hline Raised/ Parking ${ }^{2}$ Buffer & $-0.60 * *$ & $-0.70 * *$ \\
\hline Two-Way Facility & $1.28 * *$ & $1.12 * *$ \\
\hline $\begin{array}{l}\text { ADT (1,000 vehicles/day) } \\
* \text { MV Speed }\end{array}$ & $-0.0009 * *$ & $-0.001 * *$ \\
\hline Intercept: A-B & -1.46 & -1.60 \\
\hline Intercept: B-C & 0.17 & 0.05 \\
\hline Intercept: C-D & 1.59 & 1.54 \\
\hline Intercept: D-E & 2.59 & 2.54 \\
\hline Intercept: E-F & 3.65 & 3.60 \\
\hline Log Likelihood & $-3,671$ & $-3,300$ \\
\hline
\end{tabular}

${ }^{1}$ The reference facility has a posts buffer and is a one-way protected bike lane

${ }^{2}$ Parking is not expected to be occupied often

*Significant at the $95 \%$ confidence level; **Significant at the $99 \%$ confidence level 
The coefficients for the two models are relatively similar. However, the model without clip \#14 does have a better fit. Figure 18 compares the predicted distributions from these two models with the observed distributions from the video survey.

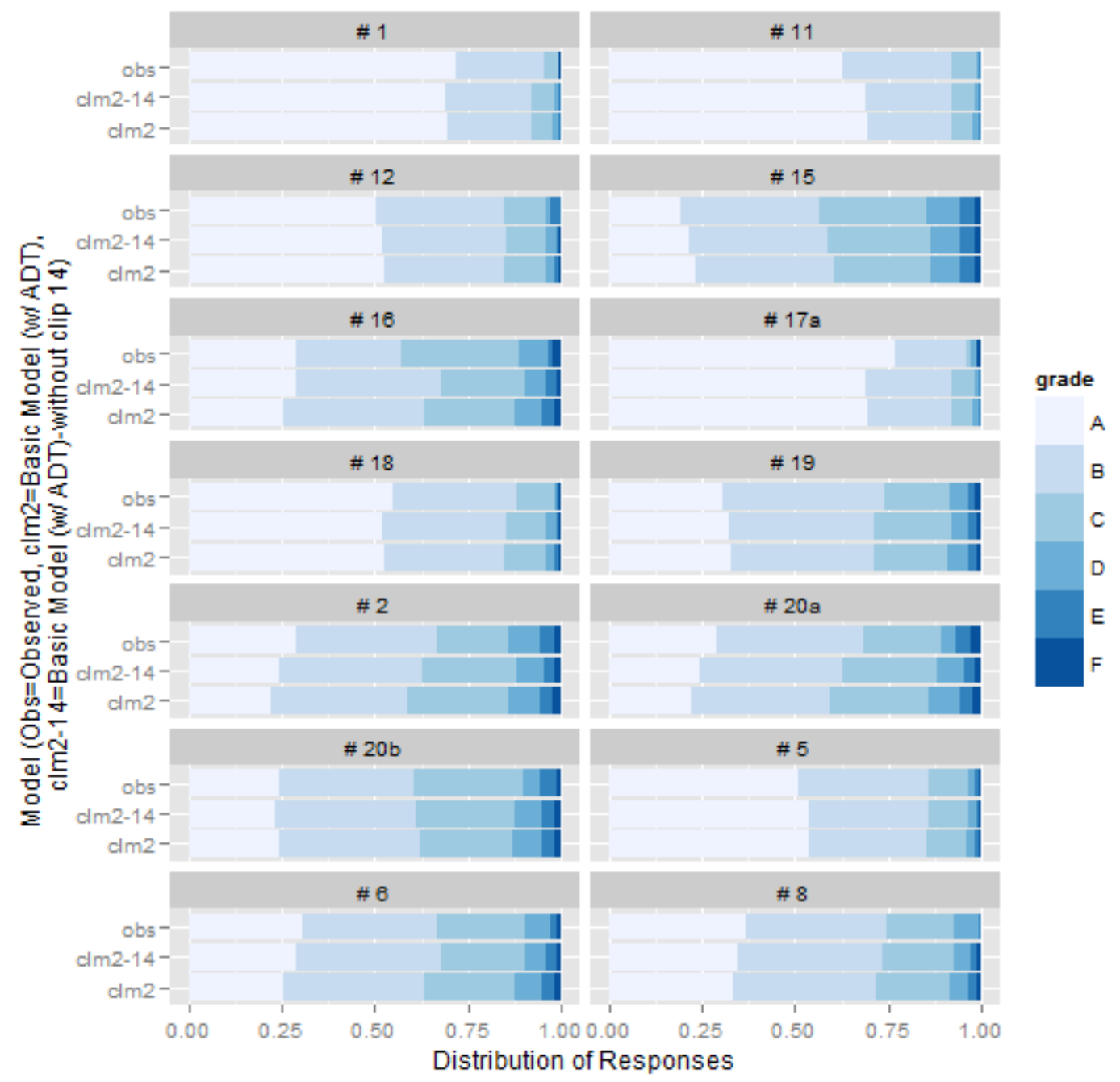

Figure 18 Comparison of Predicted and Observed Distributions - with and without Clip 14 
The difference in fit between the two models is generally small. Excluding clip \#14 provides a slightly better fit to the video survey data. The updated model predicts a distribution that is on average about $1 \%$ closer to the observed data. It also more closely predicts the observed distribution for most clips. Therefore, the model without clip \#14 is recommended for use over the model with clip \#14.

\section{Model Comparison to Danish LOS Model}

As previously noted, the Danish LOS model developed by Jensen (11) also uses a cumulative logistic model and it is the only one of the reviewed six-point LOS models that accounts for protected bike lanes. For comparison purposes, the Danish LOS model is applied to the protected bike lane clips from this study. The results of this analysis and a comparison to the predicted results from the proposed Basic Model (w/ ADT) and the observed responses are shown Figure 19 and Table 27.

Table 27 Comparison of Predicted and Observed Means - Including Danish Model

\begin{tabular}{|c|c|c|c||}
\hline Clip & Observed & $\begin{array}{c}\text { Basic } \\
\text { Model (w/ } \\
\text { ADT) }\end{array}$ & $\begin{array}{c}\text { Danish } \\
\text { Model }\end{array}$ \\
\hline 1 & A & A & B \\
\hline 2 & B & B & B \\
\hline 5 & A & A & C \\
\hline 6 & B & B & C \\
\hline 8 & B & B & B \\
\hline 11 & A & A & B \\
\hline 12 & A & A & A \\
\hline 15 & B & B & A \\
\hline 16 & B & B & A \\
\hline 18 & A & A & A \\
\hline 19 & B & B & A \\
\hline $17 a$ & A & A & B \\
\hline $20 a$ & B & B & B \\
\hline $20 b$ & B & B & B \\
\hline
\end{tabular}




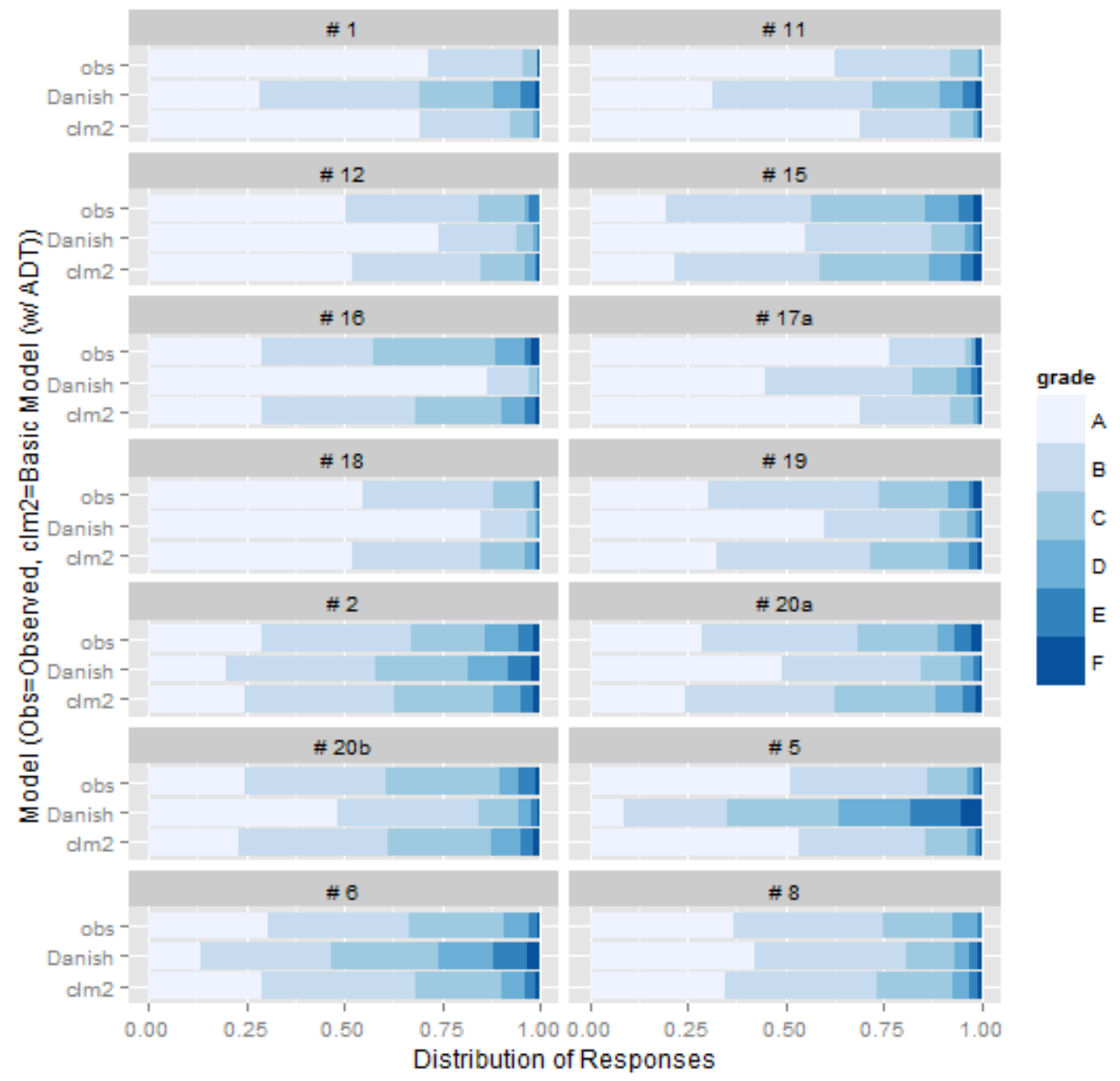

Figure 19 Comparison of Predicted and Observed Values - Including Danish Model

The Basic Model (w/ ADT) and the Danish model differ significantly in their distributions. The Basic Model (w/ ADT) provides a better fit of the observed distributions for all of the clips and matches the median observed values from the surveys. The Danish model matches the median value predicted by the Basic Model (w/ ADT) six times, is off by one value seven times, and is off by two values once. That the Danish model does not match the observed values as well as the model developed for 
this project is not surprising as this comparison is being made to the data that the Basic Model ( $w / A D T)$ is fit to. The differences in prediction between the two models may be attributed to the types of clips shown in each of the surveys, different preferences of American and Danish residents, and/or the variables considered by the respective models.

\section{Model Comparison to Green Lane Survey Results}

Included in the Green Lane surveys about each study facility is a question asking individuals who have ridden on the facility to rate how comfortable they feel on it using a similar six-point scale. The results from these surveys are not necessarily directly comparable to the results from the video survey. The Green Lane survey questions cover the entire length of the facility that the respondent has ridden, encapsulating signalized intersections and changing conditions (i.e. different buffer types facility), whereas the video survey did not include any signalized intersections and the clips show only uniform sections. In certain Green Lane surveys, respondents are asked to differentiate their comfort levels depending on the buffer, but that is not always the case. However, it remains an interesting exercise to compare the predicted results from the Basic Model (w/ ADT) and the Danish Model to the observed responses from the Green Lane surveys. Table 28 shows the median scores predicted by each model and the observed response median scores for the facilities for which the question was asked. 
Table 28 Predicted vs. Observed Median Scores for Green Lane Facilities

\begin{tabular}{|l|c|c|c|c|c|c||}
\hline \multicolumn{1}{|c|}{ Facility } & $\begin{array}{c}\text { Facility } \\
\text { Type }\end{array}$ & Buffer Type & $\begin{array}{c}\text { Respondent } \\
\text { Observed }\end{array}$ & $\begin{array}{c}\text { Basic Model } \\
\text { (w/ ADT) }\end{array}$ & $\begin{array}{c}\text { Index } \\
\text { Model }\end{array}$ & $\begin{array}{c}\text { Danish } \\
\text { Model }\end{array}$ \\
\hline \hline Milwaukee Avenue & One-way & Parked Cars & B & A & A & A \\
\hline Milwaukee Avenue & One-way & Posts & B & B & B & A \\
\hline Dearborn Street & Two-way & Parked Cars & B & B & B & B \\
\hline Barton Springs Road & One-way & Posts & B & B & B & B \\
\hline Bluebonnet Lane & Two-way & Posts & A & C & B & A \\
\hline Rio Grande Street & Two-way & Posts & A & C & B & A \\
\hline L Street & One-way & Posts & B & B & B & A \\
\hline Fell Street & One-way & Posts & B & B & B & B \\
\hline Oak Street & One-way & Posts & B & B & B & B \\
\hline Multnomah Street & One-way & Posts & B & B & B & B \\
\hline Multnomah Street & One-way & Parked Cars & $\mathrm{B}^{1}$ & A & A & B \\
\hline Multnomah Street & One-way & Planters & $\mathrm{B}^{1}$ & A & A & B \\
\hline \hline
\end{tabular}

${ }^{1}$ The survey question did not differentiate between the types of buffer, it only asked for the entire facility

The Basic Model (w/ADT) and the Index Model predict the observed median score in seven out of twelve cases, while the Danish model predicts nine out of twelve cases. In most instances the predicted median is within one score of the observed median. However, in two cases, the Basic Model (w/ ADT) predicts a score of ' $C$ ' when the observed median score was 'A.' Both of these instances occur on a two-way protected bike lane on a facility with an ADT volume of fewer than 5,500 vehicles per day. This ADT volume is below the ADT of any of the study sites from the video survey, so these sites are out of the range of the model's valid range. Combined with the speed on each roadway, these ADT volumes place them at the outer edge of the speed-volume range where ODOT recommends any type of bike lane (34), indicating that these installations likely represent outliers compared to common practice. Also, Dearborn Street was the only two-way facility in the video survey, so it is possible that the proposed logistic model is not well calibrated to two-way protected bike lanes. 
Removing the two-way term from the logistic model has been considered; however, based on responses to the online survey (discussed later in this section) it appears that individuals do perceive two-way facilities to be less comfortable than a similar one-way facility, so the term is left in. If these two sites are removed, then the Basic Model ( $w /$ ADT) and the Index Model predict the observed median score as often as the Danish model.

In regards to the three other locations for where the model does not predict the observed median score, two of the instances are related to NE Multnomah Street in Portland. The buffer on this facility varies between paint only, planters, posts, and parked cars. As the table notes, the Green Lane survey did not ask respondents to differentiate their comfort level based on the buffer type. Therefore the comparison may not be valid for this facility, either, and is included for informational purposes only.

Figure 20 shows the distribution of predicted and observed responses for the facilities for which the Green Lane surveys and the two logistic models are best compared (i.e. excluding the above discussed facilities). 


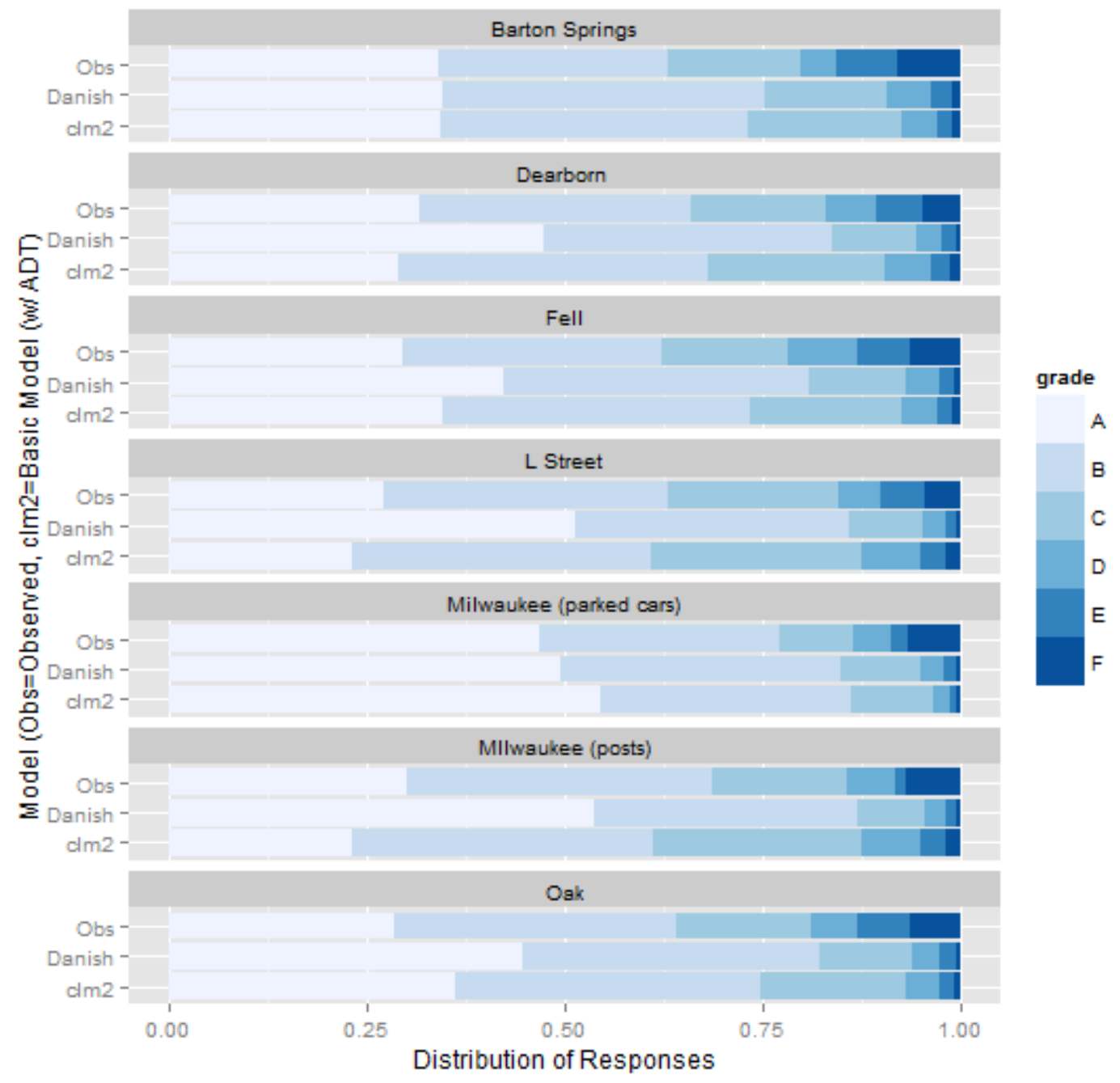

Figure 20 Predicted vs. Observed Frequencies - Green Lane Facilities

Predictions from the two models generally approximate the frequencies observed in the surveys. Again, neither model includes signalized intersections, so some variation is expected. The Basic Model w/ ADT generally tracks closer to the observed frequencies than does the Danish LOS model, as its distributions are off from observed frequencies by an average of about $23 \%$, while the Danish model is off by an average 
total of $35 \%$. Also, the Basic Model w/ ADT is never off by more than $10 \%$ for a single letter grade group.

Not all of the facilities included in Figure 20 are the same as those shown in the video clips. Barton Springs Road and L Street are not included in the video survey. Neither is Oak Street, but it is similar to Fell Street as they share similar designs and form a couplet. Milwaukee Avenue is shown in the video surveys, but only with a posts buffer. The Green Lane survey also included a question about the section with a parked cars buffer. Given that the Basic Model w/ ADT predicts frequency distributions similar to what is shown from the surveys of these facilities, the model appears to be transferable to other facilities that are within the same ADT range (approximately 8,000 to 30,000 vehicles/day), same speed range $(25-35 \mathrm{mph})$, and feature the same buffer types (i.e. parked cars, posts, or planters) as those included in the video survey. It may also be more applicable to American facilities than the Danish model.

\section{Comparison to Hypothetical Responses}

The Green Lane surveys asked respondents to rate how comfortable they would feel bicycling in a protected bike lane with a variety of buffer types. Table 29 summarizes the results of this question.

Table 29 Hypothetical Comfort Ratings - Green Lane Surveys

\begin{tabular}{|c|c|}
\hline Buffer Type & Median Score \\
\hline \hline Planters & A \\
\hline Parked Cars & B \\
\hline Posts & A \\
\hline Paint Only & B \\
\hline Raised Curb & A \\
\hline
\end{tabular}


In this hypothetical situation on a $35 \mathrm{MPH}$ commercial street, respondents to the surveys feel that they would rate any protected facility either an 'A' or 'B.' This general finding matches the results of this project's surveys. However, this study has found that parked cars are preferred to posts, while the results in the table above indicate a reverse preference. This could be due to the inability to demonstrate the buffer of a parked car in a static illustration, as was used in the survey.

\section{Model Recommendation}

The index and regression based models developed for this project performed equally well at predicting the observed median value from the Green Lane surveys. However, the Basic Model (w/ ADT) predicted the median value of the video survey clips (14 out of 14 clips) more often than did the index model (12 out of 14 clips). Given this and that the regression-based model can provide the expected distribution of comfort levels for a facility, the Basic Model (w/ ADT) is the recommended model for use; though the index model can likely be used for quick estimates to provide accurate median values in many instances.

This recommendation is made with the caveat that neither model may make accurate predictions if the ADT volume of the roadway falls out of the range of approximately 9,000 to 30,000 vehicles per day, if the speed limit is above $35 \mathrm{MPH}$, or if a buffer type other than those included in the model is used. Also, the median value of all protected bike lane clips and from the Green Lane facilities is no worse than 'B.' Given this lack of variety in median response rates, neither model is likely to be off by 
more than one letter grade so long as the subject facility falls within the model's limitations listed above. The Danish model may also serve as a reasonable substitute for low-volume facilities out of the range of these models.

\section{Online Survey Results}

As was previously described, an online survey was also used to identify how the results of such a survey might differ from the in-person survey. As a recap, the difference between the two surveys is not just their viewing methods, but is also in how participants were recruited. The in-person surveys drew from attendees of two farmer's markets and a museum event. The online surveys were sent out largely to groups of transportation professionals, advocates, and bicycle groups. Therefore, it is expected that the demographics of the two surveys will also differ. The following section describes the results of the online survey and compares them to those of the in-person survey.

\section{Online Survey Demographics}

It is previously noted that demographic factors are generally correlated, albeit weakly, with the in-person survey results and it is expected that the demographics of the online survey will differ from the in-person survey, given the different advertising methods. This section compares the demographics of the two surveys and their impacts on the scores from each survey in order to determine if any differences in ratings are due to demographics, the different administration methods of the surveys, or both. 
Figure 21, Figure 22, Figure 23, and Figure 24 summarize the differences in age groups, gender, access to a working bicycle, and riding habits between the two surveys.

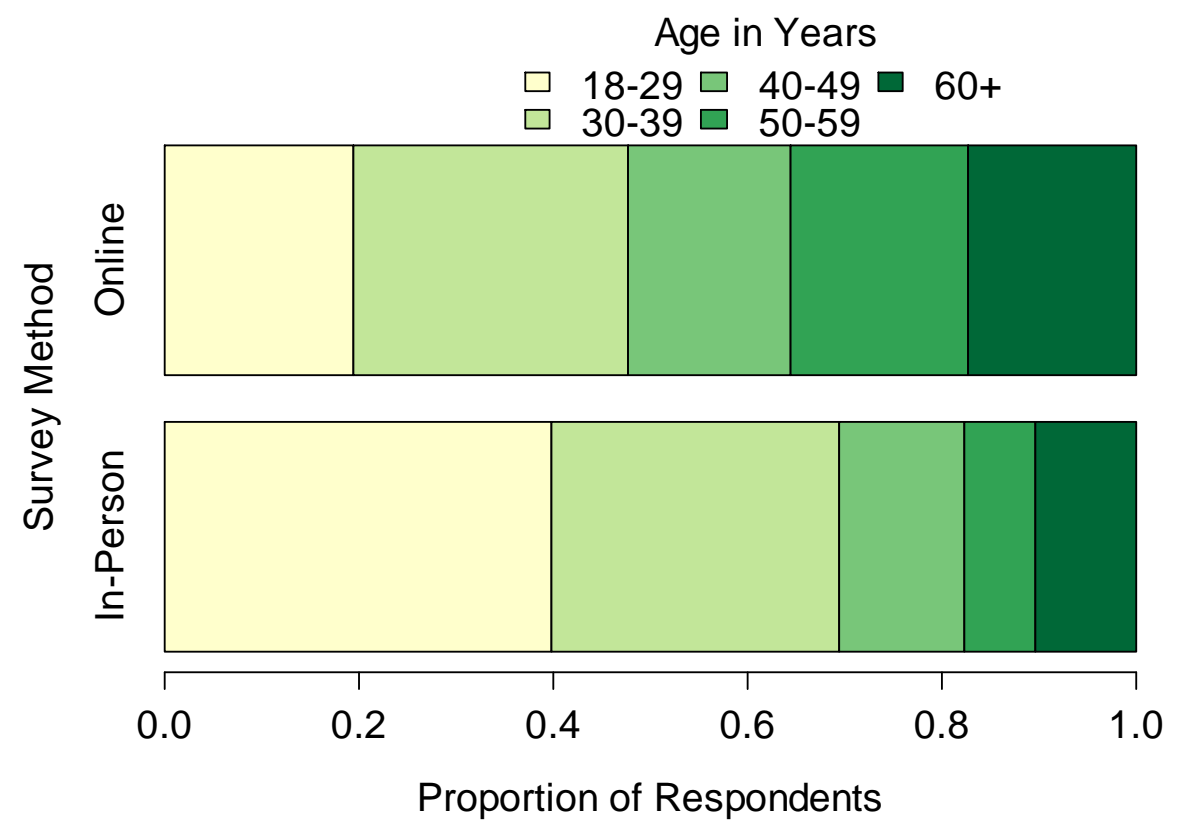

Figure 21 Respondent Age Groups - Survey Method Comparison
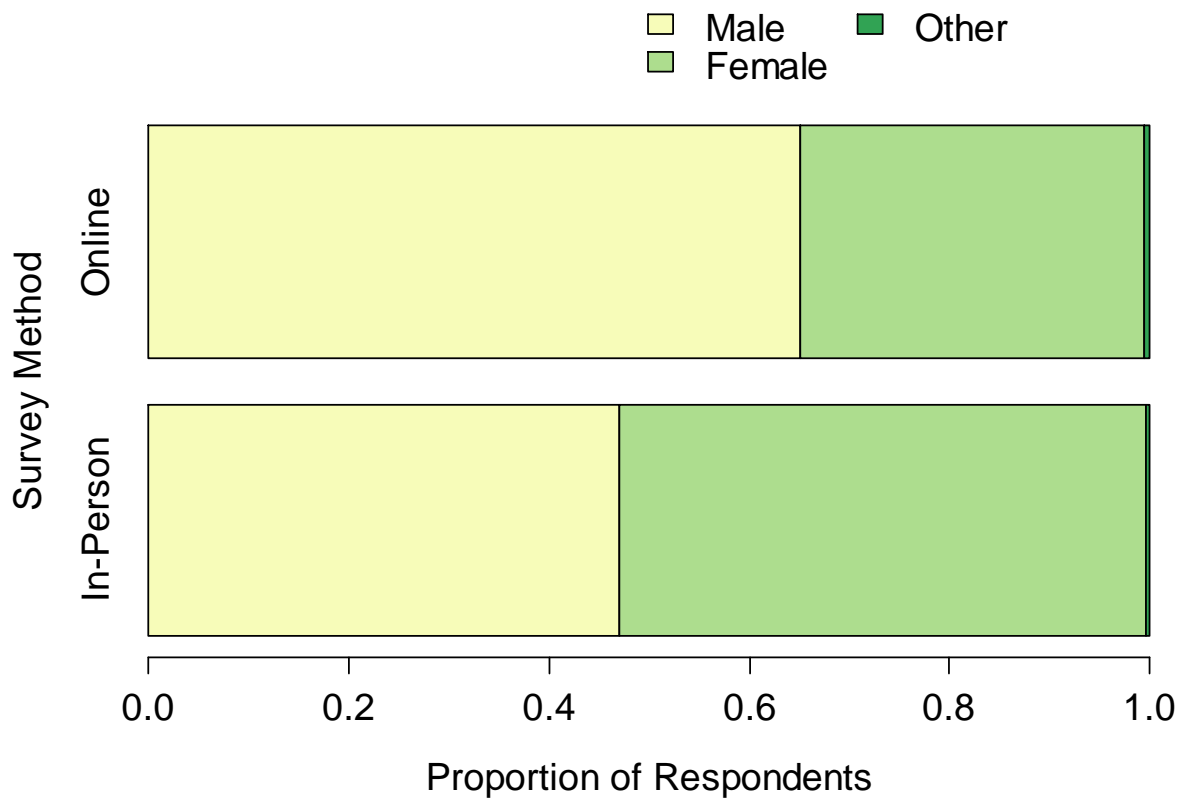

Figure 22 Respondent Gender- Survey Method Comparison 


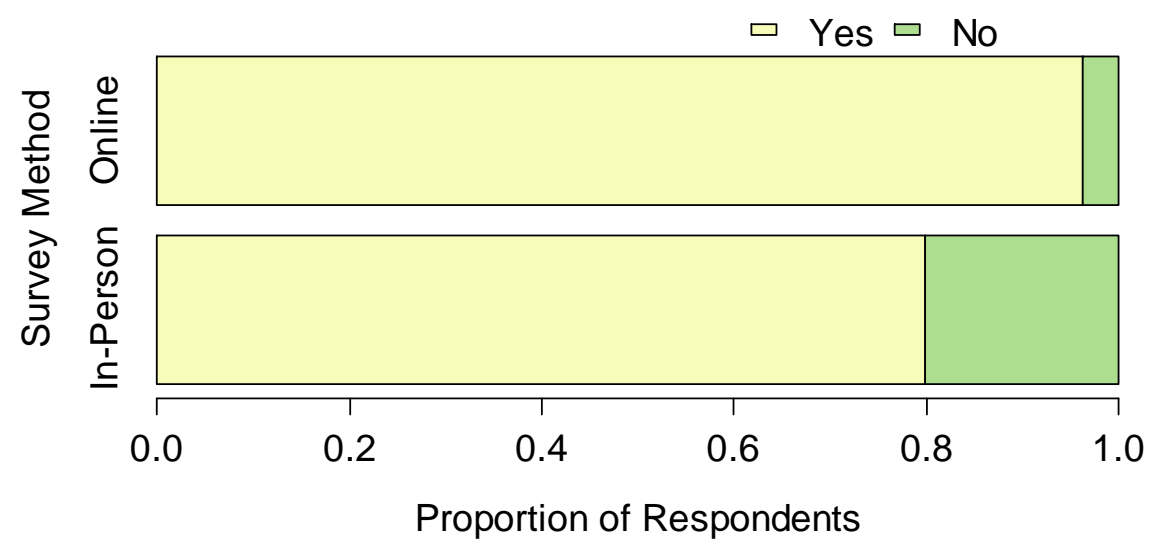

Figure 23 Access to a Working Bicycle - Survey Method Comparison

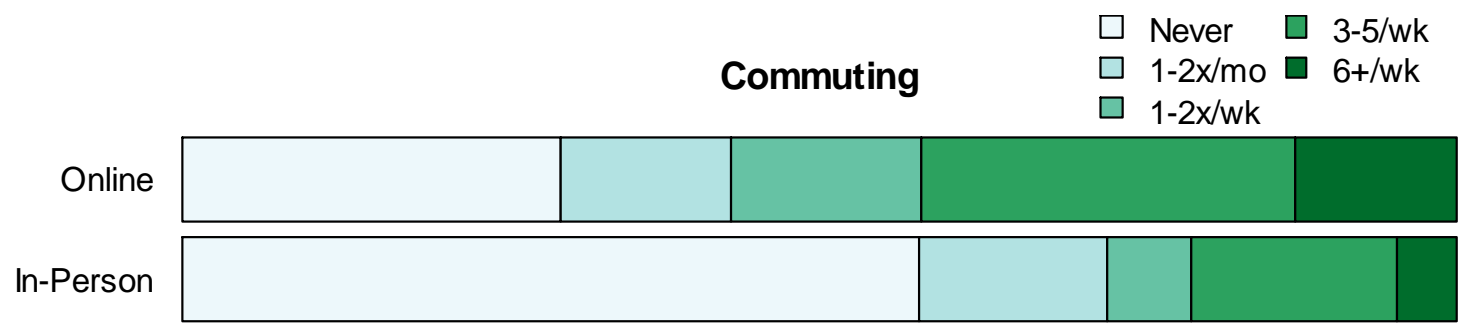

\section{Recreation}

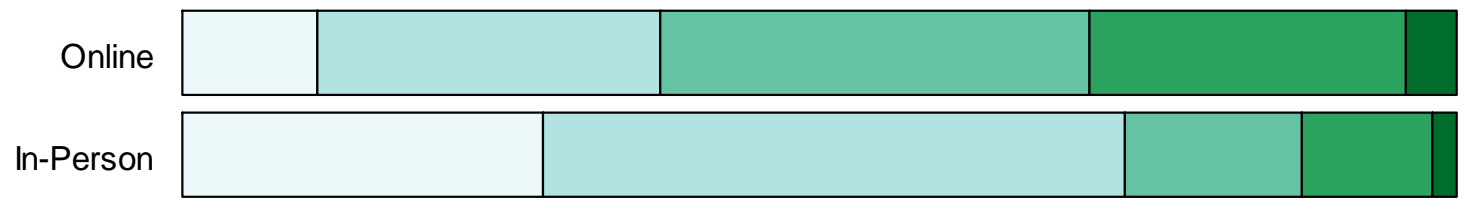

Other Purposes

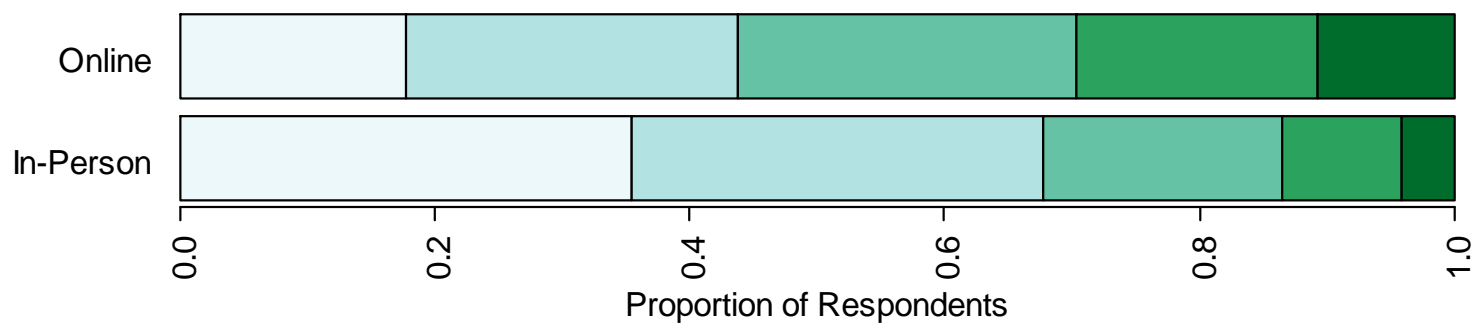

Figure 24 Respondent Riding Habits by Trip Purpose - Survey Methods Comparison 
Respondents to the online survey are typically older and more likely to be male than the in-person survey. Online survey participants also are more likely to have access to a working bicycle and they ride bicycles more frequently for all types of trip purposes, especially commuting. The findings regarding gender and riding habits are not surprising given the groups the online survey was sent out to. Previous efforts that featured advertising aimed at bicycling groups also had samples where men and experienced riders were overrepresented $(17,18,19,21)$. Chi-squared tests show that the distribution of each of these demographics shown in the above figures is significant at the 99\% confidence level, as shown in Table 30.

Table 30 In-Person vs. Online Survey Demographic Comparisons $-x^{2}$ Results

\begin{tabular}{|c|c|c|c||}
\hline Demographic & $\mathbf{X}^{2}$ Value & $\begin{array}{c}\text { Degrees of } \\
\text { Freedom }\end{array}$ & p-value \\
\hline \hline Age & 38.6 & 4 & $<0.01$ \\
\hline Gender & 18.6 & 2 & $<0.02$ \\
\hline Access to a Working Bicycle & 39.2 & 1 & $<0.01$ \\
\hline Bicycle Commuting Experience & 51.9 & 4 & $<0.01$ \\
\hline Recreational Bicycling Experience & 74.7 & 4 & $<0.01$ \\
\hline Other Bicycling Experience & 37.0 & 4 & $<0.01$ \\
\hline
\end{tabular}

\section{Scores by Individual Clip}

Table 31 compares the mean and median scores of each clip from the online and in-person surveys. 
Table 31 Scores by Clip - Online vs. In-Person Surveys

\begin{tabular}{|c|c|c|c|c|c|c|}
\hline Clip \# & Facility & Buffer Type & $\begin{array}{c}\text { Mean/ } \\
\text { Median } \\
\text { Score } \\
\text { (In- } \\
\text { Person) }\end{array}$ & $\begin{array}{c}\text { Standard } \\
\text { Deviation } \\
\text { (In- } \\
\text { Person) }\end{array}$ & $\begin{array}{c}\text { Mean/ } \\
\text { Median } \\
\text { Score } \\
\text { (Online }\end{array}$ & $\begin{array}{c}\text { Standard } \\
\text { Deviation } \\
\text { (Online) }\end{array}$ \\
\hline 9 & Off-Street Path & $\mathrm{N} / \mathrm{A}$ & $1.14 / \mathrm{A}$ & 0.64 & $1.21 / \mathrm{A}$ & 0.65 \\
\hline 1 & 1-Way PBL & Planters & $1.34 / \mathrm{A}$ & 0.63 & $1.73^{* *} / \mathrm{A}$ & 0.98 \\
\hline 11 & 1-Way PBL & Planters & $1.46 / \mathrm{A}$ & 0.68 & $1.82 * * / \mathrm{A}$ & 1.25 \\
\hline 18 & 1-Way PBL & Parked Cars & $1.60 / \mathrm{A}$ & 0.80 & $2.25^{* *} / \mathrm{B}$ & 1.12 \\
\hline 5 & 1-Way PBL & Parked Cars & $1.69 / \mathrm{A}$ & 0.89 & $2.10 * * / \mathrm{B}$ & 1.06 \\
\hline 12 & 1-Way PBL & Parked Cars & $1.72 / \mathrm{A}$ & 0.92 & $2.09 * * / \mathrm{B}$ & 1.17 \\
\hline 8 & 1-Way PBL & Posts & $1.97 / \mathrm{B}$ & 0.94 & $2.21 * * / \mathrm{B}$ & 1.13 \\
\hline 19 & 1-Way PBL & Raised/Parking $^{1}$ & $2.09 / \mathrm{B}$ & 1.05 & $2.40 * * / \mathrm{B}$ & 1.15 \\
\hline 6 & 2-Way $\mathrm{PBL}^{2}$ & Parked Cars & $2.16 / \mathrm{B}$ & 1.05 & $2.52 * * / \mathrm{B}$ & 1.25 \\
\hline 2 & 2-Way $\mathrm{PBL}^{3}$ & Parked Cars & $2.25 / \mathrm{B}$ & 1.18 & $2.46 / \mathrm{B}$ & 1.24 \\
\hline 16 & 2-Way $\mathrm{PBL}^{2}$ & Parked Cars & $2.31 / \mathrm{B}$ & 1.14 & $2.76 * * / C$ & 1.27 \\
\hline $20 \mathrm{~b}$ & 1-Way PBL & Posts & $2.32 / \mathrm{B}$ & 1.110 & $2.50 / \mathrm{B}$ & 1.08 \\
\hline $17 b$ & $\begin{array}{c}\text { Bike Lane w/ } \\
\text { Parking }\end{array}$ & None & $2.39 / B$ & 1.05 & $3.22 * * / C$ & 1.31 \\
\hline 15 & 1-Way PBL & Posts & $2.46 / \mathrm{B}$ & 1.13 & $2.88^{* *} / \mathrm{C}$ & 1.21 \\
\hline 14 & 2-Way $\mathrm{PBL}^{3}$ & Parked Cars & $2.71 / C$ & 1.13 & $2.92 / C$ & 1.32 \\
\hline 7 & Buffered Bike Lane & Double Stripe & $2.73 / \mathrm{C}$ & 1.22 & $2.67 / C$ & 1.20 \\
\hline $3 b$ & Bike Boulevard & None & $2.77 / \mathrm{B}$ & 1.49 & $2.14^{* *} / \mathrm{B}$ & 1.22 \\
\hline 10 & Buffered Bike Lane & Double Stripe & $2.86 / C$ & 1.23 & $3.07 / C$ & 1.14 \\
\hline 13 & Bike Lane & None & $3.48 / C$ & 1.25 & $3.72 * / D$ & 1.31 \\
\hline 4 & Shared Street & None & $3.78 / \mathrm{D}$ & 1.34 & $3.31 * * / C$ & 1.34 \\
\hline
\end{tabular}

${ }^{1}$ Parking is not occupied

*Difference in means is significant at the $95 \%$ confidence level (2-tail T-test)

** Difference in means is significant at the $99 \%$ confidence level (2-tail T-test)

The mean scores for most of the clips from the online survey are higher (less comfortable) than the scores for the same clips from the in-person survey. Nearly all of these differences are significant at the $95 \%$ or $99 \%$ confidence level. The median scores are higher for the online survey for seven clips and lower for one clip. The online mean scores are lower for only two clips, \#7 and 3b, but only the difference for clip \#3b is statistically significant. Standard deviations are generally larger for the online survey, too. 
The biggest difference in mean scores for which the online survey is higher is for clip \#17b. Participants in the online survey rated the bike lane with parking clip nearly one full score lower on average and it has a median score one grade lower, too. On the opposite end of the spectrum, clip \#3b, the bike boulevard clip, has an average rating that is 0.63 points better in the online survey compared to the in-person survey. Note that despite this wide difference in mean scores, the median score for this clip is the same between the two surveys.

\section{Impact of Survey Administration Method on Scores}

Given the differences in demographics and riding habits described above, it is not surprising that there is a difference in comfort scores between the online and inperson surveys. Multiple regression analysis is used to control for demographics to determine if the actual survey administration method is correlated with a difference in scores. To accomplish this, observations from individuals who watched fewer than ten clips in the online survey are removed from the sample. Then, observation data for the ten clips that online survey participants were strongly encouraged to view are subset from this reduced sample. Finally, individual clip scores from this sample are regressed on the demographic variables and a dummy variable indicating if the score came from the in-person or online survey. Table 32 contains the results of this analysis. 
Table 32 Regression of Score on Demographics and Survey Method

\begin{tabular}{|c|c|}
\hline Variable & Coefficient \\
\hline \hline Intercept & $2.52^{* *}$ \\
\hline Age (years) & $0.004^{* *}$ \\
\hline Riding Habits $^{1}$ & $-0.12^{* *}$ \\
\hline Gender (female) & -0.01 \\
\hline Gender (other) & 0.06 \\
\hline No Access to a Working Bicycle & 0.13 \\
\hline Online Survey & $0.28^{* *}$ \\
\hline $\mathrm{R}^{2}$ & 0.02 \\
\hline Model p-value & $<0.01$ \\
\hline
\end{tabular}

** Significant at the $99 \%$ confidence level

${ }^{1}$ For an increase in riding frequency for any trip purpose using the following categories in order: "Never", "1-2x/month", "1-2x/week", "3+x/week"

The results of this analysis show that when controlling for age, riding habits, access to a working bicycle, and gender, the survey administration method is a significant predictor of comfort score at the $99 \%$ confidence level. On average, individuals viewing the clips online rated them approximately 0.28 points worse than those watching the clips in-person, when these other factors are controlled for. The analysis also shows that gender is not a significant predictor and that when controlling for the other factors, men and women provide similar ratings. Whether an individual has access to a working bicycle is not a significant predictor $(p=0.05)$, but riding habits and age in years are both significant at the $99 \%$ confidence level.

\section{Open Ended Question Responses}

The online survey featured an open-ended question inviting respondents to tell the project team anything they wanted to. Most respondents chose not to respond to this question. However, several participants provided responses that offer useful insights into their ratings. These responses are reviewed to identify potential themes. 
The most common theme in the responses is commenting on the two-way facilities. Twenty-one individuals responded specifically regarding two-way travel. All but one of these responses is negative, which is consistent with the two-way travel term in the model. The reasons cited for the negative responses are most commonly a dislike of traveling against oncoming motor vehicle and bicycle traffic (eight responses each).

After two-way facilities, intersections are mentioned in 20 responses. Many of these comments mention that intersections are often where the most discomfort is experienced. It is suggested several times that signalized intersections should have been included in the study.

Other common topics include pavement condition (ten responses), noise from a squeaky bicycle chain (ten responses), and debris/puddles (seven responses) impacting responses.

\section{Summary}

\section{Demographics}

A total of 221 individuals participated in the in-person video survey. The sample from this survey generally represents a wide range of individuals, comparable to, or more diverse than, previous studies. However, it skews younger and bicycles more frequently than the general population and generally has a favorable attitude toward bicycling. The impact of these biases is likely small as the correlation between comfort ratings and age or bicycling habits is weak, though statistically significant. Similar to previous studies, younger individuals, those that ride more frequently, and men are all 
likely to feel more comfortable in a given situation than older individuals, those that ride occasionally or not at all, and women. Note that the difference in ratings between males and females in this sample is not statistically significant.

\section{Viewing Sessions}

Comfort ratings by viewing session are relatively similar. The OMSI session attracted a different demographic than did the two Farmer's Market surveys. The distribution of comfort ratings between the first Farmer's Market session and the OMSI session is statistically significant; however, the difference in mean scores between the two sessions is not significant. Otherwise, the distributions in ratings between the different sessions are similar.

\section{Facility Characteristics}

Median scores for the video clips range from ' $A$ ' to 'D.' Off-street path and protected bike lane clips have the best ratings, while a standard bike lane on an arterial and a shared collector-level street have the worst ratings.

Within the protected bike lane clips, planters are the preferred buffer type, followed by parked cars, a raised lane with unoccupied on-street parking, and then posts. Many other characteristics are correlated weakly with comfort ratings, though the correlation is statistically significant at the $95 \%$ confidence level. Note that in certain cases, the correlation is only significant if two-way travel is controlled for. These characteristics that are statistically significant for either all or only one-way protected facilities include: 
- Motor vehicle volumes

- Motor vehicle speed

- Roadway functional classification

- Unsignalized intersections and driveways

- Buffer width

- Number of motor vehicle lanes

\section{Models}

A simple index model and analytical regression-based models that predict bicyclist comfort on protected bike lanes are developed using the data from the inperson video surveys.

The index model considers the facility's buffer type and the motor vehicle ADT volume, speed, and number of travel lanes on the adjacent roadway. These variables are chosen because they have some of the highest correlations with the comfort ratings and are typically readily available data. The model is presented in Table 20 and accurately predicts the median comfort rating for twelve of the fourteen study clips.

Both OLS and CLM regression are used to develop predictive models from the video survey data. The logistic models are preferred to the OLS regression-based models as they predict the percentage of the population that would view the facility at a given comfort rating, providing a more complete picture of the facility's performance. They also limit their responses to the valid ' $A$ ' to ' $F$ ' (i.e. 1 to 6 ) range. The OLS-based models are presented for informational purposes.

Three models are presented for each analysis type. The first two are referred to as the Basic Model and the Basic Model (w/ ADT). These models consider variables 
similar to the index model, with the difference in them being that the first model considers the number of motor vehicle travel lanes, while the second considers ADT volumes instead. The third is the Exploratory Model, which is a stepwise regression analysis that considers other variables that may be more difficult to collect (e.g. peak hour motor vehicle volume in the lane adjacent to the protected bike lane).

With both types of regression, the Basic Model (w/ ADT) performs better than the Basic Model. The Exploratory Model only offers mixed results when compared to the Basic Model (w/ ADT) while requiring data that are less likely to be available. Therefore, the Basic Model ( $w / A D T)$ is the recommended model. It is also recommended the model without data from clip \#14 be used, as it has been determined that clip is an outlier due to standing water in the lane.

The Basic Model (w/ ADT) and Index model are compared to the Danish LOS model. This comparison is done using survey data from the Green Lane project, which includes a few facilities not included in the video survey dataset. Both of the models developed for this project match the Green Lane survey data better than the Danish model in terms of predicted median ratings, and in the case of the logistic model, predicted distribution of responses. These results suggest that they may be more applicable than the Danish model to American facilities; however the sample size is too small to make that claim definitively and the Green Lane surveys do not distinguish between segments and intersections, so it is not a direct comparison. 
Finally, the Basic Model (w/ ADT) is recommended for use over the index model. The regression-based model correctly predicted the median value for the video survey data and it provides a predicted distribution of user responses, giving a more complete picture of the facility's performance. This recommendation is made with the caveat that neither model may make accurate predictions if the ADT volume of the roadway falls out of the range of approximately 9,000 to 30,000 vehicles per day, if the speed limit is above $35 \mathrm{MPH}$, or if a buffer type other than those included in the model is used. Also, the median value of all protected bike lane clips and from the Green Lane facilities is no worse than 'B.' Given this lack of variety in median response rates, neither model is likely to be off by more than one letter grade so long as the subject facility falls within the model's limitations listed above.

\section{Online Survey Results}

The online survey, advertised through transportation and bicycle-focused channels, produced a sample that is older, more male, and rides more frequently than the in-person survey. Comfort ratings from the online survey are general higher (less comfortable) than those for the same clips from the in-person survey. A regression analysis that controls for gender, age, riding habits, and access to a working bicycle reveals that the survey administration method is a significant predictor of comfort rating. On average, individuals viewing the clips online rated them approximately 0.28 points worse than those watching the clips in-person, when these other factors are controlled for. 


\section{Conclusions}

This project has examined the effects of various factors on bicyclist comfort in protected bike lanes and developed a mathematical model to predict how comfortable a bicyclist is likely to feel riding in a protected bike lane under various conditions. This work is a unique contribution in that there are currently no mathematical models to predict bicyclist comfort in protected bike lanes that are based on American data. The final recommended model is a cumulative logistic model, which is the same form used by the Danish level-of-service (LOS) model (11). This gives it a different form from other American models as most mathematical models based on US data in use today are based on OLS regression $(6,19,21)$. The cumulative logistic model predicts the probability that a user will provide a given comfort score for a facility. This can also be interpreted as the percentage of the population that would view the facility at a given comfort rating; thereby providing a more complete picture of the facility's performance than can be ascertained from a mean score provided by a simple linear model.

The final model only uses variables that are readily available for most collectorlevel and above roadways (e.g. buffer type, one-way or two-way travel, motor vehicle speed, and average daily traffic volume). It has been tested on survey data from another project of actual bicyclists on a variety of protected bike lanes. The predicted median comfort ratings and distributions of those comfort ratings are generally similar to the responses from the survey. This model also predicts these ratings more accurately than does the Danish LOS model, suggesting that it may be more applicable to American 
facilities than the Danish model; though a bigger sample size involving observations of segments only is needed to make a definitive conclusion.

The model is only valid for the following situations:

- ADT volume of approximately 9,000 to 30,000 vehicles per day

- Speed limit between 25 and $35 \mathrm{MPH}$

- Buffer type is posts, parked cars, raised surface with an unoccupied parking lane, and planters

Finally, a simple index model is also developed that utilizes only a look-up table.

It accurately predicts the median comfort rating for most of the video clips and most of the facilities from the other project. It does not fit quite as well as the mathematical model, nor does it provide information about the distribution of responses. However, the median value of all protected bike lane clips and from the other facilities is no worse than 'B.' Given this lack of variety in median response rates, neither model is likely to be off by more than one letter grade so long as the subject facility falls within the model's limitations listed above, so the index model can likely be used for quick estimates to provide accurate median values in many instances

\section{Secondary Objectives}

In addition to developing the models described above, the project had a number of secondary objectives. The following is a summary of the results of these analyses.

Are protected bike lanes perceived as more comfortable than other types of on-street facilities? 
The clips featuring protected bike lanes generally received more comfortable ratings than did the clips of bike lanes and shared streets. There was some overlap between the least comfortable protected bike lane clips and the most comfortable bike lane clip; however, theses protected bike lane clips were on a busier road than the bike lane clip.

Do different buffer types impact perceived comfort?

Buffer type is a significant predictor of bicyclist comfort in the final model. Planters are the most preferred buffer type, followed by parked cars, a raised surface with an unoccupied parking lane, and then posts.

Is there a difference in perceived comfort on two-way facilities between riding with motor vehicle traffic or against motor vehicle traffic?

There was a slight difference in the mean scores between riding with and against traffic on a two-way facility. However, this difference is small and is not statistically significant.

There is a difference in perceived comfort between two-way and one-way facilities?

Controlling for motor vehicle volumes and speeds and buffer type, respondents stated a higher level of comfort on one-way facilities as compared to two-way facilities. This is further validated by responses to the online survey's open-ended question indicating concerns about oncoming motor vehicle or bicycle traffic when riding in a two-way facility. 
Motor vehicle volumes in a given video clip impact ratings (i.e. do clips of the same section with different motor vehicle volumes have different ratings?)

The mean ratings of clips of the same facility with different levels of motor vehicle traffic in the clip suggest that the number of vehicles passing the bicyclist during the video do not influence the ratings. However, a stepwise regression analysis found it to be a statistically significant predictor, with comfort decreasing as motor vehicle volumes increased.

Do online surveys produce different results than in-person surveys?

Controlling for demographic differences, respondents to the online survey typically provided less comfortable ratings by about 0.28 points on average.

Does casual advertising to transportation and bicycle related groups produce different demographics and results than outreach to the general community?

Advertising in this manner produced was effective at gathering participants; however, the resulting sample was biased toward males and frequent riders.

\section{Limitations}

The primary limitation of this study is the variety of protected bike lanes used in the clips. Due to logistical constraints and the limited number of protected bike lane installations in the US, study sites for this project were limited to the Portland area and a few locations in Chicago and San Francisco. The ability to show a wider variety of facilities was further limited by the desire to show multiple clips from the same facility 
in order to isolate the impact of motor vehicle traffic in the video, to include reference video clips of more common bicycling infrastructure, and to limit the survey to about 15 minutes. Most notably, there are multiple video clips of a two-way facility; however, they are all from Dearborn Street in downtown Chicago. Therefore, the two-way dummy variable in the model is based on one facility in a dense urban environment. Additionally, the planter and raised with unoccupied parking buffer types are represented by only one facility.

Similarly, the range of traffic conditions is somewhat constrained. Most of the video clips are taken from collector level facilities with speed limits under $35 \mathrm{MPH}$. There are no clips on roads with speeds above $35 \mathrm{MPH}$. The ADT range of study facilities is approximately 9,000 to 30,000 vehicles per day. This is a relatively wide range; however, it appears the model may not accurately represent conditions on roads with a lower ADT volume. It is unclear how comfortable individuals might feel on a road with speeds greater than $35 \mathrm{MPH}$ or an ADT volume greater than 30,000 vehicles.

Another significant limitation of this study is that it does not include intersections. This was an intentional decision made in order to isolate the variables that influence segment level comfort. The buffer alongside a protected bike lane necessarily disappears at intersections, making it seem likely that comfort is likely to be less through an intersection. A number of responses to the online survey open-ended question alluded to this, as well. 
The video collection and production methods also have limitations. A different bicycle was used in each city. The rental bike in Chicago had a squeaky chain, which ends up being audible in the Chicago clips. A few respondents to the online survey noted this in their responses to the open-ended question. The camera mount seemed to exacerbate road vibrations, especially in areas with rough or cracked pavement, which made some clips too bouncy to use, even after post-processing. Also, it was mentioned to the author after the filming was completed, that using a 30 frames-per-second (fps) filming rate, instead of the $60 \mathrm{fps}$ rate that was used, may have made the clips smoother after post-processing.

Finally, the sample used in this survey is relatively young in age and rides more frequently than the general population.

\section{Implications}

Despite the limitations listed above, this model provides a useful approximation of expected bicyclist comfort in protected bike lane segments. Previous research has shown that individuals typically prefer protected bike lanes to other on-street infrastructure $(2,4,5,6,7)$ and the data this model is based on is consistent with these findings. The model also performs well compared with other survey data and the Danish LOS model. It can be used by practitioners who wish to objectively compare the performance, in terms of quality of service, of a protected bike lane to other infrastructure types. For situations that fall outside the range of this model, the Danish LOS model may provide a useful substitute. 


\section{Future Work}

Future research related to quantifying bicyclist comfort in protected bike lanes should focus on intersection treatments. A more robust effort could potentially produce a more accurate model with a wider range of applications for segments. However, given the narrow range of median values for the protected bike lane clips, the utility of such an effort may not be as high as creating an intersection model. There are several different intersection treatments in use today, which is likely indicative of a limited understanding of how well they perform in regards to bicyclist comfort, among other factors. Such an effort should be modeled after this study and other previous efforts. Ideally, an intersection model would eventually be combined with a segment model to provide a complete picture of an entire route.

The model created for this project only includes protected bike lanes. A comprehensive model incorporated all types of bicycle facilities should be created. The resulting model should be either a simple index model or a cumulative logistic model using readily available data. It should also incorporate other types of bicycle facilities not covered in most models, including shared lane markings and painted bike lanes, if they are found to have a significant impact on bicyclist comfort. 


\section{References}

1. Inventory of Protected Green Lanes. People for Bikes. Updated February 28, 2014. http://www.peopleforbikes.org/green-lane-project/pages/inventory-ofprotected-bike-lanes. Accessed April 28, 2014.

2. Pucher, J. and R. Buehler. "Making Cycling Irresistible: Lessons from The Netherlands, Denmark and Germany." Transport Reviews, Vol. 28, No. 4, 2008, pp. 495-528.

3. Tilahun, N. Y., D. M. Levinson, and K. J. Krizek. "Trails, Lanes, or Traffic: Valuing Bicycle Facilities with an Adaptive Stated Preference Survey." Transportation Research Part A: Policy and Practice. Vol. 41, 2007, pp. 287-301.

4. Winters, M., and Teschke, K. "Route Preferences Among Adults in the Near Market for Bicycling: Findings of the Cycling in Cities Study." American Journal of Health Promotion, Vol. 25, 2010, pp. 40-47.

5. Monsere, C. M., N. McNeil, and J. Dill. "Multi-User Perspectives on Separated, On-Street Bicycle Infrastructure." In Transportation Research Record: Journal of the Transportation Research Board, No. 2314, Transportation Research Board of the National Academies, Washington, D.C., 2012, pp. 22-30.

6. Sanders, R. L. Examining the Cycle: How Perceived and Actual Bicycling Risk Influence Cycling Frequency, Roadway Design Preferences, and Support for Cycling Among Bay Area Residents. Dissertation, University of California Transportation Center, University of California, Berkeley, 2013.

7. Dill, J. and McNeil, M. "Four Types of Cyclists? Testing a Typology to Better Understand Bicycling Behavior and Potential." Working Paper, Oregon 
Transportation Research and Education Consortium, Portland State University, Portland. http://web.pdx.edu/ idill/Types of Cyclists PSUWorkingPaper.pdf. Accessed May 7, 2014.

8. Highway Capacity Manual 2010. Transportation Research Board, National Research Council, Washington, D.C., 2011.

9. Mekuria, M. C., P. G. Furth, and H. Nixon. Low-Stress Bicycling and Network Connectivity. MTI Report 11-19. Mineta Transportation Institute, May 2012.

10. Bicycle Environmental Quality Index (BEQI), Draft Report - 2009. San Francisco Department of Public Health, 2009.

11. Jensen, S. U. "Pedestrian and Bicyclist Level of Service on Roadway Segments." In Transportation Research Record: Journal of the Transportation Research Board, No. 2031, Transportation Research Board of the National Academies, Washington, D.C., 2007, pp. 43-51.

12. Petritsch, T. A., B. W. Landis, H. F. Huang, P. S. McLeod, M. Guttenplan, and L. Crider. Video Simulation of Roadway Bicycling. Presented at the $86^{\text {th }}$ Annual Meeting of the Transportation Research Board, Washington, D.C., 2007.

13. Jensen, S. U., C. Rosenkilde, and N. Jensen. Road Safety and Perceived Risk of Cycle Facilities in Copenhagen. City of Copenhagen, Denmark, 2007.

14. Sorton, A. and Walsh, T. "Bicycle Stress Level as a Tool to Evaluate Urban and Suburban Compatibility." In Transportation Research Record: Journal of the 
Transportation Research Board, No. 1438, Transportation Research Board of the National Academies, Washington, D.C., 1994, pp. 17-23.

15. Noël, N., C. Leclerc, and M. Lee-Gosselin. CRC Index: Compatibility of Roads for Cyclists in Rural and Urban Fringe Areas. Presented at the $82^{\text {nd }}$ Annual Meeting of the Transportation Research Board, Washington, D.C., 2003.

16. Jensen, S. U. Pedestrian and Bicycle Level of Service at Intersections, Roundabouts and Other Crossings. Presented at the $92^{\text {nd }}$ Annual Meeting of the Transportation Research Board, Washington, D.C., 2013.

17. Landis, B. W., V. R. Vattikuti, and M. T. Brannick. "Real-Time Human Perceptions: Toward a Bicycle Level of Service." In Transportation Research Record: Journal of the Transportation Research Board, No. 1578, Transportation Research Board of the National Academies, Washington, D.C., 1997, pp. 119-126.

18. Landis, B. W., V. R. Vattikuti, R. M. Ottenberg, T. A. Petritsch, M. Guttenplan, and L. B. Crider. "Intersection Level of Service for the Bicycle Through Movement." In Transportation Research Record: Journal of the Transportation Research Board, No. 1828, Transportation Research Board of the National Academies, Washington, D.C., 2003, pp. 101-106.

19. Petritsch, T. A., B. W. Landis, H. F. Huang, P. S. McLeod, D. Lamb, W. Farah, and M. Guttenplan. "Bicycle Level of Service for Arterials." In Transportation Research Record: Journal of the Transportation Research Board, No. 2031, 
Transportation Research Board of the National Academies, Washington, D.C., 2007, pp. 34-42.

20. Petritsch, T. A., S. Ozkul, P. McLeod, B. Landis, and D. McLeod. "Quantifying Bicyclists' Perceptions of Shared-Use Paths Adjacent to the Roadway." In Transportation Research Record: Journal of the Transportation Research Board, No. 2198, Transportation Research Board of the National Academies, Washington, D.C., 2010, pp. 124-132.

21. Harkey, D. L., D. W. Reinfurt, M. Knuiman, J. R. Stewart, and A. Sorton. Development of the Bicycle Compatibility Index: A Level of Service Concept, Final Report. Publication FHWA-RD-98-072. FHWA, U.S. Department of Transportation, 1998.

22. Hummer, J. E., N. Rouphail, R. G. Hughes, S. J. Fain, J. L. Toole, R. S. Patten, R. J. Schneider, J. F. Monahan, and A. Do. "User Perceptions of the Quality of Service on Shared Paths." In Transportation Research Record: Journal of the Transportation Research Board, No. 1939, Transportation Research Board of the National Academies, Washington, D.C., 2005, pp. 28-36.

23. City of Fort Collins Multimodal Transportation Level of Service Manual. City of Fort Collins Transportation Master Plan, Fort Collins, CO, 1997.

24. Jones, E. G., and Carlson, T. D. “Development of Bicycle Compatibility Index for Rural Roads in Nebraska." In Transportation Research Record: Journal of the 
Transportation Research Board, No. 1828, Transportation Research Board of the National Academies, Washington, D.C., 2003, pp. 124-132.

25. Flannery, A., A. T. Ali, and C. M. Cristei. Using Cumulative Logistic Regression Model for Evaluating Bicycle Facilities on Urban Arterials. Presented at the $91^{\text {st }}$ Annual Meeting of the Transportation Research Board, Washington, D.C., 2012.

26. Stinson, M. A. and Bhat, C. R. "Commuter Bicyclist Route Choice: Analysis Using a Stated Preference Survey." In Transportation Research Record: Journal of the Transportation Research Board, No. 1828, Transportation Research Board of the National Academies, Washington, D.C., 2003, pp. 107-114.

27. Dowling, R., D. Reinke, A. Flannery, P. Ryus, M. Vandehey, T. Petritsch, B. Landis, N. Rouphail, and J. Bonneson. Multimodal Level of Service Analysis for Urban Streets. NCHRP Report 616, Transportation Research Board of the National Academies, Washington, D.C., 2008.

28. Dowling, R., A. Flannery, P. Ryus, T. Petritsch, and N. Rouphail. Field Test Results of the Multimodal Level of Service Analysis for Urban Streets. NCHRP Web-Only Document 158, Transportation Research Board of the National Academies, Washington, D.C., 2010.

29. Carter, P., M. Núñez, S. Peters, J. Campbell, F. Martin, L. Raykin, and R. Milam. Complete Enough for Complete Streets? Testing the Sensitivity of HCM 2010 Multimodal LOS under Conditions of Change. Presented at the $92^{\text {nd }}$ Annual Meeting of the Transportation Research Board, Washington, D.C., 2013. 
30. Parks, J., A. Tanaka, P. Ryus, C. Monsere, N. McNeil, and M. Goodno. “An Assessment of Three Alternative Bicycle Infrastructure Quality of Service Metrics." In Transportation Research Record: Journal of the Transportation Research Board, No. 2387, Transportation Research Board of the National Academies, Washington, D.C., 2013, pp. 56-65.

31. Petritsch, T. A., B. W. Landis, and T. Scorsone. Addressing Deficiencies HCM Bike Level of Service Model for Arterial Roadways. Presented at the $94^{\text {th }}$ Annual Meeting of the Transportation Research Board, Washington, D.C., 2014.

32. Dill, J. and Gliebe, J. Understanding and Measuring Bicycling Behavior: A Focus on Travel Time and Route Choice. Publication OTREC-RR-08-03, Oregon Transportation Research and Education Consortium, 2008.

33. Weidner, T. Bike Planning Methods in Oregon Communities. Presented at Portland State University Transportation Seminar, Portland, Oregon, February 21, 2014.

34. Bicycle and Pedestrian Design Guide. Oregon Department of Transportation, 2011.

35. R: A Language and Environment for Statistical Computing. R Core Team, R Foundation for Statistical Computing, Vienna, Austria, 2013.

36. Christensen, R. H. B. ordinal - Regression Models for Ordinal Data. R package version 2013.9-30, 2013.

37. Neuwirth, E. RColorBrewer: ColorBrewer Palettes. R package version 1.0-5, 2011. 
38. Wickham, H. "The Split-Apply-Combine Strategy for Data Analysis." Journal of Statistical Software, Vol. 40, No. 1, 2011, pp. 1-29.

39. Wickham, H. ggplot2: Elegant Graphics for Data Analysis. Springer, New York, 2009.

40. Venables, W. N. and Ripley, B. D. Modern Applied Statistics with S, $4^{\text {th }}$ Edition. Springer, New York, 2002. 


\section{Appendix A - Video Clip Characteristics}

Table A-1 Video Clip Characteristics, Part 1

\begin{tabular}{|c|c|c|c|c|c|c|c|}
\hline Clip \# & Location & Facility Type & Buffer Type & $\begin{array}{c}\text { MV Volume } \\
\text { (adjacent lane - } \\
\text { vph) }\end{array}$ & $\begin{array}{l}\text { Functional } \\
\text { Classification }\end{array}$ & $\begin{array}{c}\text { MV } \\
\text { Speed }\end{array}$ & ADT \\
\hline 1 & Multnomah & 1-way CT & Planters & 257 & Collector & 25 & 9,956 \\
\hline 2 & Dearborn & 2-way (against traffic) & Parked Cars & 360 & Collector & 25 & 7,800 \\
\hline $3 a$ & Barbur & Buffered Bike Lane & Double stripe & 840 & Arterial & 35 & 15,170 \\
\hline $3 b$ & Ankeny & Bike Boulevard & $\mathrm{n} / \mathrm{a}$ & 0 & Local & 25 & 743 \\
\hline 4 & Knott & Shared Street & $\mathrm{n} / \mathrm{a}$ & 360 & Local & 30 & 2,925 \\
\hline 5 & Broadway & 1-way CT & Parked Cars & 338 & Collector & 25 & 12,800 \\
\hline 6 & Dearborn & 2-way CT (with traffic) & Parked Cars & 277 & Collector & 25 & 15,922 \\
\hline 7 & Barbur & Buffered Bike Lane & Double stripe & 360 & Arterial & 35 & 15,170 \\
\hline 8 & Fell & 1-way CT & Posts & 343 & Arterial & 30 & 28,156 \\
\hline 9 & Springwater Corridor & Off-street Path & $\mathrm{n} / \mathrm{a}$ & 0 & $\mathrm{n} / \mathrm{a}$ & 0 & 0 \\
\hline 10 & Barbur & Buffered Bike Lane & Double stripe & 1200 & Arterial & 35 & 15,170 \\
\hline 11 & Multnomah & 1-way CT & Planters & 600 & Collector & 25 & 9,956 \\
\hline 12 & Elston & 1-way CT & Parked Cars & 840 & Collector & 30 & 9,150 \\
\hline 13 & Barbur & Bike Lane & $\mathrm{n} / \mathrm{a}$ & 360 & Arterial & 35 & 15,170 \\
\hline 14 & Dearborn & 2-way (against traffic) & Parked Cars & 864 & Collector & 25 & 15,922 \\
\hline 15 & Elston & 1-way CT & Posts & 960 & Collector & 30 & 9,150 \\
\hline 16 & Dearborn & 2-way CT (with traffic) & Parked Cars & 626 & Collector & 25 & 15,922 \\
\hline $17 a$ & Multnomah & 1-way CT & Planters & 857 & Collector & 25 & 9,956 \\
\hline $17 b$ & Multnomah & Bike Lane w/ Parking & $\mathrm{n} / \mathrm{a}$ & 1080 & Collector & 25 & 8,050 \\
\hline 18 & Elston & 1-way CT & Parked Cars & 1286 & Collector & 30 & 9,150 \\
\hline
\end{tabular}




\begin{tabular}{|c|c|c|c|c|c|c|c|}
\hline Clip \# & Location & Facility Type & Buffer Type & $\begin{array}{c}\text { MV Volume } \\
\text { (adjacent lane - } \\
\text { vph) }\end{array}$ & $\begin{array}{l}\text { Functional } \\
\text { Classification }\end{array}$ & $\begin{array}{c}\text { MV } \\
\text { Speed }\end{array}$ & ADT \\
\hline 19 & Cully & 1-way CT & $\begin{array}{c}\text { Raised; Parked } \\
\text { Cars }\end{array}$ & 360 & Collector & 35 & 4,376 \\
\hline $20 a$ & Dearborn & 2-way (against traffic) & Parked Cars & 840 & Collector & 25 & 7,800 \\
\hline $20 b$ & Milwaukee & 1-way CT & Posts & 600 & Arterial & 25 & 11,814 \\
\hline
\end{tabular}

Table A-2 Video Clip Characteristics, Part 2

\begin{tabular}{|c|c|c|c|c|c|c|c|c|c|}
\hline Clip \# & Location & $\begin{array}{l}\text { Facility } \\
\text { Width }\end{array}$ & Buffer Width & $\begin{array}{c}\text { Total MV } \\
\text { Volume } \\
\text { (vph) } \\
\end{array}$ & $\begin{array}{c}\text { Unsignalized } \\
\text { Conflicts } \\
\end{array}$ & Land use & $\begin{array}{c}\text { Unsignalized } \\
\text { Conflict } \\
\text { Density (per } \\
\text { mile) } \\
\end{array}$ & $\begin{array}{c}\text { \# of } \\
\text { MV } \\
\text { Travel } \\
\text { Lanes } \\
\end{array}$ & $\begin{array}{c}\text { Center } \\
\text { Turn } \\
\text { Lane } \\
\end{array}$ \\
\hline 1 & Multnomah & $7 \mathrm{ft}$ & $6 \mathrm{ft}$ & 1157 & 0 & $\begin{array}{c}\text { Commercial/ } \\
\text { Office }\end{array}$ & 0 & 2 & 1 \\
\hline 2 & Dearborn & $\begin{array}{c}9 \mathrm{ft}(4 \mathrm{w} /, 5 \\
\text { against) }\end{array}$ & $\begin{array}{c}11 \mathrm{ft} \text { ( } 8 \text { parking, } \\
3 \text { buffer) }\end{array}$ & 360 & 0 & CBD & 0 & 2 & 0 \\
\hline $3 a$ & Barbur & $5 \mathrm{ft}$ & $3 \mathrm{ft}$ & 1560 & 2 & $\begin{array}{c}\text { Commercial/ } \\
\text { Residential }\end{array}$ & 18.46 & 3 & 1 \\
\hline $3 b$ & Ankeny & $n / a$ & $n / a$ & 120 & 2 & Residential & 18.46 & 2 & 0 \\
\hline 4 & Knott & $n / a$ & $n / a$ & 960 & 2 & Residential & 18.46 & 2 & 0 \\
\hline 5 & Broadway & $7 \mathrm{ft}$ & $\begin{array}{c}11 \mathrm{ft} \text { ( } 8 \text { parking, } \\
3 \text { buffer) }\end{array}$ & 675 & 1 & CBD & 8.65 & 2 & 0 \\
\hline 6 & Dearborn & $\begin{array}{l}8.5 \mathrm{ft}(4 \mathrm{w} /, \\
4.5 \text { against) }\end{array}$ & $\begin{array}{c}10.5 \mathrm{ft}(7.5 \\
\text { parking, } 3 \\
\text { buffer })\end{array}$ & 415 & 0 & CBD & 0 & 3 & 0 \\
\hline 7 & Barbur & $5 \mathrm{ft}$ & $3 \mathrm{ft}$ & 360 & 1 & Residential & 9.23 & 3 & 1 \\
\hline 8 & Fell & $7 \mathrm{ft}$ & $4 \mathrm{ft}$ & 1371 & 1 & $\begin{array}{c}\text { Commercial/ } \\
\text { Residential }\end{array}$ & 13.19 & 3 & 0 \\
\hline 9 & $\begin{array}{c}\text { Springwater } \\
\text { Corridor }\end{array}$ & $\mathrm{n} / \mathrm{a}$ & $\mathrm{n} / \mathrm{a}$ & 0 & 0 & Open Space & 0 & 0 & 0 \\
\hline 10 & Barbur & $5 \mathrm{ft}$ & $3 \mathrm{ft}$ & 1440 & 1 & Residential & 9.23 & 3 & 1 \\
\hline
\end{tabular}




\begin{tabular}{|c|c|c|c|c|c|c|c|c|c|}
\hline Clip \# & Location & $\begin{array}{l}\text { Facility } \\
\text { Width }\end{array}$ & Buffer Width & $\begin{array}{c}\text { Total MV } \\
\text { Volume } \\
\text { (vph) }\end{array}$ & $\begin{array}{c}\text { Unsignalized } \\
\text { Conflicts }\end{array}$ & Land use & $\begin{array}{l}\text { Unsignalized } \\
\text { Conflict } \\
\text { Density (per } \\
\text { mile) } \\
\end{array}$ & $\begin{array}{c}\text { \# of } \\
\text { MV } \\
\text { Travel } \\
\text { Lanes }\end{array}$ & $\begin{array}{c}\text { Center } \\
\text { Turn } \\
\text { Lane } \\
\end{array}$ \\
\hline 11 & Multnomah & $7 \mathrm{ft}$ & $6 \mathrm{ft}$ & 720 & 0 & $\begin{array}{l}\text { Commercial/ } \\
\text { Office }\end{array}$ & 0 & 2 & 1 \\
\hline 12 & Elston & $7 \mathrm{ft}$ & $\begin{array}{c}12 \mathrm{ft} \text { (8 parking, } \\
4 \text { buffer) }\end{array}$ & 1440 & 2 & Industrial & 18.46 & 2 & 0 \\
\hline 13 & Barbur & $5 \mathrm{ft}$ & $0 \mathrm{ft}$ & 1920 & 3 & Commercial & 27.69 & 6 & 0 \\
\hline 14 & Dearborn & $\begin{array}{l}8.5 \mathrm{ft}(4 \mathrm{w} /, \\
4.5 \text { against) }\end{array}$ & $\begin{array}{c}10.5 \mathrm{ft}(7.5 \\
\text { parking, } 3 \\
\text { buffer) }\end{array}$ & 2448 & 0 & CBD & 0 & 3 & 0 \\
\hline 15 & Elston & $7 \mathrm{ft}$ & $3 \mathrm{ft}$ & 1080 & 1 & Industrial & 9.23 & 2 & 0 \\
\hline 16 & Dearborn & $\begin{array}{l}8.5 \mathrm{ft}(4 \mathrm{w} /, \\
4.5 \text { against) }\end{array}$ & $\begin{array}{c}10.5 \mathrm{ft}(7.5 \\
\text { parking, } 3 \\
\text { buffer) }\end{array}$ & 1096 & 1 & CBD & 12.04 & 3 & 0 \\
\hline $17 a$ & Multnomah & $7 \mathrm{ft}$ & $6 \mathrm{ft}$ & 1200 & 0 & $\begin{array}{c}\text { Commercial/ } \\
\text { Office }\end{array}$ & 0 & 2 & 1 \\
\hline $17 \mathrm{~b}$ & Multnomah & $5 \mathrm{ft}$ & $0 \mathrm{ft}$ & 1440 & 1 & Residential & 9.23 & 2 & 0 \\
\hline 18 & Elston & $7 \mathrm{ft}$ & $\begin{array}{c}12 \mathrm{ft} \text { (8 parking, } \\
4 \text { buffer) }\end{array}$ & 1929 & 1 & Industrial & 9.89 & 2 & 0 \\
\hline 19 & Cully & $7 \mathrm{ft}$ & $8 \mathrm{ft}$ & 960 & 1 & Residential & 9.23 & 2 & 0 \\
\hline $20 a$ & Dearborn & $\begin{array}{c}9 \mathrm{ft}(4 \mathrm{w} /, 5 \\
\text { against) }\end{array}$ & $\begin{array}{c}11 \mathrm{ft} \text { (8 parking, } \\
3 \text { buffer) }\end{array}$ & 1320 & 0 & $\mathrm{CBD}$ & 0 & 2 & 0 \\
\hline $20 b$ & Milwaukee & $7 \mathrm{ft}$ & $3 \mathrm{ft}$ & 960 & 3 & $\begin{array}{c}\text { Commercial/ } \\
\text { Industrial }\end{array}$ & 27.69 & 2 & 0 \\
\hline
\end{tabular}




\section{Appendix B - Survey Instrument}

\section{Video Clip Questionnaire ${ }^{1}$}

Please circle the letter grade that best represents how comfortable you would feel riding a bicycle in each situation shown. Please match the clip \# on this survey sheet to the number shown on the video. Thank you!

$$
A=\text { Extremely Comfortable } F=\text { Extremely Uncomfortable }
$$

\begin{tabular}{|c|c|c|c|c|c|c|}
\hline Clip \# & \multicolumn{6}{c|}{ Rating } \\
\hline $\mathbf{1}$ & A & B & C & D & E & F \\
\hline $\mathbf{2}$ & A & B & C & D & E & F \\
\hline 3 & A & B & C & D & E & F \\
\hline 4 & A & B & C & D & E & F \\
\hline $\mathbf{5}$ & A & B & C & D & E & F \\
\hline $\mathbf{6}$ & A & B & C & D & E & F \\
\hline 7 & A & B & C & D & E & F \\
\hline $\mathbf{8}$ & A & B & C & D & E & F \\
\hline $\mathbf{9}$ & A & B & C & D & E & F \\
\hline 10 & A & B & C & D & E & F \\
\hline 1 & A & B & C & D & E & F \\
\hline
\end{tabular}

\footnotetext{
${ }^{1}$ The contents of this page and the following one fit on one page for the actual survey
} 


\begin{tabular}{|c|c|c|c|c|c|c|}
\hline 12 & A & B & C & D & E & F \\
\hline 13 & A & B & C & D & E & F \\
\hline 14 & A & B & C & D & E & F \\
\hline 15 & A & B & C & D & E & F \\
\hline 16 & A & B & C & D & E & F \\
\hline 17 & A & B & C & D & E & F \\
\hline 18 & A & B & C & D & E & F \\
\hline 19 & A & B & C & D & E & F \\
\hline 20 & A & B & C & D & E & F \\
\hline
\end{tabular}

Thank you! 


\section{Bicycling Experience Questionnaire}

1. What is your age? years

2. What is your gender?

$\square_{1}$ Male $\quad \square_{2}$ Female $\square_{3}$

3. Do you have any physical limitations that prevent you from riding a bicycle?

$\square_{1}$ Yes $\square_{2}$ No

4. Do you have access to a working bicycle?

$\square_{1}$ Yes $\square_{2}$ No

5. How often do you ride a bicycle for:

Commuting (to/from work or school) Recreation/exercise Other (to the store, park, etc...)

\begin{tabular}{|c|c|c|c|c|}
\hline Never & $\begin{array}{l}1-2 \text { times/ } \\
\text { month }\end{array}$ & $\begin{array}{c}1-2 \text { times/ } \\
\text { week }\end{array}$ & $\begin{array}{l}3-5 \text { times/ } \\
\text { week }\end{array}$ & $\begin{array}{c}6+\text { times } \\
\text { week }\end{array}$ \\
\hline$\square_{1}$ & $\square_{2}$ & $\square_{3}$ & $\square_{4}$ & $\square_{5}$ \\
\hline$\square_{1}$ & $\square_{2}$ & $\square_{3}$ & $\square_{4}$ & $\square_{5}$ \\
\hline$\square_{1}$ & $\square_{2}$ & $\square_{3}$ & $\square_{4}$ & $\square_{5}$ \\
\hline
\end{tabular}

6. Please indicate if you agree or disagree with the following statement.

I would like to ride a bicycle more than I do now

\begin{tabular}{|c|c|c|c|c|}
\hline $\begin{array}{l}\text { Strongly } \\
\text { Disagree }\end{array}$ & $\begin{array}{c}\text { Somewhat } \\
\text { Disagree }\end{array}$ & $\begin{array}{c}\text { Somewhat } \\
\text { Agree }\end{array}$ & $\begin{array}{c}\text { Strongly } \\
\text { Agree }\end{array}$ & $\begin{array}{c}\text { No } \\
\text { Opinion }\end{array}$ \\
\hline$\square_{1}$ & $\square_{2}$ & $\square_{3}$ & $\square_{4}$ & $\square_{9}$ \\
& & & & \\
\hline
\end{tabular}

Thank you! 